PRIMARY CARE PROVIDER

PrEP PRESCRIBING PRACTICES:

SOUTHERN UNITED STATES

A Dissertation
presented to
the Faculty of the Graduate School
at the University of Missouri-Columbia
In Partial Fulfillment
of the Requirements for the Degree
Doctor of Philosophy
by
DARYL TRAYLOR
Dr. Maithe Enriquez, Dissertation Supervisor
JULY 2021


The undersigned, appointed by the dean of the Graduate School, have examined the dissertation entitled

\author{
PRIMARY CARE PROVIDER \\ PrEP PRESCRIBING PRACTICES: \\ SOUTHERN UNITED STATES
}

presented by Daryl Traylor, a candidate for the degree of Doctor of Philosophy, and hereby certify that, in their opinion, it is worthy of acceptance.

Maithe Enriquez, PhD, RN, ANP-BC, FAAN

Tina Bloom, $\mathrm{PhD}, \mathrm{MPH}, \mathrm{RN}$

Linda Bullock, PhD, RN, FAAN

Mansoo Yu, PhD, MSW, MA

Melva Thompson-Robinson, DrPH, MSPE 


\section{DEDICATION}

This dissertation is dedicated to four of the most resilient people that I have ever had the honor to know:

To my paternal grandmother, Mamie Alexander Traylor: You showed me the power of a grandmother's love, how life comes full circle, and that staying true to

your word, remaining prayerful, and loving your family are the keys to a life welllived.

To my mother-in-law, Pamela Ann Scott: Everyday, you showed me what it means to love unconditionally, even when those people around you don't always love you with the same unconditional love. You also showed me how important good food, family, laughter, fun times, and loving life are to living a life that is worth living.

To my beloved wife, Eboni Elana Anderson-Traylor: You have been my best friend, motivator, and rock for 15 years. Your unlimited love, patience, humor, and support over these last 15 years are the reason why I am blessed to be where I am today. This dissertation and everything else that I will achieve in life is as much yours as they will be mine.

To my dad, Curtis Harold Traylor: Man, what can I say? You taught me to stand for what I believe in, and through your hard work, you laid the foundation that gave me the chance to reach for the stars and follow my dreams. When I fell, you were always there to pick me up, brush me off, and continue after my goals. For that, I love you Pop. 


\section{ACKNOWLEDGMENTS}

We would not accomplish the things that matter most in life without the love, kindness, and support of the people who make our accomplishments possible. I am fortunate to have so many people who have stood at my side as I have pursued my goals. There is of course my University of Missouri Sinclair School of Nursing family, in particular Chuka Emezue; you've been a good friend and motivator throughout our studies, and I am proud to call you, my brother. I also want to express my deepest gratitude to my advisor and chair, Dr. Maithe Enriquez. You took a chance on me when I first contacted you in 2018, regarding supervising my doctoral journey. You have been a dedicated mentor, motivator, and a friend. Thank you for always being firm, yet fair and thank you for allowing me to stumble occasionally as I have grown into a researcher. To my other committee members, Dr. Tina Bloom, Dr. Lind Bullock, and Dr. Melva Thompson-Robinson, I appreciate you all for your support, guidance, mentorship, friendship, and the time that you have committed to help mold me into a proper scientist. Dr. Thompson-Robinson, I especially thank you for your guidance and friendship over the last eight years; because of you, I feel that I can be among the very best public health scientists in the nation.

I would like to acknowledge the staff and faculty of the SSON for their generous support and kindness. In particular, I want to say a heart-felt thank you to Dr. Chelsea Deroche. The last time that we spoke, you told me how proud you were of me and that you saw how much I had grown since the first statistics class that I took with you. Thank you for believing in me. 
I would be negligent if I did not acknowledge the importance of the University of Missouri Sinclair Fellowship to my pursuit of my doctoral education. The generosity of the Sinclair family and the University of Missouri allowed me to pursue my doctorate as a full-time student without taking on the burden of student loans. I have been able to complete my doctorate in a timely fashion without taking on a great deal of debt. For this, I am eternally grateful.

Last but certainly not least, I am thankful for the love and support that my family and friends have given to me over my many journeys. Eboni Anderson-Traylor - My wife, best friend, partner in crime, and everything in between. When I promised your parents that I was going to take care of you, I meant that. As long as the Lord continues to bless me with life, I am going to continue doing that each and every day. Robert Henderson - My brother from another mother. When I first met you in 2007, I could never have known that 13 years later, that you would be one of the very closest friends that I've ever had. So much of this dissertation work belongs to you and when you read it, so much of what you taught me about community health is woven throughout. Thank you for being a mentor and friend. BBQ is on me! Patricia Wilburn - You and Deb welcomed me, Eboni, Pam, and JJ into your home and into your hearts. I will forever be grateful for all of the many laughs and good times that we have shared, and Eboni and I will forever be in your debt for your love and support through one of the darkest moments of our journey. We love you sister and cannot wait till we can start to create new laughs and memories. Justin Jones - You are like a son to me, and I am thrilled to see how much you have grown and matured in the years since you graduated from high school. In some ways, this dissertation was done with you in mind. If we ever see an end 
to the epidemic of homophobia, stigma, and HIV/AIDS in the African American community, it will be your generation that makes the necessary changes. PrEP is the best thing that has come along and can be a game-changer in the fight against HIV and AIDS, so I charge you with continuing the work that you are doing. Keep up the good fight. 


\section{TABLE OF CONTENTS}

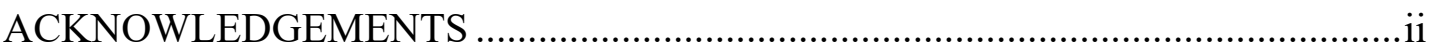

LIST OF FIGURES AND TABLES ......................................................................ii

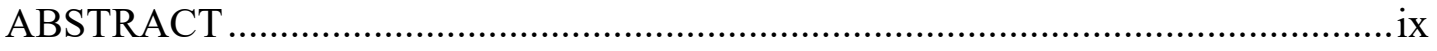

Chapter

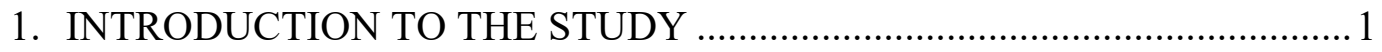

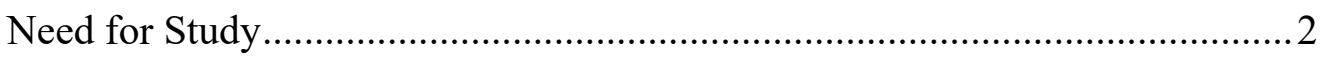

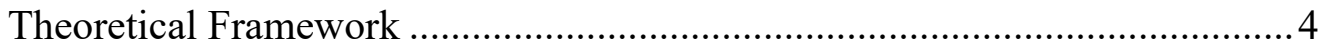

Purpose of Study and Research Questions .................................................... 6

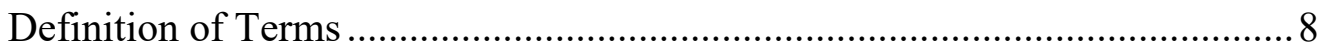

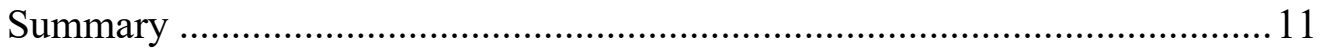

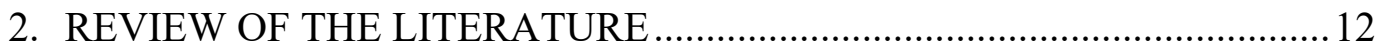

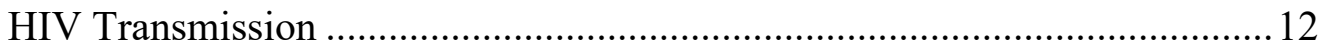

African Americans and HIV in the Southern United States............................13

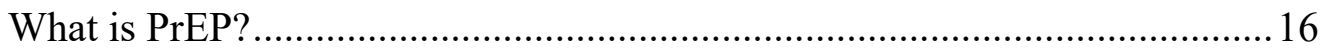

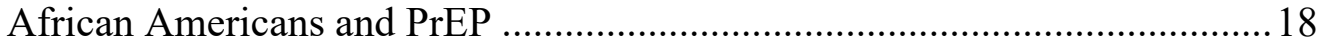

Primary Care Provider Barriers to Prescribing PrEP ……………………......23

Theoretical Framework for Study ...........................................................2

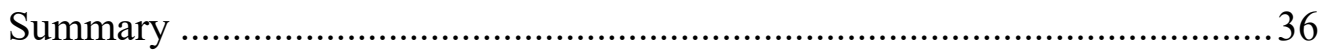

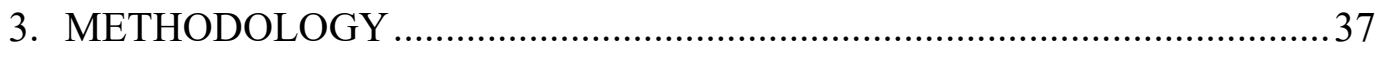

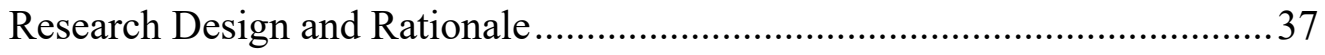

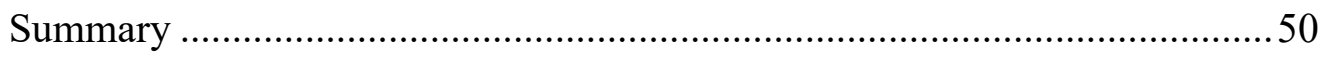

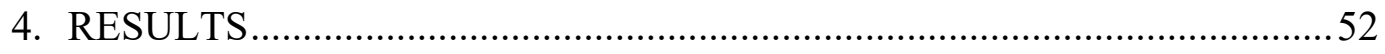




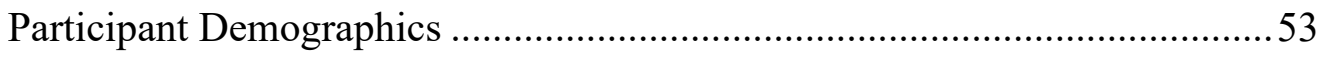

Additional Analysis .............................................................................. 58

Facilitators and Barriers to PrEP Prescribing ..............................................59

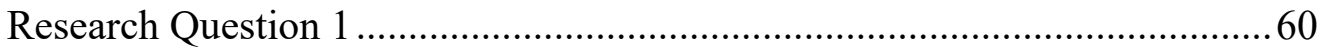

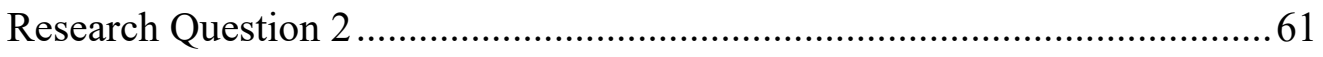

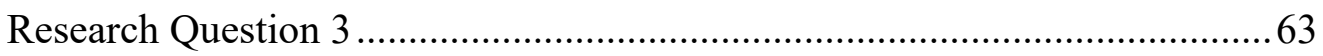

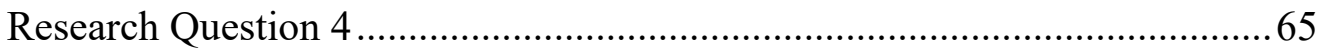

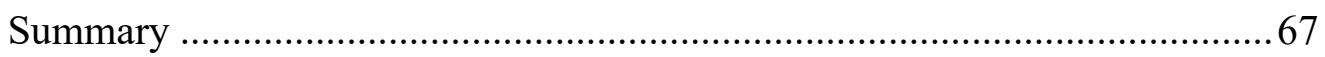

5. DISCUSSION, LIMITATIONS, AND CONCLUSION .............................6 68

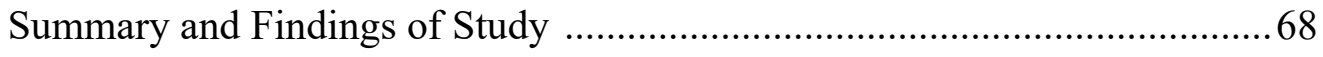

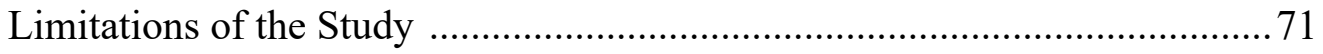

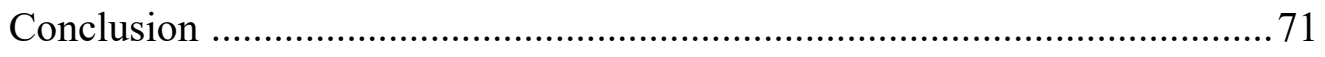

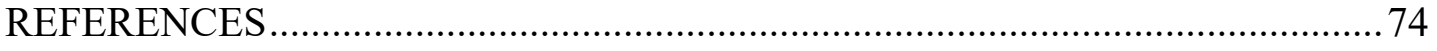

APPENDIX

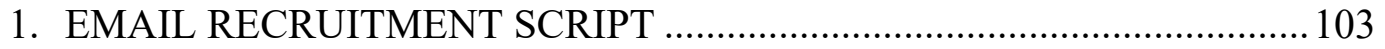

2. SOCIAL MEDIA RECRUITMENT SCRIPTS …..................................... 104

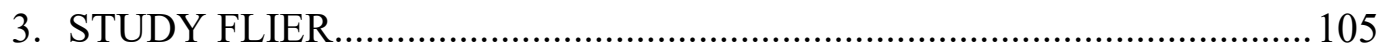

4. PERMISSION TO ADAPT SURVEY INSTRUMENT .............................. 106

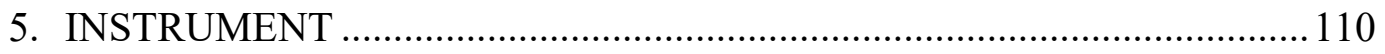

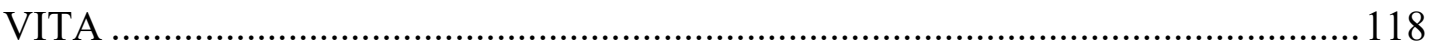




\section{LIST OF FIGURES AND TABLES}

Figure $\quad$ Page

1. Map of the United States ........................................................................... 10-11

2. Top 10 States with the Greatest Number of African Americans

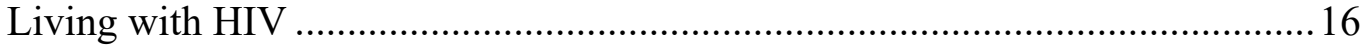

3. U.S. PrEP Uptake by Race and Ethnicity, 2016 ........................................... 19

4. TTM Stages of Change and Their Corresponding Processes of Change ..............33

5. The Relationships Between the Stages of Change, Processes of Change, Decisional Balance, and Self-efficacy in the TTM ............................................35

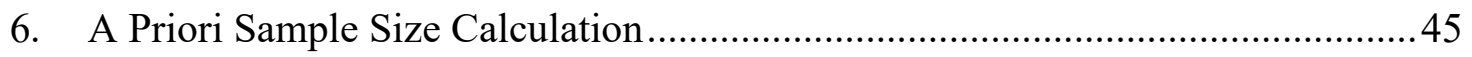

Table

Page

1. Estimated Number of Individuals in the United States, Broken Down by Race and Category, with PrEP Indications Between 2015 and 2016 ................................ 3

2. Stages of Change - Transtheoretical Model ..................................................... 6

3. Persons Living with HIV by U.S. Geographic Region and Race, 2018............... 14

4. HIV Diagnoses by U.S. Geographic Region and Race, 2018 ........................... 14

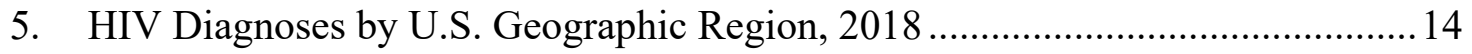

6. HIV Diagnoses, Southern United States, 2017 .......................................... 15

7. Transtheoretical Model Stages of Change - Processes of Change and Their

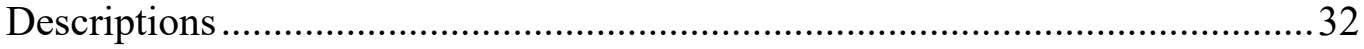

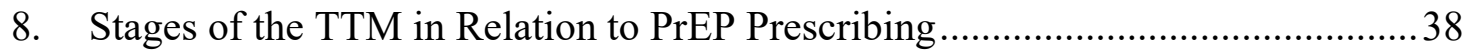

9. Summary of Hypotheses, Statistical Tests, and Scales of Measurement .........40-41

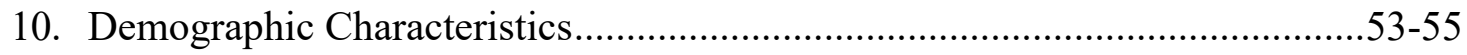

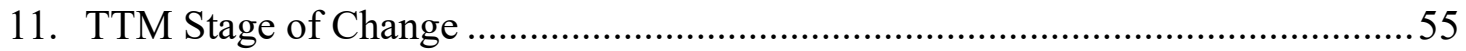

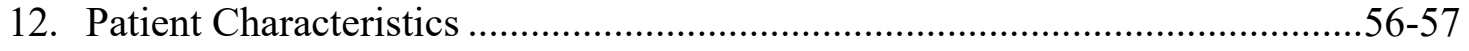


13. Crosstabulation of $\%$ of African American Patients vs. PrEP Stage of Change.

14. Crosstabulation of \% of African American Patients vs. PrEP Prescription ..........58

15. Descriptive Statistics for Facilitators to PrEP Prescribing .....................................59

16. Descriptive Statistics for Barriers to PrEP Prescribing …….............................59-60

17. Ordinal Logistic Regression Predicting PrEP Stage of Prescribing (Research Question 1)

18. Binary Logistic Regression Predicting PrEP Prescription (Research Question 2)

19. Ordinal Logistic Regression Predicting PrEP Stage of Prescribing (Research Question 3).

20. Binary Logistic Regression Predicting PrEP Prescription (Research Question 4) .66 


\title{
PRIMARY CARE PROVIDER PrEP PRESCRIBING PRACTICES: SOUTHERN UNITED STATES
}

\author{
Daryl Traylor
}

\author{
Dr. Maithe Enriquez, Dissertation Supervisor
}

\begin{abstract}
The Southern United States (U.S.) accounts for more than half of new HIV cases annually and African Americans make up the majority of new HIV diagnoses in this region. Pre-Exposure Prophylaxis (PrEP) is an effective biomedical HIV prevention strategy that is underutilized. Few studies have examined the PrEP prescribing practices of primary care providers (PCPs), particularly in the Southern U.S. This cross-sectional survey, driven by the Transtheoretical Model (TTM), examined the prescribing practices of Southern U.S. PCPs. Relationships between PCPs personal and practice variables were examined, together with TTM decisional balance variables.

Participants $(\mathrm{n}=223)$ who had more African American patients in their practice were more likely to be in a higher TTM stage of change $(p=.002)$ and were more likely to have written a PrEP prescription $(p=.001)$. Access to PrEP resources $(O R=1.85, p=$ $.001)$, streamlined insurance prior authorization processes $(O R=1.52, p=.010)$, working with staff who have PrEP knowledge $(O R=1.51, p=.033)$, having PrEP training $(O R=$ 40.26, $p<.001)$ and having patients who are motivated to take $\operatorname{PrEP}(O R=2.19, p=$ .007) were significant facilitators to PrEP prescribing. Significant barriers to PrEP prescribing included a lack of provider PrEP training $(O R=0.43, p=.003)$, lack of clinical leadership regarding $\operatorname{PrEP}(O R=0.65, p=.018)$, lack of insurance $(O R=2.74, p$ $=.002)$, and likelihood of low patient adherence to $\operatorname{PrEP}(O R=0.53, p=.001)$.
\end{abstract}


Findings indicate that this sample of PCPs were more likely to be at a higher TTM stage of change and have written a PrEP prescription if they saw more African American patients in their practice. Further, significant facilitators of PrEP prescribing included access to PrEP resources, streamlined insurance prior authorization processes, working with staff who have PrEP knowledge, having PrEP training, and having patients who are motivated to take PrEP. Significant barriers to PrEP prescribing included a lack of PrEP training, a lack of clinical leadership regarding PrEP, patient lack of insurance, and likelihood of low patient adherence. This study contributes to the body of knowledge regarding PCP PrEP prescribing practices. Findings from this study may inform future interventions that aim to enhance PrEP prescribing among primary care providers who serve Southern African American individuals at risk for acquisition of HIV disease. 


\section{CHAPTER 1: INTRODUCTION TO THE STUDY}

The Southern United States has consistently been disproportionately affected by human immunodeficiency virus (HIV) from the outset of the HIV epidemic (Drumhiller, Geter, Elmore, Gaul, \& Sutton, 2020; Reif, Safley, McAllester, Wilson, \& Whetten, 2017). In 2017, Southern states accounted for 52\% of new HIV cases annually (Centers for Disease Control and Prevention [CDC], 2019a; Henny \& Jeffries, 2019). However, only $38 \%$ of the U.S. population lives in the Southern U.S. (CDC, 2019e). Eight of the ten states, and nine of the ten metropolitan statistical areas (MSA) in the U.S. with the highest rates of new HIV diagnoses, are in the Southern U.S. (CDC, 2019b). Urban areas in the South bear the brunt of HIV; however, the Southern U.S. sees more HIV cases in suburban and rural areas as compared to other similar regions of the U.S. (CDC, 2019b; Henny \& Jeffries, 2019; Reif et al., 2017). Finally, the deep South region of the U.S., defined as Alabama, Arkansas, Florida, Georgia, Louisiana, Mississippi, North Carolina, South Carolina, Tennessee, and Texas, has the highest HIV burden in the Southern U.S. and is a significant driver of the U.S. HIV epidemic (Reif et al., 2006; Reif et al., 2017; U.S. Census Bureau, 2016). These 10 Southern states will be the focus of this study because they have large populations of African Americans who are at risk of contracting HIV. Further, these states have large MSAs where HIV is prominent.

Based on the available data, in 2017, African Americans made up 53\% of new HIV diagnoses in the Southern U.S. (CDC, 2019e; Henny \& Jeffries, 2019; Reif et al., 2017; Watson, Johnson, Zhang, \& Oster, 2019). African American men who have sex with men (MSM), gay, and bisexual individuals accounted for six out of every ten new HIV infections in Southern African Americans. The number of new HIV infections in 
African American MSM in the South is twice that of White and Hispanic/Latino MSM (CDC, 2019e). Among Southern women, 67\% of new HIV infections were in African American women (CDC, 2019e; Reif et al., 2017). The rate of HIV infection, regardless of sexual orientation, for African American women was 15 times the rate for White women, and for African American males, the rate was 5.4 times that for White males (CDC, 2019e).

An HIV prevention strategy that has been highly effective at reducing HIV risk in African Americans, when taken as prescribed, is HIV pre-exposure prophylaxis (PrEP) (Buchbinder, 2018; Donnell et al., 2014; Shover et al., 2019; Thomson et al., 2016). First approved by the U.S. Food and Drug Administration (FDA) in 2012, PrEP has emerged as an HIV prevention strategy for individuals who are HIV negative and may be at highrisk for contracting the virus (Plosker, 2013; Rice et al., 2019). Individuals who have a high-risk for acquisition of HIV infection include MSM, serodiscordant sexual partners, individuals who engage in intravenous drug use (IVDU), and individuals who have multiple sex partners (Huerga et al., 2017; Nguyen et al., 2019).

\section{Need for Study}

While PrEP uptake has increased since 2012, there has not been a substantial decrease in HIV incidence, even in cities that demonstrate high uptake (Chan et al., 2020). An estimated 500,000 African Americans in the U.S. have PrEP indications (Table 1), yet only 7,000 PrEP prescriptions were filled by African Americans between September 2015 and August 2016 (Smith, Van Handel, \& Grey 2018). During this time frame, 7,600 Latinos and 42,000 White individuals had PrEP prescriptions filled (Smith et al., 2018). States in the Southern U.S. and Washington D.C. had the highest numbers 
of African Americans with PrEP indications between 2015 and 2016 (Chan et al., 2020; Smith et al., 2018). Unfortunately, emerging research shows that primary care providers (PCPs) are missing critical opportunities to screen for PrEP indications and prescribe PrEP (Edelman et al., 2020). The literature is not clear on why PCPs are not prescribing PrEP, however. Ensuring access to PrEP will require PCPs who are aware of PrEP, comfortable discussing it with their patients, and willing to prescribe the medication (Patel et al., 2018; Smith et al., 2018).

\section{Table 1}

Estimated Number of Individuals in the United States, Broken Down by Race and Category, with PrEP Indications Between 2015 and 2016 (Smith et al., 2018).

\begin{tabular}{lllccc}
\hline \multicolumn{1}{c}{ Race } & MSM & Heterosexual & IVDU & Percentages & Totals \\
\hline Black & 309,308 & 165,171 & 26,828 & $44 \%$ & 501,307 \\
White & 236,051 & 46,454 & 28,278 & $27 \%$ & 310,783 \\
Hispanic/Latino & 219,771 & 36,131 & 15,227 & $24 \%$ & 271,129 \\
Other races & 48,838 & 10,323 & 2,175 & $5 \%$ & 61,336 \\
& & & & & \\
\cline { 4 - 6 } & & & & & Total \\
\hline
\end{tabular}

Note. $68 \%$ of the heterosexual individuals who had PrEP indications between 2015 and 2016 were female. $66 \%$ of these individuals were African American females.

One factor that has been tied to low rates of PrEP prescribing is the "purview paradox," as articulated by Krakower, Ware, Mitty, Maloney, and Mayer (2014). The "purview paradox" can be defined as PCPs believing that prescribing PrEP is beyond their scope of practice (Gallagher, 2020; Krakower et al., 2014; Mayer et al., 2020). A tenant of the "purview paradox" is that while HIV infectious disease providers can prescribe PrEP, they are relatively few compared to the number of PCPs (Gallagher, 2020; Krakower et al., 2014). HIV infectious disease specialists may also see few HIV negative patients who have PrEP indications (Mayer et al., 2020). In contrast, PCPs may 
see significant numbers of patients with PrEP indications, but they may be uncomfortable talking about or prescribing PrEP (Krakower et al., 2014; Silapaswan, Krakower, \& Mayer, 2017; Gallagher, 2020; Mayer et al., 2020).

Other factors that may be related to low PrEP prescribing and uptake include HIV stigma, the cost of PrEP, a lack of PCP HIV and PrEP knowledge, concerns regarding the development of PrEP resistance, the potential for PrEP to increase high-risk sexual behaviors, poor medication adherence, the lack of time to engage in PrEP counseling and follow-up activities, and provider perceptions that PrEP may not have high efficacy (Adams \& Balderson, 2016; Buchbinder, 2018; Ojikutu et al., 2018; Patal et al., 2018; Petroli et al., 2016; Vaughn, Dillon, \& Kedia, 2018; Silapaswan et al., 2017; Tellalian, Maznavi, Bredeek, \& Hardy, 2013;). Understanding PrEP knowledge, attitudes, behaviors, barriers, and facilitators to PrEP prescribing to African Americans in the Southern U.S. by primary care providers is a critical step to increasing PrEP uptake (Elopre et al., 2017).

\section{Theoretical Framework}

PrEP is a highly effective strategy for preventing HIV in at-risk individuals when taken as prescribed (Shover et al., 2019; Thompson et al., 2016). When combined with traditional HIV prevention approaches that emphasize HIV testing, consistent condom usage, and behavioral approaches, it may be possible to achieve significant reductions in the rate of HIV infection in African Americans (CDC, 2018; Underhill, Operario, Mimiage, Skeer, \& Mayer, 2011). Various theories have been used to plan HIV prevention interventions, and several are useful in planning PrEP interventions 
(Weinstein, Sandman, \& Blalock, 2008). This study will use the Transtheoretical Stages of Change Model (TTM) as the guiding theoretical framework for this study.

TTM, developed by Prochaska and DiClemente in the late 1970s, is a stage of change model that posits that individuals change behaviors by progressing through one of six stages of behavior change (Prochaska, Redding, \& Evers, 2008). The difference between TTM and other stages of change models such as the Precaution Adoption Process Model (PAPM), lies in the fact that TTM focus on the decision-making processes that individuals use to change a behavior over time (Prochaska \& DiClemente, 2005; Prochaska et al., 2008). Prochaska and DiClemente assumed that people do not change behaviors rapidly, rather, behavior change is a cyclical process (Prochaska et al., 2008). Further, Prochaska and DiClemente posited that individuals may move from one stage to the next in a linear fashion or they may regress to earlier stages of change from later stages (Prochaska et al., 2008).

Six stages of change make up the TTM (Figure 1) (Prochaska et al., 2008). Stage 1 of the TTM entails an individual not being ready to initiate a behavior change within six months. This individual may not be aware that there is an issue that needs to be changed but if they are, they may take the time to learn about the health issue. If this individual is aware of the need to change and decides to make a behavior change within the next six months, they are considered to be at stage 2 . In stage 3 , the individual is taking small steps to make a behavior change within the next 30 days. As individuals progress from stage 3 to stage 4, individuals have made a behavior change and are working on making their commitment to change more permanent. It is at this stage may face temptation to relapse. If an individual has successfully avoided relapse, they may 
consider themselves at stage 5. They have been in the behavior change process for more than six months, but it is important for them to realize that relapse is a danger. It is important to note that individuals may relapse (stage 6) at any stage starting with stage 2. Individuals may enter and exit the stages of change at any stage. Individuals who are in stages 3 through 5, or preparation, action, and maintenance, are most receptive to and not as resistant to change as individuals at stage 1 or 2 (Peterson et al., 2010).

\section{Table 2}

Stages of Change - Transtheoretical Model

\begin{tabular}{c|llllll}
\hline Stage & Stage 1: & Stage 2: & Stage 3: & Stage 4: & Stage 5: & Stage 6: \\
& Precontemplation & Contemplation & Preparation & Action & Maintenance & Relapse \\
$\begin{array}{c}\text { Time } \\
\text { in } \\
\text { stage }\end{array}$ & $\begin{array}{l}\text { More than six } \\
\text { months }\end{array}$ & $\begin{array}{l}\text { In the next six } \\
\text { months }\end{array}$ & $\begin{array}{l}\text { In the next } \\
\text { month }\end{array}$ & Currently & $\begin{array}{l}\text { At least six } \\
\text { months }\end{array}$ & $\begin{array}{l}\text { Any } \\
\text { time }\end{array}$ \\
\hline
\end{tabular}

Note. Adapted from "The transtheoretical model and stages of change" by J.O. Prochaska, C.A. Redding, \& K.E. Evers (2008). Health Behavior and Health Education: Theory, Research, and Practice.

TTM is also made up of several other components. These include the processes of change, or the covert and overt activities that one engages in to modify a behavior (Prochaska et al., 2008), decisional balance or the benefits versus the costs of performing a behavior (Burditt et al., 2009; Prochaska et al., 2008), and finally, self-efficacy or one's ability to cope during stressful situations (Fernandez et al., 2016; Prochaska et al., 2008).

\section{Purpose of Study and Research Questions}

The aim of this cross-sectional study is to identify factors that influence PrEP prescribing practices by PCPs in the Southern U.S. The survey instrument will be adapted from a PrEP survey administered to internal medicine residents at Johns Hopkins 
Hospital, Johns Hopkins Bayview Medical Center, Yale School of Medicine, University of Washington, and the Ohio State University (Terndrup et al., 2019). The survey assesses self-reported knowledge, attitudes, and prescribing practices related to PrEP and prior PrEP training. Four research questions will guide this study:

Research Question 1: What are the relationships between primary care provider personal and practice variables and the stage of adoption, using the TTM, of PrEP prescribing?

Personal variables will include age, race/ethnicity, gender, and sexual orientation. Practice variables will include type of primary care practitioner (physician, nurse practitioner, or physician assistant), type of degree, state of practice, years of practice, practice setting (rural, suburban, or urban), whether or not the provider has heard of PrEP, whether or not the provider has had training on PrEP, whether or not the provider routinely screens African American patients for HIV, whether or not the provider routinely screens African American patients for PrEP need, whether or not PrEP has been prescribed to any African American patients, whether or not the provider has ever referred patients out for PrEP, whether or not the provider routinely refers patients out for PrEP, and whether or not African American patients are seen in the providers primary care practice.

Research Question 2: What primary care provider personal and practice characteristics predict prescribing or not prescribing PrEP?

Research Question 3: What is the relationship between the TTM decisional balance construct and the TTM stages of change for PrEP prescribing? 
The decisional balance facilitators of PrEP prescribing will consist of the following: PrEP training during residency, staff or providers in your clinic who are knowledgeable about PrEP provision, access to resources such as PrEP prescribing guidelines and protocols, clinic in-service PrEP training, knowledge of PrEP's efficacy, patient motivation to use PrEP as prescribed, peers who prescribe PrEP, patient access to financial incentives that would lower the cost of PrEP, and streamlined prior authorization procedures.

Decisional balance barriers to PrEP prescribing will consist of lack of provider PrEP training and education, lack of clinic leadership support regarding PrEP, lack of PrEP usage guidelines, clinic and lab monitoring requirements, staffing time constraints related to HIV risk reduction and PrEP adherence counseling, lack of patient insurance coverage and patient out of pocket costs, low PrEP adherence by patients, HIV resistance developing due to PrEP, increase in risk behaviors by patients on PrEP, and insufficient evidence of PrEP's efficacy.

Research Question 4: Are there significant interactions between personal and practice variables and TTM decisional balance that predict the stage of change of PrEP prescribing?

\section{Definitions of Terms}

It is vital to define essential terms used in this study. The following terms will appear throughout the study:

1. Advanced Practice Registered Nurse (APRN): This is a nurse who has earned a master's degree and/or a Doctor of Nursing Practice (DNP). There are several 
categories of APRNs but for this study, the focus will be on nurse practitioners who practice primary care medicine (Woo et al., 2017).

2. HIV preexposure prophylaxis $(\operatorname{PrEP})$ : This is the use of $\operatorname{Truvada}^{\circledR}$ or Descovy ${ }^{\circledR}$ to prevent an individual who is HIV negative from contracting HIV (Riddell, Amico, \& Mayer, 2018).

3. HIV specialist: An HIV specialist is any physician, Advanced Practice Registered Nurse (APRN), or physician assistant (PA) who is credentialed as an "HIV Specialist" by the American Academy of HIV Medicine; or is board certified or has earned a Certificate of Added Qualification in the field of HIV medicine by the American Board of Medical Specialties; or is board certified as an infectious disease practitioner (American Academy of HIV Medicine [AAHIVM], n.d.; Grossman, 2006; Stone, Mansourati, Poses, \& Mayer, 2001).

4. Metropolitan Statistical Area: As defined by the U.S. Office of Management and Budget (OMB), a metropolitan statistical area consists of at least one urbanized area with a population of at least 50,000 individuals (Nussle, 2008).

5. MSM: Males who have sex with males; these are men who engage in sexual activities with other men irrespective of how they may sexually identify themselves (Young \& Meyer, 2005).

6. Physician Assistant (PA): PAs are licensed healthcare professionals who hold a masters and/or doctorate degree. They are able to provide patient care under the supervision of a licensed physician (Kerlon et al., 2016).

7. Primary care providers: In the U.S., a primary care provider is a physician, nurse practitioner, or physician assistant who is usually the first contact for 
patients who need general medical services or have an undiagnosed health concern (Bodenheimer, 2013). Primary care providers provide and coordinate healthcare (Bodenheimer, 2013).

8. Serodiscordant: This is a mixed-status couple where one individual is HIV positive, and the other is HIV negative (Makwe \& Giwa-Osagie, 2013).

9. Southern United States: The U.S. Census Bureau defines the Southern U.S. as Delaware, Florida, Georgia, Maryland, North and South Carolina, Virginia, West Virginia, Alabama, Kentucky, Mississippi, Tennessee, Arkansas, Louisiana, Oklahoma, and Texas (U.S. Census Bureau, 2016). The states that will be the focus of this study include Alabama, Arkansas, Georgia, Florida, Louisiana, Mississippi, North and South Carolina, Tennessee, and Texas.

\section{Figure 1}

Map of the United States

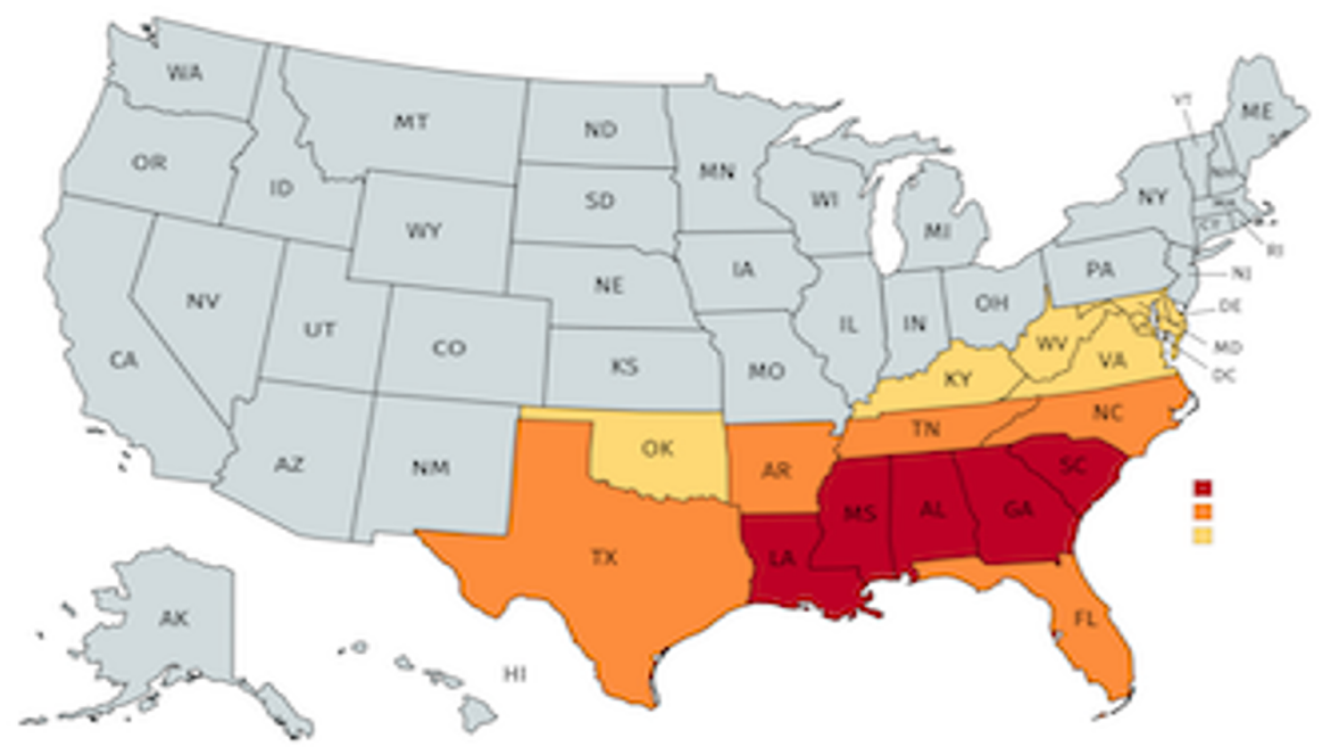

Note. The Southern U.S. is shaded in orange, yellow, and red. U.S. Census 
Bureau (2016). Census regions and divisions of the United States. Retrieved from https://www2.census.gov/geo/pdfs/mapsdata/maps/reference/us_regdiv.pdf

\section{Summary}

PrEP is a prevention strategy that effectively reduces risk for acquisition of HIV infection (Baeten et al., 2013; Buchbinder, 2018). African Americans experience a disproportionately high burden of HIV disease. Despite the availability of PrEP, African Americans residing in the Southern U.S. have a low uptake of PrEP, when compared to other at-risk populations in the U.S. (Elopre et al., 2017). HIV in Southern U.S. African Americans is a significant community and public health concern. African Americans in the South bear a disproportionate burden of HIV infection. Thus, increasing their access to PrEP, combined with HIV testing, will reduce and possibly eliminate the HIV infection disparities between African Americans and other racial and ethnic groups in the Southern U.S.

Few studies have specifically examined factors that facilitate PCP prescribing PrEP. Thus, this study's results, guided by the TTM, may help to address this knowledge gap. This study seeks to examine PCP knowledge, attitudes, and prescribing practices related to PrEP and prior PrEP training and how they may be associated with the stage of adoption of PrEP prescribing by PCPs. The results of this study may assist PCPs and public health practitioners with developing programs and interventions that will help to reduce barriers, which hinder providers from prescribing PrEP. 


\section{CHAPTER 2: REVIEW OF THE LITERATURE}

According to the U.S. Centers for Disease Control and Prevention (CDC) (2019a), the human immunodeficiency virus (HIV) ranks number five among the top 10 critical public health issues facing the United States. While the rate of new HIV diagnoses was down for all racial and ethnic groups between 2010 and 2017, in 2018, there were 37,832 new HIV infections in the U.S. (CDC 2016; CDC, 2019a; CDC, 2019b). Roughly 42\% of these new infections were in African Americans. During this time frame, there were more than 4,000 new HIV infections in heterosexual African American women, 1,700 infections in heterosexual African American men, and 9,807 new HIV infections in African American men-who-have-sex-with-men (MSM) (CDC, 2019a). At the end of 2015, there were 468,800 African Americans living with HIV (CDC, 2016). In 2017, 16,350 individuals died as a result of HIV-related causes. Of this number, 7,031 were African American (CDC, 2019a). These numbers indicate that HIV affects African Americans disproportionately, and the virus is a significant public health threat to African American communities across the U.S. (Laurencin, Murdock, Laurencin, \& Christensen, 2018).

\section{HIV Transmission}

The transmission of HIV occurs when there is exposure to blood or body fluids containing HIV or HIV-infected cells. The three major routes of transmission are sexual contact, mother-to-baby transmission, and intravenous drug use (IVDU) (Shaw \& Hunter, 2012; Showa, Nyadadza, \& Hove-Musekwa, 2019). The most common ways of HIV infection in the U.S. are vaginal or anal sex with an HIV-infected partner or sharing of injection drug needles with someone who is HIV positive. Male-to-female transmission 
of HIV is the most common route of transmission (Showa et al., 2019). Less common means of transmission include mother-to-child, being stuck by HIV-contaminated needles, oral sex, blood and blood product transfusions, being bitten by someone infected with HIV, and kissing. HIV viruses that are CCR5 tropic, that is, strains of HIV that infect $\mathrm{T}$ cells displaying the CCR5 receptor, are preferentially transmitted via all three primary routes for reasons that are not entirely understood (Ronen, Sharma, \& Overbaugh, 2015; Shaw \& Hunter, 2012; Showa et al., 2019). Once transmission occurs, viral and host markers of infection appear in the blood and plasma (Showa et al., 2019).

\section{African Americans and HIV in the Southern United States}

Nationally, African Americans, adults and adolescents, account for most new HIV diagnoses and people living with HIV or AIDS compared to other racial and ethnic groups (CDC, 2019c). In 2018, African Americans made up 13\% of the U.S. population but comprised $43 \%$ of all new HIV diagnoses in America that year (CDC, 2019c). It was reported that $31 \%$ of these diagnoses were in African American men, and $11 \%$ were among African American women (CDC, 2019c). Almost 500,000 thousand African Americans were living with HIV at the end of 2018 (CDC, 2019c). In the years since the first HIV and AIDS cases were discovered in the large urban centers along the U.S. East and West coasts, the burden of the epidemic for all racial and ethnic groups has shifted to Washington D.C. and the U.S. South (Blake, Jones Taylor, \& Sowell, 2016; Sutton, Gray, Elmore, \& Gaul, 2017).

The Southern U.S. now experiences the largest burden of HIV disease, while simultaneously lagging behind other regions of the country in its ability to provide HIV prevention and treatment to its residents (Tables 1 and 2) (Blake et al., 2016; CDC, 
2019c; McManus, \& Powers, Killelea, Tello-Trillo, \& McQuade, 2019; Sutton et al., 2017). The Southern U.S. accounted for roughly 51\% of 37,968 new HIV diagnoses in the U.S. in 2018 (Table 3) (CDC, 2019c). By comparison, the Southern U.S. population only accounts for $37 \%$ of the entire U.S. population (CDC, 2019c). The majority of HIV diagnoses nationwide occur in urban areas; however, the Southern U.S. has a significant HIV burden in suburban and rural areas (CDC, 2019c; CDC, 2020; Reif et al., 2006; Reif et al., 2017).

\section{Table 3}

Persons Living with HIV by U.S. Geographic Region and Race, 2018

\begin{tabular}{lcccccc}
\hline Region & African American & White & $\begin{array}{c}\text { Hispanic/ } \\
\text { Latino }\end{array}$ & Asian & Multiple races & Other \\
\hline Northeast & 90,762 & 54,699 & 72,151 & 3,288 & 64 & 152 \\
Midwest & 53,000 & 47,483 & 14,806 & 1,514 & 41 & 366 \\
South & 247,002 & 115,680 & 77,304 & 3,115 & 147 & 769 \\
West & 32,230 & 86,261 & 67,056 & 7,243 & 629 & 1,847 \\
\hline
\end{tabular}

\section{Table 4}

HIV Diagnoses by U.S. Geographic Region and Race, 2018

\begin{tabular}{lcccccc}
\hline Region & African American & White & $\begin{array}{c}\text { Hispanic/ } \\
\text { Latino }\end{array}$ & Asian & Multiple races & Other \\
\hline Northeast & 2,233 & 1,228 & 1,730 & 167 & 167 & 56 \\
Midwest & 2,320 & 1,679 & 642 & 148 & 0 & 99 \\
South & 10,122 & 4,283 & 4,283 & 0 & 0 & 779 \\
West & 1,355 & 2,259 & 3,163 & 377 & 0 & 377 \\
\hline
\end{tabular}

\section{Table 5}

HIV Diagnoses by U.S. Geographic Region, 2018

\begin{tabular}{ccccc}
\hline Region & Total Number of Diagnoses & Urban & Suburban & Rural \\
\hline Midwest & 4,904 & $78 \%$ & $15 \%$ & $7 \%$ \\
Northeast & 5,495 & $92 \%$ & $6 \%$ & $2 \%$ \\
South & 19,396 & $76 \%$ & $15 \%$ & $9 \%$ \\
West & 7,229 & $88 \%$ & $9 \%$ & $3 \%$ \\
\hline
\end{tabular}


African Americans residing in the Southern U.S. bear the largest burden of HIV (McManus et al., 2019; Ransome et al., 2020; Reif et al., 2017). In 2018, African Americans made up 52\% of new HIV diagnoses in the region while also accounting for $58 \%$ of those living with HIV in the Southern U.S. in 2017 (CDC, 2019c). African American men who have sex with men (MSM), gay, and bisexual individuals accounted for six out of every ten new HIV infections in African Americans in the South; the number of new HIV infections in African American MSM in the South is twice that of White and Hispanic/Latino MSM (CDC, 2019e). Among Southern women, 67\% of new HIV infections were in African American women in 2018 (CDC, 2019c). The rate of HIV infection for African American women was 15 times the rate for White women, and for African American males, the rate was 5.4 times that for White males (CDC, 2019e). Table 5 shows the breakdown of new HIV diagnoses in the Southern U.S. in 2017, while figure 2 shows the top ten states with the greatest numbers of African Americans living with HIV at the end of 2018. Five of the states are in the Southern U.S.

\section{Table 6}

HIV Diagnoses, Southern United States, 2017

\begin{tabular}{lccc}
\hline \multicolumn{1}{c}{ Race / Ethnicity } & MSM & Heterosexual Women & Heterosexual Men \\
\hline Black & 6,218 & 2,584 & 1,204 \\
Hispanic / Latino & 3,153 & 448 & 278 \\
White & 3,134 & 543 & 232 \\
\hline
\end{tabular}




\section{Figure 2}

Top 10 States with the Greatest Number of African Americans Living with HIV

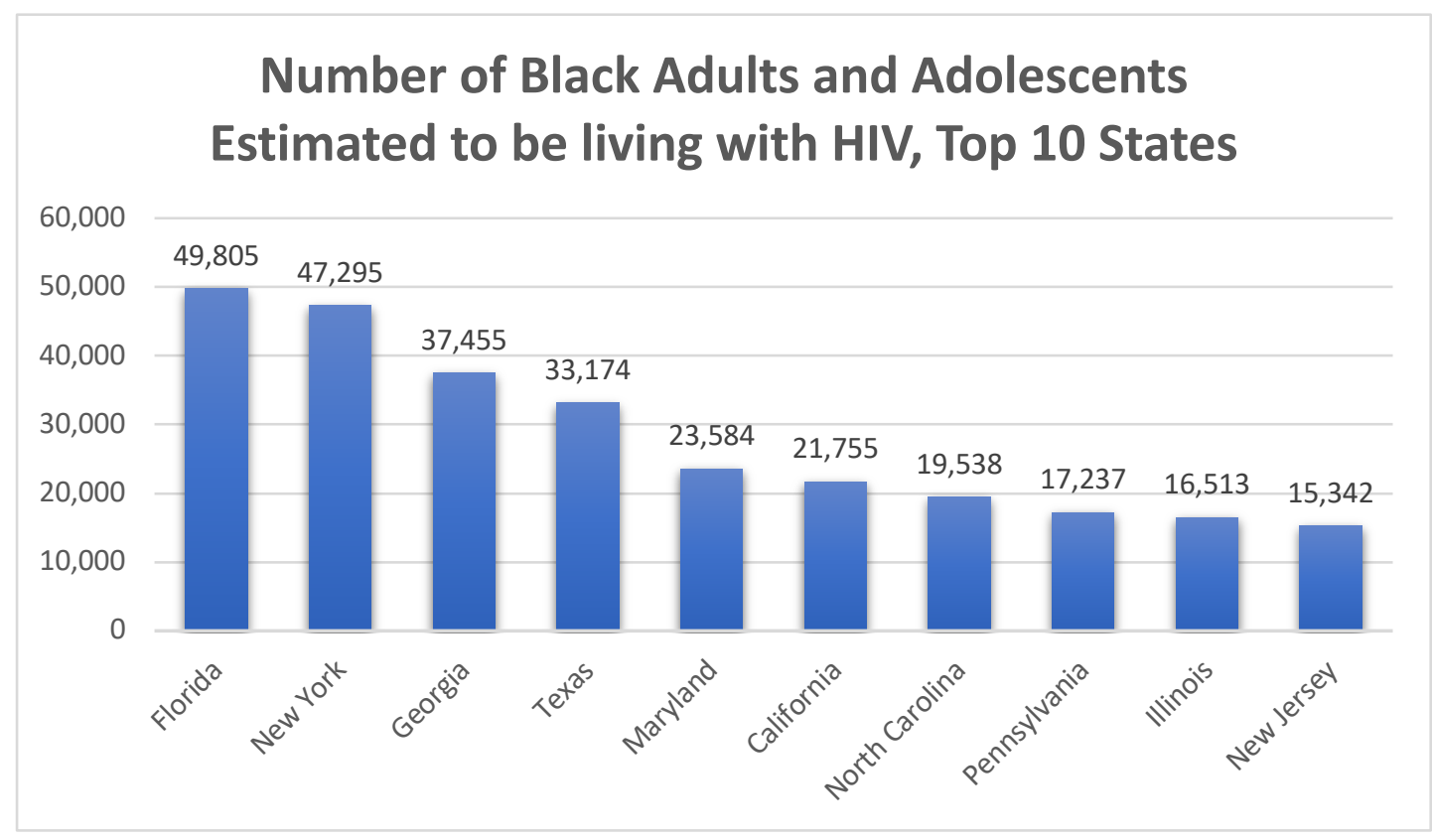

Note. Adapted from "HIV surveillance report, 2018 (preliminary), vol. 30." by Centers for Disease Control and Prevention (2019c).

\section{What is PrEP?}

In 2012, the FDA approved Truvada ${ }^{\circledR}$ to be given prophylactically to prevent the transmission of HIV. Later, in 2019, the FDA approved Descovy ${ }^{\circledR}$ as the second HIV prophylactic. When taken as prescribed, Truvada ${ }^{\circledR}$ reduces the risk of contracting HIV by sex by up to $99 \%$ and 74\% from injection drug use (Anderson et al., 2012; Baeten et al., 2012; Chan et al., 2020; Department of Health and Human Services (DHHS), 2020;

Grant et al., 2010). By comparison, Descovy ${ }^{\circledR}$ reduces the risk of contracting HIV from sexual intercourse by up to $99.7 \%$, and it has a better renal and bone loss safety profile than Truvada ${ }^{\circledR}$ (Ruane et al., 2019; Thomas et al., 2019). 
The efficacy of Truvada ${ }^{\circledR}$ has been well-established. A 2007 phase III clinical trial, the Iniciativa Profilaxis Pre-Exposicion or iPrEx study, determined that Truvada ${ }^{\circledR}$ could be safely administered to prevent HIV in MSM (Anderson et al., 2013; Grant et al., 2010). iPrEx took place at 11 clinical sites in Peru, Ecuador, Brazil, South Africa, Thailand, and the U.S. and was designed as a double-blind, placebo-controlled study (Grant et al., 2010). There were 2,499 study participants; 36 individuals who took Truvada ${ }^{\circledR}$ contracted HIV, and 64 in the control group, contracted the virus (Anderson et al., 2013; Grant et al., 2010). Individuals in the experimental group who took the drug seven days a week saw a 99\% reduction in their HIV risk, while those who took Truvada ${ }^{\circledR}$ four days per week saw a $96 \%$ reduction in HIV risk (Anderson et al., 2013).

The majority of clinical studies of Truvada ${ }^{\circledR}$ have involved MSM and transgender women. However, in a two-year study conducted in 2008 on 4,758 heterosexual, serodiscordant couples in Kenya and Uganda, 38\% of the seronegative partners were female. The trial demonstrated a 90\% reduction in HIV risk among those individuals who took the medication as directed each day (Baeten et al., 2012). Another 2007 study of 1,219 HIV-negative males and females in Botswana concluded that separate statistical conclusions for men and women could not be ascertained, but Truvada ${ }^{\circledR}$ did prevent HIV infection in sexually active adults (Thigpen et al., 2012). Two further 2009 to 2011 studies conducted in Africa on 2,120 and 5,029 HIV negative women, respectively, were discontinued due to lack of efficacy and poor medication adherence by study participants (Marrazzo et al., 2015; Van Damme et al., 2012). Many of the PrEP studies that have involved women have been discontinued because they have not shown good efficacy or there was a lack of consistent usage of PrEP (Baeten et al., 2012; Marrazzo et al., 2015; 
Van Damme et al., Thigpen et al., 2012). The reasons for this are not fully understood. Thus, more women need to take part in future PrEP studies to understand this phenomenon.

\section{African Americans and PrEP}

While African Americans, particularly those who reside in the Southern U.S., have the highest risk of contracting HIV in the U.S., they also have the lowest PrEP usage rates (McManus et al., 2019; Reif et al., 2017; Sutton et al., 2017). It is difficult to quantify the PrEP needs for African Americans because prescription data does not often

contain information about race and ethnicity, and as such is not readily available (Chan et al., 2020; McManus et al., 2019; Xie, St. Clair, Goldman, \& Joyce, 2019).

Unfortunately, current statistics on PrEP need and prescribing are difficult to ascertain, but the most current CDC estimates suggest that 1.14 to 1.2 million people in the U.S. have PrEP indications (Chan et al.; 2020; Sieglar et al., 2018; Smith, Van Handel, \& Grey, 2018; Smith et al., 2015). In 2016, there were 77,120 PrEP users in the U.S., and almost $50 \%$ of these users were located in five states: Texas, Florida, California, New York, and Illinois. During this period, the Southern U.S. accounted for more than half of all new HIV diagnoses, but only 23,091 people had a PrEP prescription in 2016 (Sieglar et al., 2018).

In 2017, 61,300 individuals nationwide had an active PrEP prescription; however, an examination of the PrEP-to-need-ratio further illuminates the need for HIV PrEP in the Southern U.S. (Sieglar et al., 2018). The PrEP-to-need ratio is calculated by dividing the number of active PrEP prescriptions by the number of new HIV diagnoses in a geographic area. A higher ratio means that the region has better PrEP coverage. The 
Northeast had a PrEP-to-need ratio of 2.9; this was the highest in the nation (Sieglar et al., 2018). The Midwest and West had ratios of 2.1 and 1.8, respectively. The Southern U.S. had the lowest PrEP-to-need ratio at 0.9 (Sieglar et al., 2018).

Smith et al. (2018) suggested that nationwide there were roughly 500,000 African Americans who had PrEP indications in 2016, compared to 26\% White and 25\% Latino. However, only 7,000 PrEP prescriptions were filled for African Americans in 2016 (Smith et al., 2018). By comparison, White people received 42,000 PrEP prescriptions in 2016 (Sieglar et al., 2018; Smith et al., 2018). African Americans make up nearly half of those who could benefit from PrEP nationwide, but the data shows that they are the least likely to have a prescription (Smith et al., 2018). NCHHSTP (2017) data also shows that African American PrEP uptake lags far behind White Americans (Figure 3).

\section{Figure 3}

\section{U.S. PrEP Uptake by Race and Ethnicity, 2016}

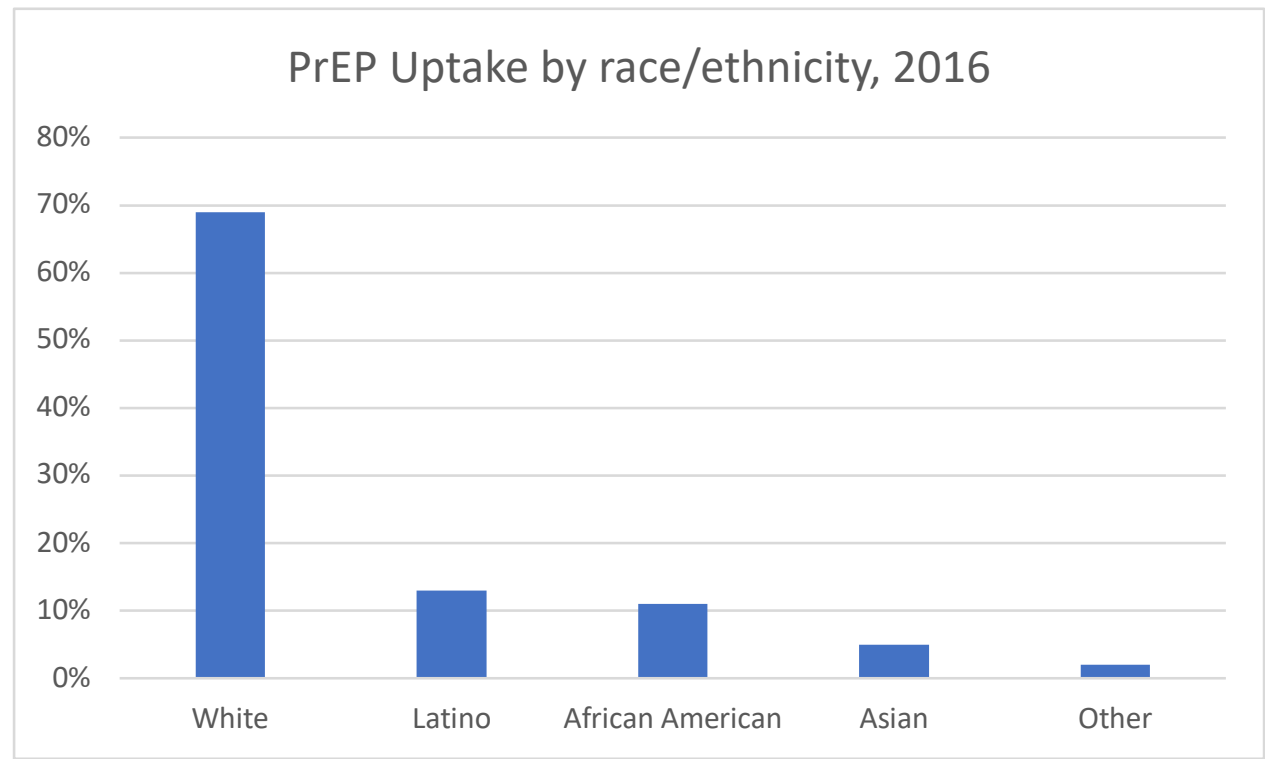

Note. Adapted from "CDC Fact sheet: HIV among African Americans.” by National Center for HIV/AIDS, Viral Hepatitis, STD, and TB Prevention (2017). 


\section{PrEP Uptake in African Americans}

There are several potential barriers that may contribute to the disproportionately low PrEP uptake seen in African Americans. For example, medical distrust within the Black community has been a barrier to healthcare long before the HIV epidemic (Armstrong et al., 2007; Golemon, 2019). Unfortunately, systemic racism and the legacy of the Tuskegee Syphilis Experiments helped to create a lasting mistrust of U.S. healthcare and medical research in Black communities (Katz et al., 2008; Quinn et al., 2019; Powell et al., 2019). Other factors that may preclude PrEP uptake in the African American community include a lack of understanding of HIV risk, poor healthcare access, HIV stigma, poverty, homophobia, and a lack of PrEP knowledge (Aaron et al., 2018; Cahill et al., 2017; Calbrese et al., 2018; Ransome et al., 2020; Siegler et al., 2018; Sullivan et al., 2019).

The research on PrEP uptake for African American MSM is mixed; however, most studies suggest that structural and cultural factors may play a role in the low rates of PrEP uptake that are seen in this group (Aaron et al., 2018; Cahill et al., 2017; Calbrese et al., 2018; Elopre et al., 2017; Goedel et al., 2020; Kanny et al., 2019; Siegler et al., 2018; Sullivan et al., 2019; Wingood et al., 2013). These factors may be due to poverty, racism, homophobia, and stigma (Goedel et al., 2020; Ransome et al., 2020). Additionally, while higher HIV risk perception is correlated with PrEP uptake, some African American MSM populations may have lower perceived HIV risk (Ojikutu et al., 2018). Further, cultural factors unique to Southern African American MSM may require specialized interventions to increase PrEP awareness in this population (Friedmann et al., 2009; Reif et al., 2017). HIV and PrEP-related stigma in the Southern U.S. may also lead to the delayed uptake of 
PrEP (Quinn et al., 2019). Results from focus groups revealed that previous and anticipated negative interactions with healthcare providers, perceived homonegativity, and mistrust of the healthcare system alienated African American MSM and contributed to barriers related to accessing PrEP (Quinn et al., 2019). Structural barriers such as the lack of insurance and transportation, the lack of PCPs who are trained to prescribe PrEP, the lack of transportation, and residing in a state where Medicaid has not expanded may also inhibit PrEP uptake in African American MSM who reside in the Southern U.S. (Ransome et al., 2020; Reif et al., 2017).

In comparison to African American MSM, African American women face similar barriers to PrEP uptake. A 2014 qualitative study by Goparaju et al., (2017) demonstrated that African American women faced several barriers to accessing PrEP. First, they were afraid that significant others, family, and friends might question their reasons for taking PrEP and suspect that they were HIV positive (Goparaju et al., 2017). In particular, hostile reactions from male partners was the expected outcome if these women used PrEP. The study participants also identified the inability to communicate with their healthcare providers about their sexual health and the need for PrEP as a major barrier (Goparaju et al., 2017). The women reported that healthcare providers rarely screened for HIV and STI risk, and the short amount of time that healthcare providers spent with patients hindered communications. Additionally, the women also identified provider stigma and judgment as a potential barrier to accessing PrEP (Goparaju et al., 2017). Finally, PrEP cost, including whether or not insurance would cover the drug and potentially high co-pays were the final barriers that the women identified that might keep 
PrEP out of reach. Despite these barriers, the study participants expressed a willingness and determination to access PrEP (Goparaju et al., 2017).

Few studies have examined PrEP uptake in African American transgender women despite the disproportionate burden of HIV in this population (Brooks et al., 2019; Poteat et al., 2019). Although transgender individuals are underrepresented in population and HIV surveillance data, some studies have estimated an HIV prevalence of between $22 \%$ and 50\% in this population (CDC, 2019g; Herbst et al., 2008; Poteat et al., 2019). A 2019 metanalysis by Becasen et al. estimated that $44 \%$ of African American transwomen have HIV. Further, around half of all African American HIV positive transgender men and women live in the Southern U.S. (CDC, 2019g).

Multiple studies have shown that transgender individuals, particularly transgender women, face barriers to accessing PrEP (Brooks et al., 2019). These include mental health issues, gender-based violence, transphobia, high rates of incarceration, economic marginalization, and high rates of sex work (Deutsch et al., 2015; Poteat et al., 2016; Sevelius et al., 2016). Other barriers that hinder transgender access to PrEP include medical mistrust, a lack of gender-affirming healthcare, fears of side effects related to taking hormones and PrEP simultaneously, and the intersections of HIV stigma, transphobia, and sex work (Deutsch et al., 2015; Poteat et al., 2016; Sevelius et al., 2016; Rael et al., 2018).

A mixed methods study conducted by Poteat et al. (2019) between 2015 and 2017 in Baltimore, MD demonstrated that there was high knowledge regarding PrEP and its use in transgender African Americans; 87 percent of the study population had heard of PrEP. However, only 18 percent of the study population had ever taken PrEP. Seventy- 
five percent of the study population were willing to take PrEP but the primary barriers to accessing PrEP were HIV stigma from medical providers and concerns with PrEP interactions with hormone therapy (Poteat et al., 2019).

PrEP is a highly effective HIV prevention tool that is underutilized by African Americans. Prescription data on the numbers of African Americans who are being prescribed PrEP is difficult to ascertain but numerous studies have demonstrated that African Americans are accessing PrEP at rates far lower than White Americans despite baring the greatest burden of HIV risk and HIV infection in the nation. These disparities highlight the need for research that examines why barriers to accessing PrEP exist as well as ways to remove these barriers.

\section{Primary Care Provider Barriers to Prescribing PrEP}

From the medical provider perspective, a lack of PrEP knowledge, the cost of PrEP, and issues with patient compliance are barriers that might prevent PrEP prescribing by PCPs (Kelly et al., 2015; Marks et al., 2017; Smith, Mendoza, Stryker, \& Rose, 2016; Terndrup et al., 2019). Other potential barriers to PCPs prescribing PrEP may include low patient compliance, high-risk heterosexual sexual behavior, the development of drug resistance, the potential of an increase in high-risk behaviors, and poor medication adherence (Adams, 2016; Clement et al., 2017; Petroll et al., 2016; Liu et al., 2014; Tellalian et al., 2013).

\section{Primary Care Provider PrEP Knowledge}

While PrEP is effective at reducing the risk of HIV infection, PrEP is under prescribed in some parts of the U.S., particularly the Southern U.S. (Clement et al., 2019). One of the often-cited barriers to PrEP prescribing is a lack of PCP knowledge 
regarding what PrEP is and under what circumstances it should be prescribed. Turner, Roepke, Wardell, and Teitelman (2017) conducted a review to identify and synthesize the state of the literature regarding provider knowledge and attitudes related to prescribing PrEP. Turner et al. (2017) defined PrEP knowledge as information, awareness, and/or skills acquired through experience or education. Attitudes were defined as whether or not providers perceived PrEP as beneficial or harmful. Twenty-nine studies were located and 11 were ultimately included in the review. Most of the studies were conducted between 2006 and 2015 and the quality of the studies ranged from low to moderate.

Studies suggest that addressing PCP knowledge and skills regarding PrEP may be key to increasing the rates of PCPs prescribing PrEP (Turner et al., 2017; Terndrup et al., 2019). A 2012 study by Arnold et al. revealed significant HIV and PrEP knowledge gaps in PCPs. These gaps included a lack of knowledge regarding how to identify individuals with PrEP indications and a lack of knowledge regarding PrEP prescribing and monitoring guidelines (Arnold et al., 2012; Tellalian et al., 2013). In contrast, Blumenthal et al. (2015) and Tellalian et al. found that increased knowledge regarding identyfying patients with PrEP indications and knowledge of the CDC PrEP prescribing guidelines is associated with higher rates of PrEP prescribing and future intent to prescribe in PCPs and infectious disease specialists. A survey administered to general internal medicine physicians showed that the physicians prescribed PrEP at higher rates if they reported having knowledge of PrEP (Blackstock et al., 2017; Mayer et al., 2020). Finally, PCPs who are aware of their patients HIV risk factors has been correlated with greater patient awareness of PrEP (Eaton et al., 2015; Mehta et al., 2011). 
Petroll et al. (2017) and Turner et al. (2017) found that infectious disease (ID) practitioners were more knowledgeable about and willing to prescribe PrEP than PCPs. Additionally, advanced practice nurses (APRNs) and physician assistants (PAs) were more likely than primary care physicians to prescribe PrEP (Turner et al., 2017). The most frequently identified barriers to PrEP prescribing among PCPs were limited PrEP knowledge and concerns about cost and insurance coverage (Petroll et al., 2017; Turner et al., 2017). These findings suggest that PCPs with experience caring for patients with HIV and prescribing antiretroviral therapy had more knowledge about PrEP and were more willing to prescribe it. Further, it was determined that knowledge of the CDC guidelines regarding PrEP prescribing influenced PrEP prescribing practices (Turner et al., 2017). It was concluded that the success of PrEP is linked to increased education and training for primary care providers.

Southern PCP PrEP prescribing. To date, most studies examining PCP PrEP prescribing practices have focused on national samples. Few studies have specifically examined Southern PCP provider PrEP adoption behaviors (Clement et al., 2018; Clement et al., 2019). A 2015 online survey given to providers at a large academic medical center in North Carolina assessed provider knowledge about PrEP and prescribing practices (Clement et al., 2018). Later, an educational intervention was provided to 14 PCP offices in North Carolina in 2016 (Clement et al., 2018).

115 providers initially completed the survey, with 78 reporting that they saw MSM patients. Of that number, only 17 had ever prescribed PrEP. 60 PCPs acknowledged that the lack of PrEP knowledge was the primary barrier to prescribing PrEP (Clement et al., 2018). When the survey was repeated after the educational 
intervention, 79 PCPs responded (Clement et al., 2018). Of this number, 71 reported seeing MSM patients and 28 reported prescribing PrEP. Clement et al. (2018) found that PCPs who participated in the intervention were more likely to have prescribed PrEP (OR 4.84, CI 1.77-13.21). The identified lack of PrEP knowledge in PCPs motivated an institution-wide educational intervention to address this issue (Clement et al., 2018). Ultimately, this study points to the need to continue to educate and raise PrEP awareness among PCPs in the Southern U.S.

\section{HIV Stigma and Provider Perceptions Towards PrEP}

Social biases and HIV stigma among healthcare providers may pose a barrier to PrEP access (Marshall et al., 2017). Few studies have directly addressed PCP stigma as it relates to PrEP but a number of studies have demonstrated that healthcare provider stigma is an issue for individuals seeking HIV-related prevention and treatment services (Geter et al., 2018; Goparaju et al, 2017). While it has been documented that people living with HIV (PLWH) experience healthcare-related stigma, its manifestation varies by sociocultural and socioecological context (Marshall et al., 2017). Accordingly, it has been difficult to assess the depth and impact of stigma on PLWH.

PLWH and patients who have PrEP indications report that HIV stigma is prevalent in the U.S. (Goparaju et al., 2017; Zukosi et al., 2009; Sayles et al., 2007; Stringer et al., 2016). While recent data is difficult to locate, between 2005 and 2007, more than $25 \%$ of PLWH reported feeling stigmatized by their healthcare providers (Sayles et al., 2007; Schuster et al., 2005). Some of the behaviors that were noted in clinicians included double gloving, wearing protective masks and suits, and avoiding patient appointments (Blake et al., 2008; Sayles et al., 2007; Lindau et al., 2006; 
Rintamaki et al., 2007). In extreme cases, healthcare providers have been reported to have refused to touch patients, perform physical examinations, and some patients even reported being denied service (Lindau et al., 2006; Rintamaki et al., 2007; Schuster et al., 2005; Wingood et al., 2007).

There are only a small number of studies that have assessed HIV and PrEP-related stigma from the perspective of healthcare providers (Geter et al., 2018; Goparaju et al, 2017). However, Stringer et al. (2017) conducted a cross sectional study that examined HIV-related stigma in 651 southern healthcare workers. Data suggested that being White, Protestant, working in an HIV clinic, the lack of availability of PrEP, and the perceptions that anti-discrimination policies would not be enforced correlated with higher levels of HIV-related stigma in healthcare workers. Some providers, including PCPs, have indicated that they are not willing to prescribe to high-risk heterosexuals and IV drug users (Adams \& Balderson, 2016).

While the unwillingness to prescribe to these two groups does not in and of itself mean that a PCP harbors stigma related to PrEP, these beliefs may hinder the development of relationships with patients have PrEP indications (Adams \& Balderson, 2016). Previous research suggests that the more contact that providers have with PLWH, the greater is the likelihood that the provider will have positive attitudes towards their patients (Andrewin \& Chien, 2008; Feyissa et al., 2012; Rogers et al., 2014; Brown et al., 2003). Further, research indicates that HIV training is correlated with lower levels of HIV-related stigma in healthcare providers and the presence and enforcement of institutional policies to protect PLWH is also related to a decrease in healthcare provider stigma (Feyissa et al., 2012; Li et al., 2007; Mayer et al., 2020). 


\section{Cost of PrEP}

It is unclear if the cost of PrEP, the lack of health insurance, or issues with obtaining prior authorization, influence provider PrEP prescribing practices. Some research suggests that the cost of PrEP and whether or not it is covered by health insurance may be factors that influence PrEP prescribing practices (Horberg \& Raymond, 2013; O’Bryne et al., 2019). According to the CDC, Truvada ${ }^{\circledR}$ has an annual cost of $\$ 8,000$ to $\$ 14,000$ for individuals without insurance (CDC, 2019c). Since 2012, Gilead has increased the cost of Truvada ${ }^{\circledR}$ by about $45 \%$ (Luthra \& Gorman, 2018). While Gilead does waive up to $\$ 4,800$, via co-pay coupons, in out-of-pocket PrEP costs for customers who have commercial insurance, many health plans are restricting the use of co-pay coupons by not allowing them to count towards patients' deductibles (Luthra \& Gorman, 2018; McManus et al., 2020). The overall effect of this is that patients are now responsible for an increasing share of their PrEP costs (O'Bryne et al., 2019).

Another potential barrier to PrEP access is that insurance coverage under the Patient Protection and Affordable Care Act (PPACA) varies based on the plan. The Ryan White program covers HIV medication for individuals with HIV disease, as does Medicare Part D, but some Medicaid and private plans only started covering PrEP in 2019 (Horberg \& Raymond, 2013; Horberg, 2013; Scott \& Volberding, 2019). Additional factors that influence the cost of PrEP include laboratory costs, provider fees, and PrEP training for providers (Horberg \& Raymond, 2013; McManus et al., 2020; O’Bryne et al., 2019). Horberg and Raymond (2013) posit that while the relationship between the high cost of PrEP and provider prescribing practices remains unclear, this is an area that is worthy of additional study. 
An issue that is related to the cost of PrEP are disparities related to the need to have prior authorization to access PrEP. McManus et al. (2020) conducted a cross sectional study to determine if regional differences exist in prior authorization requirements for PrEP. McManus et al. (2020) examined 16,853 qualified health plans (QHPs) in the 2019 Affordable Care Marketplace; each plan that was studied included Affordable Care Act-compliant individual and small-group market plans (McManus et al., 2020). The census regions studied were the Northeast, West, Midwest, and the South.

The results of this study showed that nationally, 18.9\% of QHPs required prior authorization for PrEP. The percentage varied based on region and the Midwest and South had the greatest percentage of plans that required prior authorization at $13.3 \%$ and $37.3 \%$ respectively. QHPs in the South were almost 16 times as likely to require prior authorization as compared to QHPs in the Northeast. The Midwest and West were only 5.69 and 2.65 times as likely respectively (McManus et al., 2020). The reasons for these disparities are unknown; however, the higher rates of prior authorization for PrEP in the South may be a barrier to PCPs prescribing PrEP. Discriminatory QHP designs that mandate stringent prior authorization requirements may be a systemic barrier that contributes to low PrEP prescribing by PCPs in the Southern U.S. (McManus et al., 2020).

\section{Theoretical Framework for Study}

Few studies on health care provider prescribing behaviors have a sound theoretical foundation (Murshid \& Mohaidin, 2017). Medication prescribing by healthcare providers is a complex phenomenon that is motivated by various factors. Many of the existing studies examining provider prescribing behavior examine this 
behavior from an exploratory instead of a theoretical basis (Murshid \& Mohaidin, 2017). Therefore, it is important to consider the use of appropriate theoretical frameworks for examining provider prescribing behaviors for PrEP.

None of the studies evaluated for this review discussed their theoretical underpinnings. Theoretical frameworks are useful because they can help researchers choose appropriate research questions, guide experimental methods, describe and generalize various aspects of the phenomenon under study, and identify limits to those generalizations (Shepherd \& Suddaby, 2017). This study will make use of the Transtheoretical Stages of Change Model (TTM) as its guiding theoretical framework. The TTM has been used in a variety of community and public health interventions, including studies that seek to assess the intent to perform a behavior and how behavior change occurs.

TTM has emerged as a leading stages of change model that is used to explain how individuals change their behavior (Prochaska et al., 2008). TTM has been used to explain how individuals change health behaviors (Prochaska et al., 1992). For example, TTM has been used to describe behavior change related to smoking cessation, the adoption of healthy eating behaviors, and condom usage (Horwath, 1999; Pallonen et al., 2009; Prochaska, DiClemente, \& Norcross, 1992). Researchers has consistently shown TTM's ability to help decipher human behavior change processes; however, no studies were located that discussed healthcare provider prescribing behavior. Next, the constructs of the TTM model will be described. TTM consists of the following constructs: Stages of Change, Processes of Change, Decisional Balance, and Self Efficacy. 


\section{Stages of Change}

To explain how and when individuals make a behavior change, TTM posits that behavior change occurs across five stages. While the stages are traditionally presented in a linear fashion, individuals may enter or exit the behavior change stages at any point and individuals may move froward or backwards by skipping stages (Prochaska, Norcross, \& DiClemente, 1994). To successfully make a behavior change, individuals cycle through multiple decisions at each stage before making a final decision to change a behavior (Prochaska et al., 2008). Part of long-term behavior change, according to Levesque, Prochaska, and Prochaska (1999), involves settling on the desired behavior change and then making it a regular part of the individuals daily life. The five stages of change are defined as the following (Levesque et al., 1999):

1.Precontemplation: Individuals have no intention to change their behavior within the next six months.

2. Contemplation: Individuals plan to take action to change their behavior within the next six months.

3.Preparation: Individuals plan to take action within the next 30 days to change their behavior and have taken steps towards this goal.

4. Action: Individuals have changed their behaviors for less than six months.

5. Maintenance: Individuals have maintained a behavior change for more than six months.

Some iterations of TTM include a "Relapse" and "Termination" phase. At the Termination phase, individuals are successfully maintaining their behavior change and are $100 \%$ confident that they will not relapse (Prochaska et al., 2008). In contrast, when individuals relapse, the patient reverts to prior health behaviors and individuals at this phase may re-enter the stages of change at an earlier stage of change (Prochaska et al., 2008). While "Relapse" and "Termination" are useful TTM constructs, they will not be assessed as part of this study. 


\section{Processes of Change}

The TTM Processes of Change are the strategies that individuals use to progress through the stages of change (Nigg et al., 2011; Prochaska et al., 2008). The processes of change are important because they may provide a useful roadmap to guide the development of interventions. To date, ten processes of change have been formulated as seen in table 6. Research has shown that successful behavior change interventions focus on different processes of change at particular stages of change (Figure 4) (Nigg et al., 2011). The use of matched processes of change and stages of change gives a special quality to TTM: Interventions can be designed as stage-matched behavior change interventions as opposed to action-oriented stage interventions (Nigg et al., 2011).

\section{Table 7}

Transtheoretical Model Stages of Change - Processes of Change and Their Descriptions

\begin{tabular}{ll}
\hline \multicolumn{1}{c}{ Process of Change } & \multicolumn{1}{c}{ Description } \\
\hline Consciousness-raising & $\begin{array}{l}\text { Finding information that supports a } \\
\text { behavior change }\end{array}$ \\
Dramatic relief & $\begin{array}{l}\text { Negative emotions that go along with } \\
\text { unhealthy behaviors } \\
\text { Realizing the negative impact of the } \\
\text { unhealthy behavior }\end{array}$ \\
Environmental reevaluation & $\begin{array}{l}\text { Realizing that the social norms are } \\
\text { changing in the direction of supporting the } \\
\text { behavior change }\end{array}$ \\
Social liberation & $\begin{array}{l}\text { Realizing that behavior change is an } \\
\text { important part of one's identity }\end{array}$ \\
Self-reevaluation & $\begin{array}{l}\text { Making a commitment to change } \\
\text { Increasing the reward for the positive } \\
\text { behavior change }\end{array}$ \\
Self-liberation & $\begin{array}{l}\text { Seeking social support to help make the } \\
\text { behavior change } \\
\text { Reinforcement management } \\
\text { Substitution of healthier alternative } \\
\text { behaviors and thoughts for the unhealthy } \\
\text { behavior }\end{array}$ \\
Helping relationships & $\begin{array}{l}\text { Removing reminders and cues for the } \\
\text { unhealthy behavior }\end{array}$ \\
Counter conditioning &
\end{tabular}




\section{Figure 4}

TTM Stages of Change and Their Corresponding Processes of Change

\begin{tabular}{|c|c|c|c|}
\hline Precontemplation & Contemplation & Preparation & Mainten \\
\hline \multicolumn{4}{|c|}{ Consciousness-Raising } \\
\hline \multicolumn{4}{|l|}{ Dramatic Relief } \\
\hline \multicolumn{4}{|c|}{ Environmental Reevaluation } \\
\hline \multicolumn{4}{|l|}{ Social Liberation } \\
\hline & Self-Reevaluation & & \\
\hline & & Self-Liberation & \\
\hline & & & Reinforcement Management \\
\hline & & & Helping Relationships \\
\hline & & & Counter-Conditioning \\
\hline & & & Stimulus Control \\
\hline
\end{tabular}

Note. Adapted from "The transtheoretical model and stages of change" by Prochaska, J.O., Redding, C.A., \& Evers, K.E. (2008). In K. Glanz, B.K. Rimer, \& K. Viswanath (Eds.), Health behavior and health education (4 ${ }^{\text {th }}$ ed., pp. 97-117). San Francisco, CA: Wiley.

\section{Decisional Balance}

In addition to the stages of change and the processes of change, TTM has a construct, decisional balance, that helps to explain how individuals weigh the benefits (pros/facilitators) and costs (cons/barriers) in regard to changing a behavior (Burditt et al., 2009; Prochaska et al., 2008). The decisional balance construct, an outgrowth of work done by Janis and Mann (1977), was added to TTM in 1985 by Velicer et al. Velicer et al. (1985) devised a 24-item decisional balance instrument to study smoking cessation decision making processes across the stages of change. Research has shown that 
decisional balance is an excellent predictor of behavior change (Fernandez et al., 2016; Gullette et al., 2009; Liu et al., 2018). During the early TTM stages of change, individuals typically perceive more cons that are associated with changing a behavior (Prochaska et al., 2008). In contrast, during the later TTM stages of change, individuals tend to perceive more pros to changing a behavior (Prochaska et al., 2008). Overall, changing behaviors involves individuals weighing the pros and cons (i.e., decisional balance) that are associated with changing a behavior and decisional balance has been shown to be an excellent predictor of behavior change as individuals progress through the different TTM stages of change (Prochaska et al., 2008).

\section{Self-Efficacy}

The self-efficacy construct, adapted from Bandura's (1982) Self-Efficacy Theory, refers to one's ability to cope during stressful situations (Fernandez et al., 2016; Prochaska et al., 2008). The perceived self-efficacy of an individual has been shown to influence decision-making regarding making a behavior change, the amount of effort invested in making the behavior change, and the ability to maintain the behavior change over a long period of time (Fernandez et al., 2016). When matched to the stages of change, self-efficacy is found to be lowest at the pre-contemplation stage and peaks at the maintenance stage (Burditt et al., 2009). Self-efficacy has been found to increase in a linear fashion across the stages of change. Additionally, this construct has been experimentally shown to be an important predictor of progress through the TTM stages of change (Oka, 2003). Figure 5 demonstrates the relationships between the stages of change, processes of change, decisional balance, and self-efficacy in the TTM (Burkholder \& Nigg, 2002). 


\section{Figure 5}

The Relationships Between the Stages of Change, Processes of Change, Decisional Balance, and Self-efficacy in the TTM

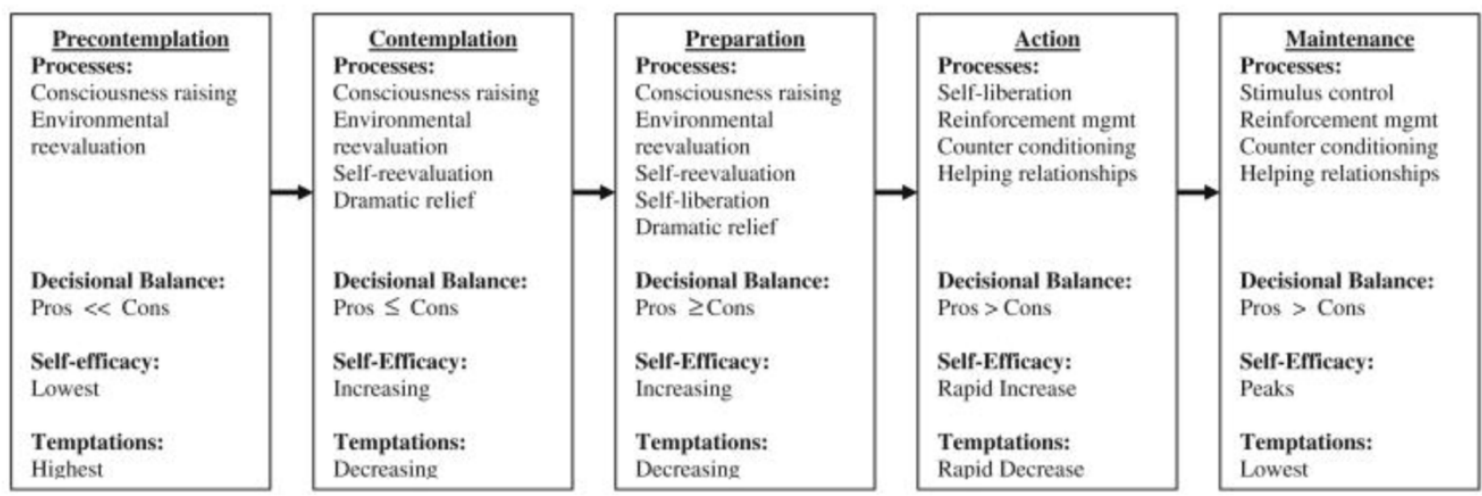

Note. Adapted from "Overview of the transtheoretical model” by Burkholder, G.J., \&

Nigg, C. (2002). In P.M. Burbank \& D. Riebe (Eds.), Promoting exercise and behavior change in older adults: Interventions with the transtheoretical model (p. 57-84). Springer.

\section{Limitations}

Like all behavioral theories, TTM has its limitations. For starters, TTM does not address the socioeconomic contexts in which change occurs (Nigg et al., 2011). Research has shown that socioeconomic context is an important predictor of behavior change (Gaalema et al., 2017). Next, no set criteria determines a person's stage of change and many of the instruments that are used to determine an individual's stage of change are not always validated by empirical data (Armitage, 2009; Littell \& Girvin, 2002; Paxton et al., 2008; West, 2005). The TTM does not address the length of time that is needed for an individual to advance from one stage to the next (Nigg et al., 2011). Finally, TTM assumes that an individual's decision making related to behavior change is a logical, coherent process, which is not always the case (West, 2005). 


\section{Summary}

The existing literature shows that PrEP is a highly effective HIV prevention strategy. However, the uptake of PrEP among African Americans lags behind that of other U.S. at-risk groups. There are few studies that have examined PrEP prescribing practices among national or Southern PCPs and the studies regarding whether or not a lack of PrEP education and cost are barriers to PCP PrEP prescribing, are contradictory. Additionally, few studies have examined the role of stigma in PCP PrEP prescribing decisions; most studies have examined stigma in PrEP prescribing from the patient perspective. An interesting element of the majority of these studies is that they have not explicitly described the use of a theoretical framework to attempt to describe barriers to HIV PrEP prescribing. These gaps in the literature suggest that the current proposed study may fill some of the existing gaps regarding PCP PrEP prescribing practices. The next chapter, chapter 3 , will address the research methodology, sample size, and the statistical procedures used to test the research hypotheses. 


\section{CHAPTER 3: METHODOLOGY}

Pre-exposure prophylaxis (PrEP) is a highly effective strategy to reduce the risk of acquiring HIV (Buchbinder, 2018). However, PrEP uptake by African Americans residing in the Southern U.S. is low (Chan et al., 2020). An estimated 500,000 African Americans have PrEP indications (Smith et al., 2018), but in the most recent year for which data is available, only 7,000 to 8,700 African Americans were taking PrEP (Huang

et al., 2018). Studies have examined the factors that contribute to low PrEP uptake among African Americans (Aaron et al., 2018; Brooks et al., 2019; Cahill et al., 2017; Calbrese et al., 2018; Elopre et al., 2017; Goedel et al., 2020; Goparaju et al., 2017; Kanny et al., 2019; Ojikutu et al., 2018; Poteat et al., 2019; Quinn et al., 2019; Ransome et al., 2020; Reif et al., 2017; Siegler et al., 2018; Sullivan et al., 2019). However, few studies have focused on the role of primary care provider ( $\mathrm{PCP}$ ) prescribing practices with regard to PrEP uptake in the Southern U.S.

This cross-sectional study examined the factors that influenced the PrEP prescribing practices of PCPs. In this chapter, the research design and the justification for its use are described. The research questions and hypotheses, participant recruitment, data analysis, and sample size were also described. The chapter concluded with descriptions of the data collection procedure, human subjects' protections, and a description of the survey instrument.

\section{Research Design and Rationale}

This cross-sectional study used a convenience sample to examine factors that influence the PrEP prescribing behaviors of PCPs in the Southern U.S. Further, the study provided a quantitative examination of the PCP personal and professional variables that 
align with the Transtheoretical Stages of Change Model (TTM) that predict prescribing versus not prescribing PrEP. Next, the study provided quantitative information about what variables predict whether a PCP will prescribe PrEP. Finally, the study provided information that may validate the use of TTM as an appropriate model to use when assessing PCP PrEP prescribing practices. The outcome variables of interest to this study were the stage of adoption of PrEP prescribing and prescribing or not prescribing PrEP. The stages of the TTM, as they relate to PrEP prescribing are (Table 8):

\section{Table 8}

Stages of the TTM in Relation to PrEP Prescribing

\begin{tabular}{ll}
\hline \multicolumn{1}{c}{ Stage } & \multicolumn{1}{c}{ Answer } \\
\hline Pre-contemplation & No and I do not intend to in the next 6 \\
& months \\
Contemplation & No, but I intend to in the next 6 months \\
Preparation & No, but I intend to in the next 30 days \\
Action & Yes, I have been for less than 6 months \\
Maintenance & Yes, I have been for more than 6 months \\
\hline
\end{tabular}

The key predictors of interest are PCP provider characteristics and personal variables.

\section{Research Questions and Hypotheses}

Research Question 1: What is the relationship between personal and practice variables and the stage of change of PrEP prescribing?

$\mathrm{H}_{0}$ 1: No relationship exists between personal and practice variables and the stage of change of PrEP prescribing.

Personal variables included age, race/ethnicity, gender, and sexual orientation. Practice variables included type of primary care practitioner (physician, nurse practitioner, or physician assistant), type of degree, state of practice, years of practice, practice setting (rural, suburban, or urban), whether or not the provider had heard of 
PrEP, whether or not the provider had training on PrEP, whether or not the provider routinely screened African American patients for HIV, whether or not the provider routinely screened African American patients for PrEP need, whether or not PrEP had been prescribed to any African American patients, whether or not the provider had ever referred patients out for PrEP, whether or not the provider routinely referred patients out for PrEP, and whether or not African American patients were seen in the provider's primary care practice.

$H_{a} 1$ : A relationship exists between personal and practice variables and the stage of change of PrEP prescribing.

Research Question 2: Do primary care provider's personal and practice variables predict prescribing or not prescribing PrEP?

$\mathrm{H}_{0}$ 2: Personal and practice variables do not predict prescribing or not prescribing PrEP.

$\mathrm{H}_{\mathrm{a}} 2$ : Personal and practice variables do predict prescribing or not prescribing PrEP.

Research Question 3: What is the relationship between TTM decisional balance and the stage of change of PrEP prescribing? Decisional balance facilitators of PrEP prescribing included PrEP training during residency, staff or providers in the clinic who were knowledgeable about PrEP provision, access to PrEP prescribing guidelines and protocols, clinic inservice PrEP training, knowledge of PrEP's efficacy, patient motivation to use PrEP as prescribed, peers who prescribed PrEP, patient access to financial incentives that would lower the cost of PrEP and streamlined prior authorization procedures. 
Decisional balance barriers to PrEP prescribing included lack of provider PrEP training and education, lack of clinic leadership support regarding PrEP, lack of PrEP usage guidelines, clinic and lab monitoring requirements, staffing time constraints related to HIV risk reduction and PrEP adherence counseling, lack of patient insurance coverage and patient out-of-pocket costs, low PrEP adherence by patients, HIV resistance developing due to PrEP, increase in risk behaviors by patients on PrEP, and insufficient evidence of PrEP's efficacy.

$\mathrm{H}_{0}$ 3: No relationship exists between TTM decisional balance and the stage of change of PrEP prescribing.

$\mathrm{H}_{\mathrm{a}} 3$ : A relationship exists between TTM decisional balance and the stage of change of PrEP prescribing.

Research Question 4: Do primary care provider's TTM decisional balance predict prescribing or not prescribing PrEP?

$\mathrm{H}_{0} 4$ : TTM decisional balance does not predict prescribing or not prescribing PrEP.

$\mathrm{H}_{\mathrm{a}} 4$ : TTM decisional balance does predict prescribing or not prescribing PrEP.

\section{Table 9}

Summary of Hypotheses, Statistical Tests, and Scales of Measurement

\begin{tabular}{llll}
\hline Hypothesis & $\begin{array}{l}\text { Statistical } \\
\text { Test }\end{array}$ & $\begin{array}{l}\text { Independent } \\
\text { Variable/Scale of } \\
\text { Measurement }\end{array}$ & $\begin{array}{l}\text { Dependent } \\
\text { Variable/Scale of } \\
\text { Measurement }\end{array}$ \\
\hline $\begin{array}{l}\mathrm{H}_{0} 1 \text { : There is no } \\
\text { relationship between } \\
\text { personal and practice } \\
\text { variables and the stage } \\
\begin{array}{l}\text { of change of PrEP } \\
\text { prescribing. }\end{array}\end{array}$ & $\begin{array}{l}\text { Ordinal } \\
\text { Logistic }\end{array}$ & $\begin{array}{l}\text { Personal (Age/Interval } \\
\text { Gender/Nominal }\end{array}$ & $\begin{array}{l}\text { Stage of Change } \\
\text { of Prescribing }\end{array}$ \\
& & $\begin{array}{l}\text { Race/Ethnicity/Nominal } \\
\text { Sexual Orientation/ }\end{array}$ & PrEP/Ordinal \\
& & Nominal) & \\
\hline
\end{tabular}




\section{$\mathrm{H}_{\mathrm{a}} 1$ : There is a relationship between personal and practice variables and the stage of change of PrEP prescribing.}

$\mathrm{H}_{0}$ 2: Personal and practice variables do not predict prescribing or not prescribing PrEP.

$\mathrm{H}_{\mathrm{a}}$ 2: Personal and practice variables predict prescribing or not prescribing PrEP.

$\mathrm{H}_{0} 3$ : There is no relationship between TTM decisional balance and the stage of change of PrEP prescribing.

$\mathrm{H}_{\mathrm{a}} 3$ : There is a relationship between TTM decisional balance and the stage of change of PrEP prescribing.

$\mathrm{H}_{0} 4$ : TTM decisional balance does not predict prescribing or not prescribing PrEP.

$\mathrm{H}_{\mathrm{a}} 4$ : TTM decisional balance does predict prescribing or not prescribing PrEP.
Practice Variables (Type

of primary care

practitioner/Nominal

Years of practice/Ordinal

Practice Setting/Nominal

Receipt of Training on

PrEP/Nominal

State/Nominal)

Binary
Logistic
Regression

Personal (Age/Interval

Gender/Nominal

Race/Ethnicity/ Nominal

Sexual Orientation/

Nominal)

Practice Variables (Type

of primary care

practitioner/Nominal

Years of practice/Ordinal

Practice Setting/Nominal

Receipt of Training on

PrEP/Nominal

State/Nominal)

Ordinal

Logistic

Regression

TTM decisional balance facilitators and barriers

Stage of Change of Prescribing (Individual items/Ordinal)
Prescribing

Behavior/

Nominal
PrEP/Ordinal

\section{Binary \\ TTM decisional balance \\ Prescribing \\ Logistic facilitators and barriers \\ Behavior/ \\ Regression \\ (Individual items/Ordinal) \\ Nominal}




\section{Setting and Sample}

Participants for this study consisted of PCPs who practiced in one or more of the following states: Alabama, Arkansas, Georgia, Florida, Louisiana, Mississippi, North and South Carolina, Tennessee, and Texas. According to the CDC (2019), these southern states have larger populations of African Americans at risk of contracting HIV. Further, these states have large MSAs where HIV is prominent (Reif et al., 2017; U.S. Census Bureau, 2016). Other inclusion criteria included: 1) being a licensed physician, nurse practitioner, or physician assistant, 2) practicing in a primary care area of health, and 3) the ability to read, write, and understand English.

\section{Participant Recruitment}

Participants for this study were recruited from Alabama, Arkansas, Georgia, Florida, Louisiana, Mississippi, North and South Carolina, Tennessee, and Texas. Participant recruitment used a multi-pronged approach. An online Qualtrics ${ }^{\circledR}$ survey was distributed through several Facebook pages, including Paul A. Ambrose 2020-2021, Black Men in Medicine, Minority Medical Mentoring, MUSSON PhD Students, PhinishEd/FinishEdD, Texas Family Physicians, Physician Community, American College of Osteopathic Family Physicians, American Medical Association Change MedEd, and the Association of Primary Care Providers in the Americas. Physicians, nurse practitioners, and physician assistants have professional memberships within these various groups. Further, each of these groups had granted permission to post the survey. A.T. Still University-School of Osteopathic Medicine in Arizona (ATSU-SOMA) has affiliations with community health centers (CHCs) in Wichita Falls, TX and Beaufort, SC; and, as a current adjunct faculty member at ATSU-SOMA, the graduate student 
researcher was given permission to disseminate the survey to the ATSU-affiliated CHCs, upon IRB approval from the University of Missouri and ATSU.

External committee member, Dr. Melva Thompson-Robinson, facilitated contact with Ms. LaShannon Spencer, the Chief Executive Officer of the Community Health Centers of Arkansas. The graduate student researcher received permission to disseminate the research instrument to the community health centers $(\mathrm{CHCs})$ in this network via electronic mail. Ms. Spencer also agreed to assist with the dissemination of the survey instrument to CHC colleagues in Louisiana, Mississippi, Alabama, and Tennessee. Dr. Tala Dajani, a physician and ATSU-SOMA faculty member, granted the graduate student researcher access to three national email listservs, including two for primary care physicians and one for APRNs. The Texas Nurse Practitioner Association distributed this study's survey instrument to its membership via two email blasts in March and April. Finally, ATSU-affiliated PCPs in Florida, Georgia, and Alabama had agreed to disseminate the survey instrument to colleagues in those states.

Recruitment flyers, which contained a QR code linking participants to the survey, were disseminated to PCPs via word of mouth, LinkedIn, and several PCP hashtag communities on Twitter. A Facebook page was also developed for the study. The page contained a brief description of the study's objectives and intended sample population. PCPs were invited to take the survey through the Qualtrics ${ }^{\circledR}$ link that was embedded within the page. Finally, targeted Facebook advertising was used to promote the research to those Facebook pages that have members meeting the study's demographic; and advertising took place for one month to maximize participant response. 


\section{Protection of Human Subjects}

Before conducting the study, permission was obtained from the University of Missouri Institutional Review Board (IRB). Steps to protect human subjects included administering the survey over a secured website. No participant names, email addresses, or birth dates were collected as part of the survey. The Internet Protocol (IP) addresses were stripped from the survey responses before uploading them to SPSS Version 26. The SPSS Version 26 database was password protected, and only the primary investigator and dissertation chair had access to this information.

Participants were notified that their participation in the study was strictly voluntary. Other protections included notifying participants that they were free to stop answering survey questions at any time. The informed consent that was provided before the survey instrument, explained to participants that they could skip any questions they did not wish to answer. The contact information for the primary investigator, dissertation chair, and the University of Missouri IRB offices was noted on the consent page and at the end of the survey.

\section{Alpha Level and Sample size}

The alpha level in a study is the probability of rejecting the null hypothesis under the assumption that the null hypothesis is true. In the social sciences, the alpha level is $p$ $<.05$ (Brace, Kemp, \& Snelgar, 2013). It is the probability of making a Type I error.

\section{Power Analysis for Sample Size}

A power analysis for a logistic regression was conducted using $\mathrm{G}^{*}$ Power 3.1.9.4 (Faul, Erdfelder, Lang, \& Buchner, 2007; Faul, Erdfelder, Buchner, \& Lang, 2013) to determine the appropriate sample size for the analysis. The effect size parameter for the 
power analysis was selected using the guidelines established by Lipsy and Hurley (1998), who suggested an odds ratio of 2 for a medium effect size. The power analysis revealed that for a medium effect size, an alpha of .05 , and a power of .80 , the desired sample size was 219. This is illustrated in figure 6. While the minimum sample size needed was 219 , a sample of 300 was collected to minimize the effect of incomplete surveys.

\section{Figure 6}

\section{A Priori Sample Size Calculation}

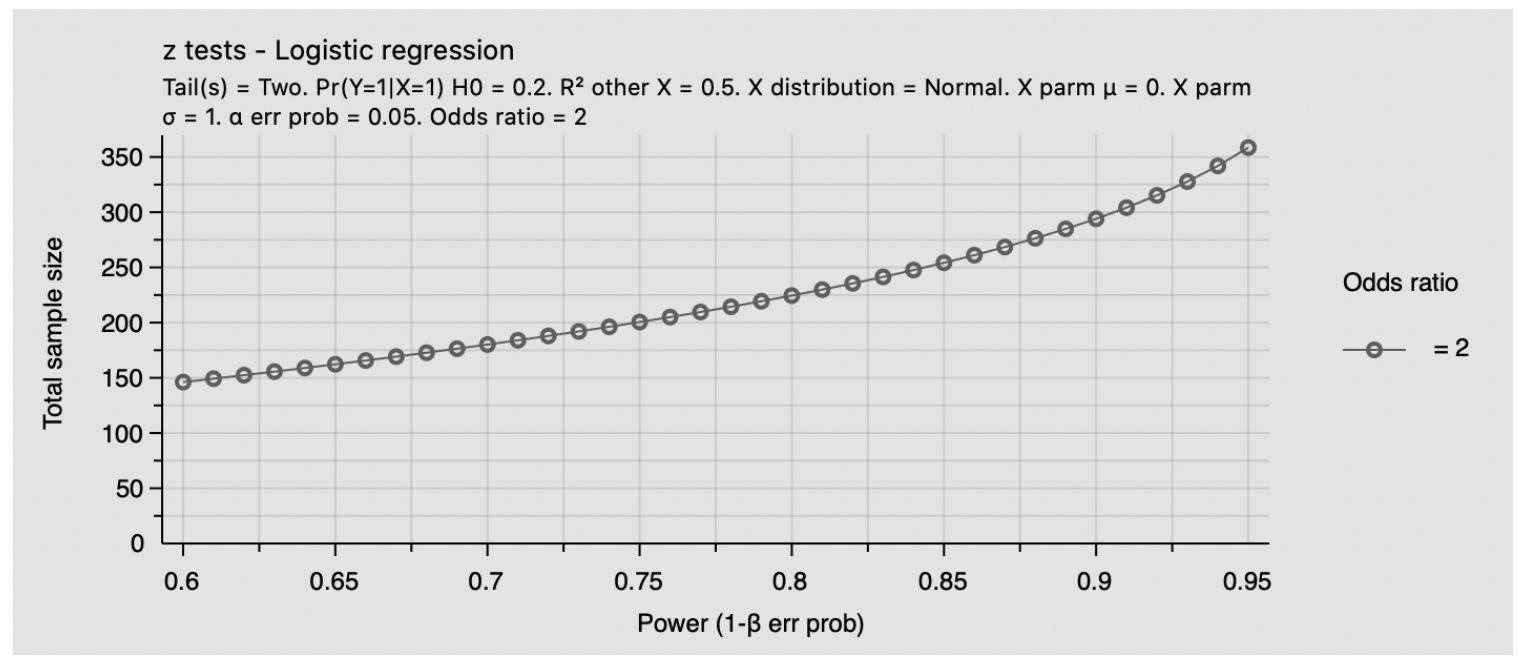

\section{Procedures for Data Collection}

After the University of Missouri-Columbia's IRB approved the study, survey dissemination via social media and other discussed channels occurred over a seven-week timeframe. Each invitation to participate in the study included a sentence inviting PCPs in the Southern U.S. to participate in a study about HIV PrEP prescribing practices. PCPs were invited to click on the survey link if interested in participating.

Upon clicking the website that linked to the Qualtrics ${ }^{\circledR}$ survey, participants were able to view the study information page, which included the informed consent. The informed consent explained the study's purpose. Survey participants also saw the 
eligibility and inclusion criteria for the study. After reading this material, participants were given a chance to check a box stating that they agreed to participate in the study or a separate check box indicating that they did not wish to participate. Those participants who checked "yes," were taken to the next part of the survey that assessed whether they met the study inclusion criteria. The inclusion questions were as follows:

- Do you provide consent to participate in this study?

- Are you 18 years of age or older?

- Are you a licensed physician, advanced practice registered nurse, of physician assistant?

- Do you currently practice primary care medicine?

- Do you practice in one or more of the following states? Check all that apply. _ Arkansas

Alabama

_ Georgia

- Florida

_ Louisiana

- Mississippi

_ North Carolina

— South Carolina

— Tennessee

- Texas

_ None of the above

If participants did not meet the inclusion criteria, they were taken to a screen that thanked them for their participation, and they were exited from the survey.

\section{Data Analysis}

Data was analyzed using SPSS Version 26. Before analysis, the data was screened for missing responses, strange patterns, and inconsistencies in the data. The data was visually inspected and frequency distributions and summary statistics were run to detect outliers. To address Research Questions 1 and 3, an ordinal logistic regression was conducted. An ordinal logistic regression is appropriate to conduct when the aim of the research involves determining the relationships between multiple independent (predictor) 
variables and a single ordinal dependent (criterion) variable (Field, 2013). In this analysis, the independent variables for RQ 1 included the personal variables of age, race/ethnicity, gender, and sexual orientation. The practice variables consisted of the type of primary care practitioner (i.e., physician, nurse practitioner, or physician assistant), years of practice, practice setting (i.e., urban, suburban, rural), state of practice, and the receipt of training on HIV and PrEP.

For RQ 3, the independent variables for TTM decisional balance facilitators of PrEP prescribing included PrEP training during residency (for physicians), staff or providers in their clinic who were knowledgeable about PrEP provision, access to resources such as PrEP prescribing guidelines and protocols, clinic in-service PrEP training, knowledge of PrEP's efficacy, patient motivation to use PrEP as prescribed, peers who prescribed PrEP, patient access to financial incentives that would lower the cost of PrEP, and streamlined prior authorization procedures. Decisional balance barriers to PrEP prescribing included lack of provider PrEP training and education, lack of clinic leadership support regarding PrEP, lack of PrEP usage guidelines, clinic and lab monitoring requirements, staffing time constraints related to HIV risk reduction and PrEP adherence counseling, lack of patient insurance coverage and patient out-of-pocket costs, low PrEP adherence by patients, HIV resistance developing due to PrEP, increase in risk behaviors by patients on PrEP, and insufficient evidence of PrEP's efficacy.

The dependent variable was the TTM stages of change. The TTM stage of change was an ordinal variable, with higher levels reflecting a higher stage of change. The significance of the overall model was assessed using the $\chi^{2}$ test; if this test was significant at an alpha level of .05, the null hypothesis was rejected. If the overall model was 
significant, coefficients for each independent variable were examined to determine the relationships between the personal and practice variables, as well as the TTM stage of change regarding the adoption of PrEP prescribing.

To address Research Questions 2 and 4, binary logistic regression was conducted. A binary logistic regression is appropriate to conduct when the aim of the research involves determining the relationships between multiple independent (predictor) variables and a single dichotomous dependent (criterion) variable (Field, 2013; Stevens, 2009). In this analysis, the independent variables included the personal variables and practice variables and the TTM decisional balance variables used for the analysis of Research Questions 1 and 3, respectively. The final set of independent variables included in the model were determined using the forward entry (conditional) method. The dependent variable was whether or not the participant prescribed PrEP (prescribed or not prescribed). The overall model's significance was assessed using the $\chi^{2}$ test; if the test was significant at an alpha level of .05 , the null hypothesis was rejected. If the overall model was significant, coefficients for each independent variable were examined to determine what personal and practice variables and what TTM decisional balance barriers predicted the prescription of PrEP for questions 2 and 4.

Before interpreting the results for each regression, multicollinearity was assessed by calculating variance inflation factors (VIFs). Stevens (2009) suggested that variance inflation factors greater than 10 indicate severe multicollinearity. If severe multicollinearity was detected in the regression, variables with high VIFs were removed from the model. 
Descriptive statistics, to include mean and standard deviation where appropriate, were calculated regarding the overall sample size of the participants, sample sizes relating to the type of providers who completed the survey, the degree completed, age, gender, sexual orientation, race/ethnicity, geographic location of practice, zip code, number of years of practice, whether or not the provider saw African American patients, whether or not the provider was asked about HIV PrEP by an African American patient, whether or not they had referred an African American patient to an infectious disease doctor for PrEP, whether or not they screened their African American patients for PrEP, whether or not they had heard of PrEP, and whether or not they had received PrEP training.

\section{Data Collection Tool}

This study's survey was based on the HIV PrEP survey (Terndrup et al., 2019). Terndrup et al. (2019) administered the HIV PrEP survey to internal medicine residents at Johns Hopkins University, Yale University School of Medicine, University of Washington, and the Ohio State University. The instrument for this study was adapted to include the TTM staging algorithm. There were five screening and consent questions, one TTM staging question, two TTM decisional balance questions regarding barriers and facilitators to PrEP prescribing, and 21 questions regarding provider personal demographic and practice variables. Table 9 listed the predictor and outcome variables that were used in this study. The original survey by Terndrup et al. (2019) was based on previously published research that used a similar instrument developed by Blackstock et al. (2017) for an HIV PrEP survey of primary care physicians. 
The first five questions of the instrument were consent and screening questions. Question number two asked whether or not providers had regularly written PrEP prescriptions for their African American patients. This question was based on the TTM staging algorithm. Questions three and four asked providers to rate facilitators and barriers to PrEP prescribing using a five-point Likert scale. The remaining 21 questions were personal and practice demographic questions that assessed: 1) the provider's geographic location and setting of their practice, 2) their years of practice, 3) whether African American patients were seen, 4) the percentage of African American patients who were screened for and given a prescription for PrEP, and 4) the provider's gender, race/ethnicity, and sexual orientation.

\section{Validity and Reliability Testing}

Dr. Joy H. Lewis, a physician and ATSU-SOMA faculty member, reviewed the survey for completeness and face validity. Dr. Lewis has expertise in survey design using the TTM model. Dr. Ebony Whisenant, another physician and ATSU-SOMA faculty member, has experience prescribing PrEP at her family medicine clinical practice. To assess for face validity, four ATSU-SOMA physician-faculty members reviewed the instrument for clarity and readability. Changes in wording and questionnaire length were made based on their feedback.

\section{Summary}

In this chapter, information about the methodology for this study was presented. The research design, target population and setting, sample size, and data analysis procedures were explained. Further, the eligibility criteria, human subjects' protections, 
and instrumentation were described. In Chapter 4, the results of this study will be presented. 


\section{CHAPTER 4: RESULTS}

The purpose of this cross-sectional study, which was guided by the Transtheoretical Stage of Change Model (TTM), was to examine factors that influence PrEP prescribing practices of primary care providers (PCPs). A total of 330 PCPs provided consent to participate in the online Qualtrics survey. The survey began with five eligibility questions:

- Do you provide consent to participate in this study?

- Are you 18 years of age or older

- Are you a licensed physician, advanced practice registered nurse, of physician assistant?

- Do you currently practice primary care medicine?

- Do you practice in one or more of the following states? Check all that apply. _ Arkansas

- Alabama

- Georgia

Florida

_ Louisiana

_ Mississippi

- North Carolina

— South Carolina

- Tennessee

- Texas

_ None of the above

Participants who did not meet these eligibility questions were thanked for their participation and then exited from the survey. Of the 330 participants, one hundred and seven respondents were removed because they did not finish all sections of the survey. This left a total of 223 participants in the final dataset. Among the 223 included participants, there was a total of 196 missing values, which was approximately $2 \%$ of the data. Remaining missing responses were handled using pairwise exclusion, meaning that each analysis included all of the participants who provided responses to all of the variables for that analysis; no values were replaced or imputed. 


\section{Participant Demographics}

The mean age of the health care providers $(n=223)$ who participated in this study was 44.04 years $(S D=10.81)$. The majority of participants were male $(57.8 \%)$, identified as heterosexual $(80.7 \%)$, White $(50.7 \%)$, and non- Hispanic $(81.6 \%)$. Participants were mostly physicians $(66.8 \%)$, and the largest proportion of participants had completed a medical doctor degree $(n=100,44.8 \%)$. On average, participants had practiced primary care for 13.65 years $(S D=9.77)$. The majority of these health care providers practiced in Texas (52.9\%), Georgia (13.5\%), South Carolina (6.3\%), and Arkansas (4.9\%). Most PCPs practiced in an urban area $(n=151,67.7 \%)$. Table 10 displays the demographic characteristics of the study sample.

\section{Table 10}

Demographic Characteristics

\begin{tabular}{lll}
\hline Characteristic & Number & Percentage \\
\hline State practicing as a Primary Care Provider & 11 & 4.9 \\
Arkansas & 7 & 3.1 \\
Alabama & 30 & 13.5 \\
Georgia & 10 & 4.5 \\
Florida & 6 & 2.7 \\
Louisiana & 9 & 4.0 \\
Mississippi & 8 & 3.6 \\
North Carolina & 14 & 6.3 \\
South Carolina & 6 & 2.7 \\
Tennessee & 118 & 52.9 \\
Texas & 3 & 1.3 \\
Multiple & 1 & 0.4 \\
No response & & \\
Geographic area & & \\
Urban & 151 & 67.7 \\
Suburban & 31 & 13.9 \\
Rural & 35 & 15.7 \\
No response & 6 & 2.7 \\
& & \\
\hline
\end{tabular}




\begin{tabular}{|c|c|c|}
\hline \multicolumn{3}{|l|}{ Gender } \\
\hline Male & 129 & 57.8 \\
\hline Female & 85 & 38.1 \\
\hline Genderqueer/Non-conforming & 4 & 1.8 \\
\hline Transgender & 2 & 0.9 \\
\hline Prefer not to answer & 2 & 0.9 \\
\hline No response & 1 & 0.4 \\
\hline \multicolumn{3}{|l|}{ Sexual orientation } \\
\hline Heterosexual & 180 & 80.7 \\
\hline Gay & 17 & 7.6 \\
\hline Lesbian & 12 & 5.4 \\
\hline Bisexual & 4 & 1.8 \\
\hline Other & 4 & 1.8 \\
\hline Prefer not to answer & 4 & 1.8 \\
\hline No response & 2 & 0.9 \\
\hline \multicolumn{3}{|l|}{ Race } \\
\hline American Indian or Alaskan Native & 4 & 1.8 \\
\hline Asian & 15 & 6.7 \\
\hline Black or African American & 48 & 21.5 \\
\hline Native Hawaiian or Pacific Islander & 2 & 0.9 \\
\hline White & 113 & 50.7 \\
\hline Multiracial or multiple selections & 18 & 8.1 \\
\hline Other & 4 & 1.8 \\
\hline Prefer not to answer & 19 & 8.5 \\
\hline \multicolumn{3}{|l|}{ Hispanic } \\
\hline Yes & 38 & 17.0 \\
\hline No & 182 & 81.6 \\
\hline No response & 3 & 1.3 \\
\hline \multicolumn{3}{|l|}{ Type of practitioner } \\
\hline Physician & 149 & 66.8 \\
\hline Advanced Practice Registered Nurse & 51 & 22.9 \\
\hline Physician Assistant & 22 & 9.9 \\
\hline No response & 1 & 0.4 \\
\hline \multicolumn{3}{|l|}{ Highest degree completed } \\
\hline Doctor of Osteopathic Medicine (D.O.) & 49 & 22.0 \\
\hline Medical Doctor (M.D.) & 100 & 44.8 \\
\hline Master of Science - Nursing (MSN) or equivalent & 30 & 13.5 \\
\hline Doctor of Nursing Practice (DNP) & 20 & 9 \\
\hline $\begin{array}{l}\text { Master of Science - Physician Assistant (MSPA) or } \\
\text { equivalent }\end{array}$ & 19 & 8.5 \\
\hline
\end{tabular}


Doctor of Medical Science - Physician Assistant

(DMSPA) or equivalent

No response

3

1.3

Table 11 displays descriptive statistics regarding participants' Transtheoretical Stages of Change ranking, and Table 12 displays descriptive statistics regarding participants' characteristics of the patients served by the health care providers in this study. Most participants were either at the lowest stage of $\operatorname{PrEP}$ prescription $(n=72$, $32.3 \%)$ or the highest stage $(n=69,30.9 \%)$. Most participants did not routinely screen African American patients for $\operatorname{HIV}(n=130,58.3 \%)$, for PrEP need $(n=149,66.8 \%)$, write them PrEP prescriptions ( $n=182,82.1 \%$ ), or referred them for PrEP prescriptions $(n=185,83.0 \%)$. More than half of the participants indicated that they had not ever written a PrEP prescription for an African American patient ( $n=128,57.4 \%)$, and 70.4\% had not received PrEP training $(n=157)$. However, the majority of participants were aware of PrEP before participating in the study $(n=181,81.2 \%)$. The majority of participants indicated $50 \%$ of their patients or less were African American $(n=178$, $79.8 \%)$.

\section{Table 11}

\section{TTM Stage of Change}

\begin{tabular}{lll}
\hline Characteristic & Number & Percentage \\
\hline & 72 & 32.3 \\
Does not prescribe and does not intend to within 6 months & 37 & 16.6 \\
Does not prescribe but intends to within 6 months & 18 & 8.1 \\
Does not prescribe but intends to within 30 days & 27 & 12.1 \\
Has prescribed for less than 6 months & 69 & 30.9 \\
Has prescribed for more than 6 months & & \\
\hline
\end{tabular}




\section{Table 12}

\section{Patient Characteristics}

\begin{tabular}{lll}
\hline Characteristic & Number & Percentage
\end{tabular}

Do you routinely screen your African American patients for HIV?

Yes

No

No response

Do you routinely screen your African American patients for PrEP need?

Yes

No

Have you ever written a prescription for PrEP for an African American patient?

Yes

No

Do you routinely write PrEP prescriptions for your African American patients?

Yes

No

Have you ever referred an African American patient for a PrEP prescription?

Yes

No

No response

Do you routinely refer African American patients for PrEP prescriptions?

Yes

No

No response

Have you received specific training on PrEP?

Yes

No

No response

Before this survey, had you ever heard of PrEP?

Yes

No

No response
65

92

130

41.3

1

58.3

0.4

74

33.2

149

66.8

95

42.6

128

57.4

40

17.9

183

92

41.3

130

58.3

0.4

$\begin{array}{ll}36 & 16.1\end{array}$

$185 \quad 83.0$

2

0.9

157

29.1

1

0.4

181

81.2

$41 \quad 18.4$




\begin{tabular}{|c|c|c|}
\hline \multicolumn{3}{|c|}{$\%$ of patients in your practice who are African American } \\
\hline $0 \%$ & 4 & 1.8 \\
\hline $1-25 \%$ & 97 & 43.5 \\
\hline $26-50 \%$ & 81 & 36.3 \\
\hline $51-75 \%$ & 21 & 9.4 \\
\hline $76-100 \%$ & 16 & 7.2 \\
\hline No response & 4 & 1.8 \\
\hline \multicolumn{3}{|c|}{$\%$ of patients in your practice who are White } \\
\hline $0 \%$ & 3 & 1.3 \\
\hline $1-25 \%$ & 51 & 22.9 \\
\hline $26-50 \%$ & 76 & 34.1 \\
\hline $51-75 \%$ & 53 & 23.8 \\
\hline $76-100 \%$ & 34 & 15.2 \\
\hline No response & 6 & 2.7 \\
\hline \multicolumn{3}{|c|}{$\%$ of patients in your practice who are American Indian or Alaskan Native } \\
\hline $0 \%$ & 68 & 30.5 \\
\hline $1-25 \%$ & 101 & 45.3 \\
\hline $26-50 \%$ & 2 & 0.9 \\
\hline $76-100 \%$ & 1 & 0.4 \\
\hline No response & 51 & 22.9 \\
\hline \multicolumn{3}{|c|}{$\%$ of patients in your practice who are Hispanic } \\
\hline $0 \%$ & 6 & 2.7 \\
\hline $1-25 \%$ & 114 & 51.1 \\
\hline $26-50 \%$ & 65 & 29.1 \\
\hline $51-75 \%$ & 22 & 9.9 \\
\hline $76-100 \%$ & 7 & 3.1 \\
\hline No response & 9 & 4.0 \\
\hline \multicolumn{3}{|c|}{$\%$ of patients in your practice who are Asian } \\
\hline $0 \%$ & 32 & 14.3 \\
\hline $1-25 \%$ & 160 & 71.7 \\
\hline $26-50 \%$ & 10 & 4.5 \\
\hline $51-75 \%$ & 1 & 0.4 \\
\hline No response & 20 & 9.0 \\
\hline \multicolumn{3}{|c|}{$\%$ of patients in your practice who are Native Hawaiian or Pacific Islander } \\
\hline $0 \%$ & 122 & 54.7 \\
\hline $1-25 \%$ & 41 & 18.4 \\
\hline No response & 60 & 26.9 \\
\hline
\end{tabular}




\section{Additional Analysis}

Chi-square tests of independence were conducted to determine if the stage of change of PrEP prescription and prescription of PrEP differed depending on the participant's self-reported proportion of African American patients (dichotomized as " $50 \%$ or less" of their patients are African American versus "more than 50\%" of their patients are African American). Tables 13 and 14 below show the crosstabulations of these variables. The chi-square test for PrEP stage of change was significant, $\chi^{2}(4)=$ $17.27, p=.002$, indicating that participants with more African American patients were more likely to be in a higher stage of change. The chi-square test for PrEP prescription was significant, $\chi^{2}(1)=16.41, p=.001$, indicating that participants with more African American patients were more likely to have written a PrEP prescription.

\section{Table 13}

Crosstabulation of \% of African American Patients vs. PrEP Stage of Change

\begin{tabular}{lccccc}
\hline $\begin{array}{l}\text { \% of Patients Who are African } \\
\text { American }\end{array}$ & $\begin{array}{c}\text { Stage 1 } \\
(\text { row } \%)\end{array}$ & $\begin{array}{c}\text { Stage 2 } \\
(\text { row \%) }\end{array}$ & $\begin{array}{c}\text { Stage 3 } \\
n(\text { row } \%)\end{array}$ & $\begin{array}{c}\text { Stage } 4 \\
n(\text { row } \%)\end{array}$ & $\begin{array}{c}\text { Stage 5 } \\
(\text { row } \%)\end{array}$ \\
\hline $\begin{array}{l}50 \% \text { or less patients African } \\
\text { American }\end{array}$ & $66(36 \%)$ & $33(18 \%)$ & $15(8 \%)$ & $10(11 \%)$ & $48(26 \%)$ \\
$\begin{array}{l}\text { More than 50\% patients African } \\
\text { American }\end{array}$ & $4(11 \%)$ & $3(8 \%)$ & $3(8 \%)$ & $7(19 \%)$ & $20(54 \%)$ \\
\hline
\end{tabular}

\section{Table 14}

Crosstabulation of \% of African American Patients vs. PrEP Prescription

\begin{tabular}{lcc}
\hline$\%$ of Patients Who are African American & $\begin{array}{c}\text { Prescribed PrEP } \\
n \text { (row \%) }\end{array}$ & $\begin{array}{c}\text { Never prescribed PrEP } \\
n(\text { row } \%)\end{array}$ \\
\hline $50 \%$ or less patients African American & $67(37 \%)$ & $115(63 \%)$ \\
More than 50\% patients African American & $27(73 \%)$ & $10(27 \%)$ \\
\hline
\end{tabular}




\section{Facilitators and Barriers to PrEP Prescribing}

The participants rated potential facilitators and barriers in terms of their importance to the participants' decisions to prescribe PrEP using a Likert scale ranging from 1 (not important) to 5 (extremely important). Tables 15 and 16 display means and standard deviations for the participants' ratings of the facilitators and barriers. The item rated as most important, on average, was "lack of insurance coverage" $(M=4.70, S D=$ 0.80). The item rated as least important, on average, was "clinic inservice PrEP training" $(M=1.83, S D=1.30)$.

\section{Table 15}

\section{Descriptive Statistics for Facilitators to PrEP Prescribing}

\begin{tabular}{lcc}
\hline Variable & $M$ & $S D$ \\
\hline PrEP training during residency & 2.35 & 1.57 \\
Staff or providers who are knowledgeable about PrEP provision & 3.27 & 1.45 \\
Access to resources such as PrEP prescription guidelines and protocols & 3.63 & 1.53 \\
On-site support & 2.67 & 1.47 \\
Clinic inservice PrEP training & 1.83 & 1.30 \\
Knowledge of PrEP's efficacy & 2.85 & 1.70 \\
Patient motivation or "buy in" & 4.25 & 1.19 \\
Peers who prescribe PrEP & 3.18 & 1.66 \\
Patient access to financial incentives that would lower the cost of PrEP & 2.77 & 1.51 \\
Streamlined insurance prior authorization procedures & 4.32 & 1.25 \\
\hline
\end{tabular}

\section{Table 16}

Descriptive Statistics for Barriers to PrEP Prescribing

\begin{tabular}{lcc}
\hline Variable & $M$ & $S D$ \\
\hline Lack of provider training/education regarding PrEP & 4.27 & 1.20 \\
Lack of clinic leadership support regarding PrEP & 3.10 & 1.42 \\
Lack of clinical guidelines/protocols for prescribing/monitoring PrEP & 3.87 & 1.38 \\
Clinic and lab monitoring requirements & 2.73 & 1.41 \\
Staffing time constraints & 4.29 & 1.07 \\
Lack of insurance coverage and out of pocket costs for PrEP & 4.70 & 0.08 \\
Likelihood of low adherence to PrEP & 3.32 & 1.51 \\
Likelihood of HIV resistance developing & 2.27 & 1.49 \\
\hline
\end{tabular}




\section{Research Question 1}

Research Question 1: What is the relationship between personal and practice variables and the stage of change of PrEP prescribing?

$\mathrm{H}_{0} 1$ : There is no relationship between personal and practice variables and the stage of change of PrEP prescribing. Personal variables include age, gender, race, ethnicity, and sexual orientation. Practice variables include the type of primary care practitioner, years of practice, practice setting, and receipt of training on PrEP.

$\mathrm{H}_{\mathrm{a}} 1$ : There is a relationship between personal and practice variables and the stage of change of PrEP prescribing.

To address Research Question 1, an ordinal logistic regression was conducted. In this analysis, the independent variables were the personal variables of age, race/ethnicity, gender, and sexual orientation. The practice variables were the type of primary care practitioner (i.e., physician, nurse practitioner, or physician assistant), years of practice, practice setting (i.e., urban, suburban, rural), and the receipt of training on PrEP. The dependent variable was the stage of change of PrEP prescribing. The stage of change was an ordinal variable with five levels, with higher levels reflecting a stage of greater adoption. Multicollinearity was assessed by calculating VIFs; all VIFs were below 10, indicating that no severe multicollinearity was present.

The overall model was significant, $\chi^{2}(17)=170.77, p<.001$, indicating that the set of predictors collectively significantly predicted the stage of change. The null hypothesis was rejected. Table 17 displays the individual regression coefficients for the 
model. Race was a significant predictor, such that participants who did not identify as White were 3.97 times more likely to be in a higher stage of change $(p<.001)$. Setting was a significant predictor, such that participants who practiced in urban $(O R=8.65, p<$ $.001)$ and suburban settings $(O R=6.14, p=.004)$ were more likely to be in a higher stage of change. Having PrEP training was a significant predictor, such that participants who had PrEP training were 18.41 times more likely to be in a higher stage of change $(p<$ $.001)$.

\section{Table 17}

Ordinal Logistic Regression Predicting PrEP Stage of Prescribing (Research Question 1)

\begin{tabular}{llllllll}
\hline & & & & & & \multicolumn{2}{c}{$95 \%$ CI OR } \\
\cline { 6 - 8 } Variable & Estimate & Std. Error & Wald & Sig. & Odds Ratio & Lower & Upper \\
\hline Age & -0.04 & 0.03 & 1.97 & .160 & 0.96 & 0.90 & 1.02 \\
Years practicing & 0.01 & 0.03 & 0.18 & .670 & 1.01 & 0.95 & 1.08 \\
Male & 0.61 & 2.10 & 0.09 & .771 & 1.84 & 0.03 & 111.83 \\
Female & 0.92 & 2.09 & 0.19 & .659 & 2.51 & 0.04 & 150.96 \\
Genderqueer & 1.04 & 2.16 & 0.23 & .629 & 2.83 & 0.04 & 195.78 \\
Transgender & -2.30 & 2.29 & 1.01 & .316 & 0.10 & 0.00 & 8.96 \\
Non-White & 1.38 & 0.35 & 15.40 & $.001^{*}$ & 3.97 & 1.99 & 7.89 \\
Hispanic & -0.06 & 0.41 & 0.02 & .890 & 0.94 & 0.42 & 2.12 \\
Heterosexual & -0.08 & 1.54 & 0.00 & .956 & 0.92 & 0.04 & 18.84 \\
Gay & 2.27 & 1.70 & 1.79 & .181 & 9.69 & 0.35 & 270.97 \\
Lesbian & 0.45 & 1.60 & 0.08 & .777 & 1.57 & 0.07 & 35.87 \\
Bisexual & 0.95 & 1.87 & 0.26 & .611 & 2.59 & 0.07 & 100.79 \\
Physician & 0.06 & 0.51 & 0.01 & .912 & 1.06 & 0.39 & 2.85 \\
Advanced PRN & 0.31 & 0.61 & 0.25 & .618 & 1.36 & 0.41 & 4.49 \\
Urban & 2.16 & 0.54 & 16.02 & $.001^{*}$ & 8.65 & 3.01 & 24.90 \\
Suburban & 1.82 & 0.63 & 8.22 & .004 & 6.14 & 1.78 & 21.22 \\
Had PrEP training & 2.91 & 0.41 & 50.19 & $.001^{*}$ & 18.41 & 8.22 & 41.22 \\
\hline
\end{tabular}

* Correlation is significant at the 0.001 level.

\section{Research Question 2}

Research Question 2: Do primary care provider's personal and practice variables predict prescribing or not prescribing PrEP? 
$\mathrm{H}_{0} 2$ : Personal and practice variables do not predict prescribing or not prescribing PrEP.

$\mathrm{H}_{\mathrm{a}}$ 2: Personal and practice variables predict prescribing or not prescribing PrEP.

To address Research Question 2, a binary logistic regression was conducted. In this analysis, the independent variables were the personal variables and practice variables used for the analysis of Research Question 1. The final set of independent variables included in the model were determined using the forward entry (conditional) method. The dependent variable was whether or not the participant prescribed PrEP (prescribed or not prescribed).

The final overall model was significant, $\chi^{2}(8)=136.34, p<.001$, indicating that the set of predictors collectively significantly predicted the prescription of PrEP. The null hypothesis was rejected. Table 18 displays the individual regression coefficients for the final model. Race was a significant predictor, such that participants who did not identify as White were 5.86 times more likely to prescribe $\operatorname{PrEP}(p<.001)$. Sexual orientation was a significant predictor, such that participants who identified as gay $(O R=359.51, p=$ $.002)$, lesbian $(O R=19.24, p=.034)$, and bisexual $(O R=62.75, p=.030)$ were more likely to prescribe PrEP. Setting was a significant predictor, such that participants who practiced in urban settings $(O R=11.36, p<.008)$ were more likely to prescribe PrEP. Having PrEP training was a significant predictor, such that participants who had PrEP training were 40.26 times more likely to prescribe $\operatorname{PrEP}(p<.001)$. 


\section{Table 18}

Binary Logistic Regression Predicting PrEP Prescription (Research Question 2)

\begin{tabular}{llllllll}
\hline & & & & & & \multicolumn{2}{c}{$95 \%$ CI OR } \\
\cline { 7 - 8 } Variable & Estimate & Std. Error & Wald & Sig. & Odds Ratio & Lower & Upper \\
\hline Non-White & 1.77 & 0.48 & 13.58 & $.001 *$ & 5.86 & 2.29 & 14.99 \\
Heterosexual & 2.11 & 1.17 & 3.22 & .073 & 8.21 & 0.82 & 81.89 \\
Gay & 5.89 & 1.93 & 9.28 & .002 & 359.51 & 8.16 & 15838.94 \\
Lesbian & 2.96 & 1.40 & 4.47 & .034 & 19.24 & 1.24 & 298.28 \\
Bisexual & 4.14 & 1.90 & 4.74 & .030 & 62.75 & 1.51 & 2609.31 \\
Urban & 2.43 & 0.92 & 6.98 & .008 & 11.36 & 1.87 & 68.95 \\
Suburban & 1.81 & 1.04 & 3.01 & .083 & 6.08 & 0.79 & 46.80 \\
Had PrEP training & 3.70 & 0.60 & 37.56 & $.001 *$ & 40.26 & 12.35 & 131.24 \\
\hline
\end{tabular}

* Correlation is significant at the 0.001 level.

\section{Research Question 3}

Research Question 3: What is the relationship between TTM decisional balance and the stage of change of PrEP prescribing?

$\mathrm{H}_{0} 3$ : There is no relationship between TTM decisional balance and the stage of change of PrEP prescribing.

$\mathrm{H}_{\mathrm{a}} 3$ : There is a relationship between TTM decisional balance and the stage of change of PrEP prescribing.

To address Research Question 3, an ordinal logistic regression was conducted. In this analysis, the independent variables were the individual survey items asking about the importance of specific facilitators and barriers to PrEP prescribing (TTM decisional balance). The dependent variable was the stage of change of PrEP prescribing. Multicollinearity was assessed by calculating VIFs; all VIFs were below 10, indicating that no severe multicollinearity was present.

The overall model was significant, $\chi^{2}(20)=135.78, p<.001$, indicating that the set of predictors collectively significantly predicted the stage of change. The null 
hypothesis was rejected. Table 19 displays the individual regression coefficients for the model. Access to PrEP resources $(O R=1.70, p<.001)$ and streamlined insurance $(O R=$ $1.52, p=.010)$ were significant positive predictors, indicating that participants who rated these factors as more important were more likely to be in a higher stage of change. Lack of insurance coverage $(O R=1.99, p=.004)$, lack of provider PrEP training $(O R=0.67, p$ $=.020)$, likelihood of low adherence $(O R=0.66, p=.018)$, and likelihood of HIV resistance developing $(O R=0.64, p=.012)$ were significant negative predictors, indicating that participants who rated these factors as more important were less likely to be in a higher stage of change.

\section{Table 19}

Ordinal Logistic Regression Predicting PrEP Stage of Prescribing (Research Question 3)

\begin{tabular}{|c|c|c|c|c|c|c|c|}
\hline \multirow[b]{2}{*}{ Variable } & \multirow[b]{2}{*}{ Estimate } & \multirow[b]{2}{*}{$\begin{array}{l}\text { Std. } \\
\text { Error }\end{array}$} & \multirow[b]{2}{*}{ Wald } & \multirow[b]{2}{*}{ Sig. } & \multirow[b]{2}{*}{$\begin{array}{l}\text { Odds } \\
\text { Ratio }\end{array}$} & \multicolumn{2}{|c|}{$95 \%$ CI OR } \\
\hline & & & & & & Lower & Upper \\
\hline PrEP training during residency & -0.04 & 0.11 & 0.14 & .705 & 0.96 & 0.77 & 1.19 \\
\hline $\begin{array}{l}\text { Staff or providers who are } \\
\text { knowledgeable about PrEP } \\
\text { provision }\end{array}$ & 0.25 & 0.14 & 3.24 & .072 & 1.28 & 0.98 & 1.67 \\
\hline $\begin{array}{l}\text { Access to resources such as PrEP } \\
\text { prescription guidelines and } \\
\text { protocols }\end{array}$ & 0.53 & 0.14 & 14.02 & $.001^{*}$ & 1.70 & 1.29 & 2.25 \\
\hline On-site support & -0.02 & 0.12 & 0.03 & .853 & 0.98 & 0.77 & 1.25 \\
\hline Clinic inservice PrEP training & -0.08 & 0.16 & 0.28 & .597 & 0.92 & 0.68 & 1.25 \\
\hline Knowledge of PrEP's efficacy & 0.07 & 0.15 & 0.21 & .650 & 1.07 & 0.80 & 1.44 \\
\hline Patient motivation or "buy in" & 0.22 & 0.16 & 1.85 & .174 & 1.25 & 0.91 & 1.71 \\
\hline Peers who prescribe PrEP & 0.00 & 0.12 & 0.00 & .984 & 1.00 & 0.78 & 1.27 \\
\hline $\begin{array}{l}\text { Patient access to financial } \\
\text { incentives that would lower the } \\
\text { cost of PrEP }\end{array}$ & 0.14 & 0.14 & 1.02 & .312 & 1.15 & 0.88 & 1.51 \\
\hline $\begin{array}{l}\text { Streamlined insurance prior } \\
\text { authorization procedures }\end{array}$ & 0.42 & 0.16 & 6.72 & .010 & 1.52 & 1.11 & 2.09 \\
\hline $\begin{array}{l}\text { Lack of provider } \\
\text { training/education regarding } \\
\text { PrEP }\end{array}$ & -0.40 & 0.17 & 5.40 & .020 & 0.67 & 0.48 & 0.94 \\
\hline $\begin{array}{l}\text { Lack of clinic leadership support } \\
\text { regarding PrEP }\end{array}$ & -0.26 & 0.14 & 3.50 & .061 & 0.77 & 0.59 & 1.01 \\
\hline $\begin{array}{l}\text { Lack of clinical } \\
\text { guidelines/protocols for } \\
\text { prescribing/monitoring PrEP }\end{array}$ & -0.16 & 0.14 & 1.17 & .279 & 0.86 & 0.65 & 1.13 \\
\hline
\end{tabular}




\begin{tabular}{|c|c|c|c|c|c|c|c|}
\hline $\begin{array}{l}\text { Clinic and lab monitoring } \\
\text { requirements }\end{array}$ & 0.06 & 0.15 & 0.15 & .697 & 1.06 & 0.79 & 1.42 \\
\hline $\begin{array}{l}\text { Staffing time constraints related } \\
\text { to risk reduction and PrEP } \\
\text { adherence counseling }\end{array}$ & -0.03 & 0.19 & 0.03 & .853 & 0.97 & 0.67 & 1.39 \\
\hline $\begin{array}{l}\text { Lack of insurance coverage and } \\
\text { out-of-pocket patient costs for } \\
\text { PrEP }\end{array}$ & 0.69 & 0.24 & 8.12 & .004 & 1.99 & 1.24 & 3.19 \\
\hline $\begin{array}{l}\text { Likelihood of low adherence to } \\
\text { PrEP }\end{array}$ & -0.41 & 0.17 & 5.63 & .018 & 0.66 & 0.47 & 0.93 \\
\hline $\begin{array}{l}\text { Likelihood of HIV resistance } \\
\text { developing }\end{array}$ & -0.45 & 0.18 & 6.34 & .012 & 0.64 & 0.45 & 0.90 \\
\hline $\begin{array}{l}\text { Patients may engage in riskier } \\
\text { behavior while on PrEP }\end{array}$ & -0.09 & 0.15 & 0.35 & .554 & 0.91 & 0.68 & 1.23 \\
\hline $\begin{array}{l}\text { Insufficient evidence of PrEP's } \\
\text { effectiveness }\end{array}$ & -0.07 & 0.18 & 0.13 & .715 & 0.94 & 0.66 & 1.33 \\
\hline
\end{tabular}

* Correlation is significant at the 0.001 level.

\section{Research Question 4}

Research Question 4: Does primary care provider's TTM decisional balance predict prescribing or not prescribing PrEP?

$\mathrm{H}_{0} 4$ : TTM decisional balance does not predict prescribing or not prescribing PrEP.

$\mathrm{H}_{\mathrm{a}} 4$ : TTM decisional balance does predict prescribing or not prescribing PrEP.

To address Research Question 4, a binary logistic regression was conducted. In this analysis, the independent variables were the individual survey items asking about the importance of specific facilitators and barriers to PrEP prescribing (TTM decisional balance) used in Research Question 3. The final set of independent variables included in the model were determined using the forward entry (conditional) method. The dependent variable was whether or not the participant prescribed PrEP (prescribed or not prescribed).

The final overall model was significant, $\chi^{2}(9)=131.51, p<.001$, indicating that the set of predictors collectively significantly predicted the prescription of PrEP. The null 
hypothesis was rejected. Table 20 displays the individual regression coefficients for the final model. Knowledgeable staff $(O R=1.51, p=.033)$, access to resources $(O R=1.85$, $p=.001)$, patient motivation $(O R=2.19, p=.007)$, patient access to financial incentives $(O R=1.97, p<.001)$ were significant positive predictors, indicating that participants who rated these factors as more important were more likely to prescribe PrEP. Lack of insurance coverage $(O R=2.74, p=.002)$, provider training $(O R=0.43, p=.003)$, lack of clinical leadership $(O R=0.65, p=.018)$, likelihood of low adherence $(O R=0.53, p=$ $.001)$, and likelihood of HIV resistance developing $(O R=0.43, p<.001)$ were significant negative predictors, indicating that participants who rated these factors as more important were less likely to prescribe PrEP.

\section{Table 20}

Binary Logistic Regression Predicting PrEP Prescription (Research Question 4)

\begin{tabular}{|c|c|c|c|c|c|c|c|}
\hline \multirow[b]{2}{*}{ Variable } & \multirow[b]{2}{*}{ Estimate } & \multirow[b]{2}{*}{$\begin{array}{l}\text { Std. } \\
\text { Error }\end{array}$} & \multirow[b]{2}{*}{ Wald } & \multirow[b]{2}{*}{ Sig. } & \multirow[b]{2}{*}{$\begin{array}{l}\text { Odds } \\
\text { Ratio }\end{array}$} & \multicolumn{2}{|c|}{$95 \%$ CI OR } \\
\hline & & & & & & Lower & Upper \\
\hline $\begin{array}{l}\text { Staff or providers who are } \\
\text { knowledgeable about PrEP } \\
\text { provision }\end{array}$ & 0.41 & 0.19 & 4.55 & .033 & 1.51 & 1.03 & 2.20 \\
\hline $\begin{array}{l}\text { Access to resources such as PrEP } \\
\text { prescription guidelines and } \\
\text { protocols }\end{array}$ & 0.61 & 0.18 & 11.93 & $.001^{*}$ & 1.85 & 1.30 & 2.62 \\
\hline Patient motivation or "buy in" & 0.78 & 0.29 & 7.20 & .007 & 2.19 & 1.24 & 3.88 \\
\hline $\begin{array}{l}\text { Patient access to financial } \\
\text { incentives that would lower the } \\
\text { cost of PrEP }\end{array}$ & 0.68 & 0.18 & 14.12 & $.001 *$ & 1.97 & 1.38 & 2.81 \\
\hline $\begin{array}{l}\text { Lack of provider } \\
\text { training/education regarding } \\
\text { PrEP }\end{array}$ & -0.86 & 0.29 & 8.92 & .003 & 0.43 & 0.24 & 0.75 \\
\hline $\begin{array}{l}\text { Lack of clinic leadership support } \\
\text { regarding PrEP }\end{array}$ & -0.43 & 0.18 & 5.57 & .018 & 0.65 & 0.45 & 0.93 \\
\hline $\begin{array}{l}\text { Lack of insurance coverage and } \\
\text { out-of-pocket patient costs for } \\
\text { PrEP }\end{array}$ & 1.01 & 0.33 & 9.29 & .002 & 2.74 & 1.43 & 5.24 \\
\hline $\begin{array}{l}\text { Likelihood of low adherence to } \\
\text { PrEP }\end{array}$ & -0.64 & 0.20 & 10.36 & $.001^{*}$ & 0.53 & 0.36 & 0.78 \\
\hline $\begin{array}{l}\text { Likelihood of HIV resistance } \\
\text { developing }\end{array}$ & -0.84 & 0.22 & 14.78 & $.001^{*}$ & 0.43 & 0.28 & 0.66 \\
\hline
\end{tabular}

* Correlation is significant at the 0.001 level. 


\section{Summary}

A series of logistic regressions were conducted on a sample of 223 primary care providers to answer the research questions. The results for Research Question 1 showed that there was a relationship between personal and practice variables and the stage of change of PrEP prescribing; the null hypothesis was rejected. The results for Research Question 2 showed that personal and practice variables predicted the prescription of PrEP; the null hypothesis was rejected. The results for Research Question 3 showed that there was a relationship between TTM decisional balance and the stage of change of PrEP prescribing; the null hypothesis was rejected. The results for Research Question 4 showed that TTM decisional balance predicted the prescription of PrEP; the null hypothesis was rejected.

In chapter 5, the results will be interpreted and the limitations of the study, implications for clinical practice, and recommendations for future research will be discussed. 


\section{CHAPTER 5: DISCUSSION, LIMITATIONS, AND CONCLUSION}

This cross-sectional study examined factors that influence PrEP prescribing by primary care providers (PCPs) in the Southern United States. Guided by the Transtheoretical Stages of Change Model (TTM), the study sought to identify what PCP personal and provider variables were associated with prescribing versus not prescribing PrEP. The TTM was used to stage providers in relationship to their desire to prescribe, or not prescribe, PrEP. The study also sought to determine whether or not there was a relationship between TTM decisional balance (i.e., barriers and facilitators), and whether or not a PCP's TTM decisional balance predicted prescribing, or not prescribing PrEP. The average age of the participants $(n=223)$ was 44.04 years. The majority of participants were White, non-Hispanic males. In this study, most PCPs practiced in Texas $(52.9 \%)$, and the majority of the participants practiced in urban areas (67.7\%). Most participants were physicians $(66.8 \%)$ with a medical doctorate (44.8\%). Finally, participants practiced primary care for an average of 13.65 years.

\section{Summary of Study}

A critical lack of PCPs who prescribe PrEP exists (Chan et al., 2020; Leech et al., 2020). Many PCPs refer their patients to infectious disease (ID) providers or worse yet, they do not screen for HIV and PrEP need and thus, do not make referrals to ID providers (Mayer et al., 2020). The overall effect of this lack of PCP PrEP prescribing results in a lack of access to PrEP for their patients, particularly their African American patients. Some studies have shown that PCPs who have been exposed to PrEP information, either in medical school or residency, or through some type of training after the completion of 
residency, are more willing to screen their patients for PrEP indications and prescribe PrEP (Blumenthal et al., 2015; Krakower et al., 2014).

While PCPs lack of commitment to prescribing PrEP can be attributed to several factors, PCPs have most frequently identified a lack of knowledge about PrEP prescribing and concerns about insurance coverage for PrEP as two of the largest barriers to PrEP prescribing (Leech et al., 2020; Patel et al., 2018; Petroll et al., 2017). While research has focused on barriers and facilitators to PrEP prescribing from the patient perspective, few studies have examined this phenomenon from the perspective of PCPs, highlighting the need for such studies (Leech et al., 2020).

The research studies that have examined PCP reluctance to prescribe PrEP have been constructive in that they have shed light on some of the barriers to PrEP prescribing by PCPs, but much remains to be discovered about why PCPs are not prescribing PrEP. As previously mentioned, the most frequently cited barriers to PrEP prescribing by PCPs are a lack of PrEP knowledge and concerns about insurance coverage. However, little is known about the settings (i.e., urban vs. suburban vs. rural) under which providers are most likely to prescribe and whether or not personal and professional factors such as race, age, gender, type of provider (i.e., APRN vs. physician vs. physician assistant), or number of years in practice influence PrEP prescribing. Additionally, many studies examining PrEP prescribing by PCPs have not been guided by a readily discernable theoretical framework.

\section{Findings of Study}

The findings of this study revealed that participants who had more African American patients in their practice were more likely to be in a higher TTM stage of 
change regarding their desire to prescribe PrEP, and were more likely to have written a PrEP prescription. Further, access to PrEP resources, streamlined insurance prior authorization processes, working with staff who had PrEP knowledge, having PrEP training, and having patients who were motivated to take PrEP were significant facilitators of PrEP prescribing. Conversely, significant barriers to PrEP prescribing included a lack of provider PrEP training, lack of clinical leadership regarding PrEP, patients lacking insurance, and the likelihood of low patient adherence to PrEP.

According to TTM, the decisional balance facilitators of making a behavior change are outweighed by the decisional balance barriers to making that change for individuals at lower stages of change (Gullette et al., 2009). The decisional balance for that individual is said to be in favor of maintaining the existing behavior. As an individual progresses through the TTM stages of change, the decisional balance facilitators of making a behavior change begin to outweigh the barriers to making the change. Individuals at a higher TTM stage of change would be expected to have more facilitators for behavior change and fewer barriers to behavior change. Conversely, individuals at a lower TTM stage of change would be expected to have more barriers than facilitators for behavior change (Liu et al., 2018). However, this study did not demonstrate the expected distribution of TTM decisional balance barriers and facilitators based on participants TTM stage of change. Participants simply answered questions based on what they perceived to be barriers or facilitators to PrEP prescribing, irrespective of wether or not they prescribed PrEP. The study did find that the most important barrier to PrEP prescribing was a lack of insurance coverage while the most 
important facilitator of PrEP prescribing was patient motivation to use PrEP consistently, as prescribed.

\section{Limitations of the Study}

The study has several limitations. First, it is geographically limited to the Southern U.S. and is therefore not representative of other areas of the U.S. Further, the study demonstrates that PrEP prescribing is more likely in urban and suburban areas in the Southern U.S. while rural areas did not see the same rates of PrEP prescribing in this study. The study used a convenience sample that was recruited from a variety of social media sites, email listservs, and direct email communication, thus, generalizability of the findings is limited. Further, the risk of exposure to COVID-19 meant that no face-to-face participant recruiting could be done; being able to recruit in face-to-face venues may have yielded a greater sample size. All data were self-reported, and this may have introduced bias into the study. Revision of the instrument should be considered, particularly the barriers and facilitator questions; these two questions may not have been clear to participants. Finally, the majority of participants in the study did not see large numbers of African American patients; this forced a change to research questions 2 and 4. A question should have been included in the screening that asked whether or not participants had a patient base of $50 \%$ or greater African American patients. This may have yielded a sample of participants who saw more African American patients.

\section{Conclusion}

Despite its limitations, this study's findings contribute to knowledge about PCP PrEP prescribing practices in the Southern U.S. Few studies in the literature have focused on PCP understanding PrEP prescribing barriers and facilitators from the perspective of 
the PCP (Mayer et al., 2020; Silapaswan et al., 2017). This study may provide information that may be used to identify PCPs who do not routinely screen their patients for HIV or PrEP indications so that they may be provided with additional resources to encourage PrEP prescribing behaviors. Findings from this study suggest that PCPs who are at a higher stage of change on the TTM are more likely to prescribe PrEP than those at lower change levels. Additionally, findings suggested that PCPs who have PrEP training, work with other PCPs and clinic staff who are knowledgeable about PrEP and have supportive clinical leadership regarding PrEP prescribing may be at higher stages of change on the TTM and be more willing to prescribe PrEP. Attention should be paid to PCP PrEP education as well as encouraging the development of clinical policies that support PrEP prescribing by PCPs. Information regarding patient financial incentives for PrEP should be provided to providers and ways to encourage PrEP adherence among patients should be taught to PCPs.

In the future, this study should be repeated with the addition of a screening question regarding whether participants see $50 \%$ or more African American patients. This will help to yield a sample of PCPs who see large numbers of African American patients; it would then be possible to better understand the facilitators and barriers to PrEP prescribing for African Americans in the Southern U.S. Next, a qualitative study, using interviews and focus groups, should be conducted to better understand the facilitators and barriers to PrEP prescribing for African Americans residing in the Southern U.S. The results of this study may be useful in helping to support and justify PCP PrEP education initiatives that are designed to increase PrEP knowledge and to reduce concerns about PrEP's safety. 
A major PrEP barrier that was identified in this study was PCP concerns about a lack of patient insurance and the financial means to afford PrEP. It may be useful to provide education to PCPs regarding insurance rules and regulations regarding the approval of PrEP prescribing for patients but more importantly, means of streamlining prior authorization for PrEP should be explored. Further, misconceptions surrounding the development of resistance to PrEP accounts for some of the reluctance to prescribe in this study’s participants (Bagchi \& Holzemer, 2018; Mullins et al., 2018); education should be provided regarding the importance of regular HIV testing for patients who are being prescribed PrEP. Finally, the use of TTM as a means of identifying those PCPs who do not screen their African American patients for HIV or PrEP indications provides an opportunity to future intervention research. Part of this research would need to entail who would be best positioned to screen PCPs using the TTM as well as determining how screening would take place. 


\section{References}

Aaron, E., Blum, C., Seidman, D., Jo Hoyt, M., Simone, J., Sullivan, M., \& Smith, D.K. (2018). Optimizing delivery of HIV preexposure prophylaxis for women in the United States. AIDS Patient Care and STDs, 32(1), 16-23.

https://dx.doi.org/10.1089/apc.2017.0201

Adams, L.M., \& Balderson, B.H. (2016). HIV providers' likelihood to prescribe preexposure prophylaxis (PrEP) for HIV prevention differs by patient type: A short paper. AIDS Care, 28(9), 1154-1158.

https://doi.org/10.1080/09540121.2016.1153595

Anderson, P.L., Glidden, D.V., Liu, A., Buchbinder, S., Lama, J.R., Guanira, J.V., ... Grant, R.M. (2012). Emtricitabine-Tenofovir concentrations and pre-exposure prophylaxis efficacy in men who have sex with men. Science Translational Medicine, 4(151), 151ra125. https://doi.org/10.1126/scitranslmed.3004006

Andrewin, A., \& Chien, L-Y. (2008). Stigmatization of patients with HIV/AIDS among doctors and nurses in Belize. AIDS Patient Care \& STDs, 22(11), 897-906. https://doi.org/10.1089/apc.2007.0219

Armitage, C.J. (2009). Is there utility in the transtheoretical model? British Journal of Health Psychology, 14(2), 195-210. https://doi.org/10.1348/135910708X368991

Armstrong, K., Ravenell, K.L., McMurphy, S., \& Putt, M. (2007). Racial/ethnic differences in physician distrust in the United States. American Journal of Public Health, 97(7), 1283-1289. https://doi.org/10.2105/AJPH.2005.080762

Arnold, E.A., Hazelton, P., Lane, T., Christopoulos, K.A., Galindo, G.R., Steward, W.T., \& Morin, S.F. (2012). A qualitative study of provider thoughts on implementing 
pre-exposure prophylaxis (PrEP) in clinical settings to prevent HIV infection. PLoS One, 7(7), e40603. https://doi.org/10.1371/journal.pone.0040603

Baeten, J.M., Donnell, D., Ndase, P., Mugo, N.R., Campbell, J.D., Wangisi, J., .. Celum, C. (2012). Antiretroviral prophylaxis for HIV prevention among heterosexual men and women. New England Journal of Medicine, 367(5), 399-410. https://dx.doi.org/10.1056\%2FNEJMoa1108524

Bagchi, A.D., \& Holzemer, W. (2018). Support for PrEP among New Jersey health care workers. Journal of the Association of Nurses in AIDS Care, 29(6), 849-857. https://doi.org/10.1016/j.jana.2018.06.003

Bandura, A. (1982). Self-efficacy mechanism in human agency. American Psychologist, 37(2), 122-147. https://psycnet.apa.org/doi/10.1037/0003-066X.37.2.122

Becasen, J.S., Denard, C.L., Mullins, M.M., Higa, D.H., \& Sipe, T.A. (2019). Estimating the prevalence of HIV and sexual behaviors among the US transgender population: A systematic review and meta-analysis, 2006-2017. American Journal of Public Health, 109(1), e1-e8. https://doi.org/10.2105/AJPH.2018.304727

Bodenheimer, T.S. (2013). Proposed Solutions to the physician shortage without training more physicians. Health Affairs (Project Hope), 32(11), 18811886. https://doi.org/10.1377/hlthaff.2013.0234

Bonett, D.G. (2002). Sample size requirements for testing and estimating coefficient alpha. Journal of Educational and Behavioral Statistics, 27(4), 335-340. https://doi.org/10.3102\%2F10769986027004335

Blake, B.J., Jones Taylor, G.A., Reid, P., Kosowski, M. (2008). Experiences of women in obtaining human immunodeficiency virus testing and healthcare services. Journal 
of the American Academy of Nurse Practitioners, 20(1), 40-46.

https://doi.org/10.1111/j.1745-7599.2007.00283.x

Blake, B.J., Jones Taylor, G.A., \& Sowell, R.L. (2016). Exploring experiences and perceptions of older African American males aging with HIV in the rural Southern United States. American Journal of Men's Health, 11(2), 221-232. https://doi.org/10.1177\%2F1557988316662875

Blackstock, O.J., Moore, B.A., Berkenblit, G.V., Calabrese, S.K., Cunningham, C.O., Fiellin, D.A., ... Edelman, J.E. (2016). A cross-sectional online survey of HIV pre-exposure prophylaxis adoption among primary care physicians. Journal of General Internal Medicine, 32(1), 62-70. https://doi.org/10.1007/s11606-016$3903-z$

Blumenthal, J., Jain, S., Krakower, D., Sun, X., Young, J., Mayer, K., Haubrich, R., \& the CCTG 598 Team. (2015). Knowledge is power! Increased provider knowledge scores regarding pre-exposure prophylaxis (PrEP) are associated with higher rates of PrEP prescription and future intent to prescribe PrEP. AIDS and Behavior, 19(5), 802-810.

Brace, N., Kemp, R., \& Snelgar, R. (2013). SPSS for Psychologists. New York, NY: Routledge Taylor \& Francis Group.

Brooks, R.A., Cabral, A., Nieto, O., Fehrenbacher, A., \& Landrian, A. (2019). Experiences of pre-exposure prophylaxis stigma, social support, and information dissemination among Black and Latina transgender women who are using preexposure prophylaxis. Transgender Health, 4(1), 188-196.

https://dx.doi.org/10.1089\%2Ftrgh.2019.0014 
Brown, L., Macintyre, K., \& Trujillo, L. (2003). Interventions to reduce HIV/AIDS stigma: What have we learned? AIDS Education and Prevention, 15(1), 49-69. https://doi.org/10.1521/aeap.15.1.49.23844

Buchbinder, S.P. (2018). Maximizing the benefits of HIV preexposure prophylaxis. Topics in Antiviral Medicine, 25(4), 138-142. Retrieved from https://www.ncbi.nlm.nih.gov/pmc/articles/PMC5935218/

Burditt, C., Robbins, M.L., Paiva, A., Velicer, W.F., Koblin, B., \& Kessler, D. (2009). Motivation for blood donation among African Americans: Developing measures for stages of change, decisional balance, and self-efficacy constructs. Journal of Behavioral Medicine, 32, 429-442. https://dx.doi.org/10.1007/s10865-009-9214-7

Cahill, S., Taylor, S.W., Elsesser, S.A., Mena, L., Hickson, D., \& Mayer, K.H. (2017). Stigma, medical mistrust, and perceived racism may affect PrEP awareness and uptake in Black compared to White gay and bisexual men in Jackson, Mississippi and Boston, Massachusetts. AIDS Care, 29(11), 1351-1358. https://doi.org/10.1080/09540121.2017.1300633

Calbrese, S.K., Earnshaw, V.A., Krakower, D.S., Underhill, K., Vincent, W., Magnus, M., ... Dovidio, J.F. (2018). A closer look at racism and heterosexism in medical students' clinical decision-making related to HIV pre-exposure prophylaxis (PrEP): Implications for PrEP education. AIDS and Behavior, 22, 1122-1138. https://doi.org/10.1007/s10461-017-1979-z

Centers for Disease Control and Prevention. (2016). HIV surveillance report, 2016, 28. [PDF]. http://www.cdc.gov/hiv/library/reports/hiv-surveillance.html 
Centers for Disease Control and Prevention. (2019a, April 10). HIV: Prevention status reports (PSR). Retrieved January 20, 2020, from https://wwwn.cdc.gov/psr/NationalSummary/NSTable.aspx

Centers for Disease Control and Prevention. (2019b). Estimated HIV incidence and prevalence in the United States, 2010-2016. HIV Surveillance Supplemental Report, 24(1). [PDF]. Retrieved from http://www.cdc.gov/hiv/library/reports/hivsurveillance.html

Centers for Disease Control and Prevention. (2019c, May). Diagnoses of HIV infection among adults and adolescents in metropolitan statistical areas—-United States and Puerto Rico, 2017. HIV Surveillance Supplemental Report 2019, 24(2). [PDF]. Retrieved from http://www.cdc.gov/hiv/library/reports/hivsurveillance.html Centers for Disease Control and Prevention. (2019d). HIV surveillance report, 2018 (preliminary), 30. [PDF]. Retrieved from http://www.cdc.gov/hiv/library/reports/hiv-surveillance.html Centers for Disease Control and Prevention. (2019e, December 3). PrEP. Retrieved on January 22, 2020 from https://www.cdc.gov/hiv/basics/prep.html

Centers for Disease Control and Prevention. (2019f, September). HIV in the southern United States. National Center for HIV/AIDS, Viral Hepatitis, STD, and TB Prevention. https://www.cdc.gov/hiv/pdf/policies/cdc-hiv-in-the-south-issuebrief.pdf

Centers for Disease Control and Prevention. (2019g, November 12). HIV and transgender people. Retrieved from https://www.cdc.gov/hiv/group/gender/transgender/index.html 
Centers for Disease Control and Prevention. (2020a, January 20). HIV and African Americans. Retrieved from https://www.cdc.gov/hiv/group/racialethnic/africanamericans/index.html Centers for Disease Control and Prevention (2020b, July 30). HIV in the United States by region. Retrieved from https://www.cdc.gov/hiv/statistics/overview/geographicdistribution.html

Chan, S.M., Chappel, A.R., Joynt Maddox, K.E., Hoover, K.W., Huang, Y.A., Zhu, W.,... Lew, N.D. (2020). Pre-exposure prophylaxis for preventing acquisition of HIV: A cross-sectional study of patients, prescribers, uptake, and spending in the United States, 2015-2016. PLoS Medicine. https://doi.org/10.1371/journal.pmed.1003072

Clement, M.E., Johnston, B.E., Eagle, C., Taylor, D., Rosengren, A.L., Goldstein, B.A., \& Sena, A.C. (2019). Advancing the HIV pre-exposure prophylaxis continuum: A collaboration between a public health department and a federally-qualified community health center in the Southern United States. AIDS Patient Care and STDs, 33(8). Retrieved from https://doi.org/10.1089/apc.2019.0054

Clement, M.E., Seidelman, J., Wu, J., Alexis, K., McGee, K., Okeke, N.L., Samsa. G., \& McKellar, M. (2018). An educational initiative in response to identified PrEP prescribing needs among PCPs in the Southern US. AIDS Care, 30(5), 650-655. https://doi.org/10.1080/09540121.2017.1384534

Department of Health and Human Services. (2019, December 3). Pre-exposure prophylaxis. Retrieved on January 22, 2020 from https://www.hiv.gov/hiv- 
basics/hiv-prevention/using-hiv-medication-to-reduce-risk/pre-exposureprophylaxis

Deutsch, M.B., Glidden, D.V., Sevelius, J., Keatley, J., McMahan, V., Guanira, J., ... iPrEX investgators. (2015). HIV pre-exposure prophylaxis in transgender women: A subgroup analysis of the iPrEX trial. The Lancet, 2(12), e512-e519. https://doi.org/10.1016/S2352-3018(15)00206-4

Donnell, D., Baeten, J.M., Bumpus, N.N., Brantley, J., Bangsberg, D.R., Haberer, J.E.,... Celum, C. (2014). HIV protective efficacy and correlates of Tenofovir blood concentrations in a clinical trial of PrEP for HIV prevention. Journal of the Acquired Immune Deficiency Syndrome, 66(3), 340-348. https://dx.doi.org/10.1097\%2FQAI.0000000000000172

Drumhiller, K., Geter, A., Elmore, K., Gaul, Z., \& Sutton, M.Y. (2020). Perceptions of patient HIV risk by primary care providers in high-hiv prevalence areas in the Southern United States. AIDS Patient Care and STDs, 34(3), 102-110. https://doi.org/10.1089/apc.2019.0219

Durand, S., \& Cimarelli, A. (2011). The inside out of lentiviral vectors. Viruses, 3(2), 132-159. https://dx.doi.org/10.3390\%2Fv3020132

Eaton, L.A., Driffin, D.D., Bauermeister, J., Smith, H., Conway-Washington, C. (2015). Minimal awareness and stalled update of pre-exposure prophylaxis (PrEP) among at risk, HIV-negative, Black men who have sex with men. AIDS Patient Care and STDs, 29(8), 423-429. https://dx.doi.org/10.1089\%2Fapc.2014.0303

Edelman, J.E., Moore, B.A., Calabrese, S.K., Berkenblit, G., Cunningham, C.O., Ogbuagu, O., ... Blackstock, O. (2020). Preferences for implementation of HIV 
pre-exposure prophylaxis (prep): Results from a survey of primary care providers. Preventive Medicine Reports, 17(2020). 101012.

https://doi.org/10.1016/j.pmedr.2019.101012

Elopre, L., Kudroff, K., Westfall, A.O., Overton, E.T., \& Mugavero, M.J. (2017). The right people, right places, and right practices: Disparities in PrEP access among African American men, women, and MSM in the deep south. Journal of the Acquired Immunodeficiency Syndrome, 74(1), 56-59.

https://dx.doi.org/10.1097\%2FQAI.0000000000001165

Esbjornsson, J., Jansson, M., Mansson, Honge, B.L., Lindman, J., Medina, C., ... Wejse, C. (2019). HIV-2 as a model to identify a functional HIV cure. AIDS Research and Therapy, 16(24). https://doi.org/10.1186/s12981-019-0239-x

Faul, F., Erdfelder, E., Lang, A.G., \& Buchner, A. (2007). G*Power 3: A flexible statistical power analysis program for the social, behavioral, and biomedical sciences. Behavior Research Methods, 39, 175-191.

Faul, F., Erdfelder, E., Buchner, A., \& Lang, A. G. (2013). G*Power Version 3.1.9.4 [computer software]. Uiversität Kiel, Germany.

Feldt, L.S., Woodruff, D.J., \& Salih, F.A. (1987). Statistical inference for coefficient alpha. Applied Psychological Measurement, 11(1), 93-103. https://doi.org/10.1177\%2F014662168701100107

Fernandez, A.C., Amoyal, N.R., Paiva, A.L., \& Prochaska, J.O. (2016). Motivation for HPV vaccination among young adult men: Validation of TTM decisional balance and self-efficacy constructs. American Journal of Health Promotion, 30(3), 163171. https://doi.org/10.4278\%2Fajhp.131108-QUAN-570 
Feyissa, G.T., Abebe, L., Girma, E., \& Woldie, M. (2012). Stigma and discrimination against people living with HIV by healthcare providers, Southwest Ethiopia. $B M C$ Public Health, 12(1), 522. https://doi.org/10.1186/1471-2458-12-522

Field, A. (2013). Discovering statistics using SPSS (4th ed.). Thousand Oaks, CA: Sage.

Frankfort-Nachmias, C., \& Nachmias, D. (2008). Research methods in the social sciences ( $7^{\text {th }}$ ed.). New York, NY: Worth Publisher.

Friedman, S.R., Cooper, H.L.F., \& Osborne, A.H. (2009). Structural and social contexts of HIV risk among African Americans. American Journal of Public Health, 99(6), 1002-1008. https://dx.doi.org/10.2105\%2FAJPH.2008.140327

Gaalema, D.E., Elliott, R.J., Morford, Z.H., Higgins, S.T., \& Ades, P.A. (2017). Effect of socioeconomic status on propensity to change risk behaviors following

Gaalema, D.E., Elliott, R.J., Morford, Z.H., Higgins, S.T., \& Ades, P.A. (2017). Effect of socioeconomic status on propensity to change risk behaviors following myocardial infarction: Implications for healthy lifestyle medicine. Progress in Cardiovascular Diseases, 60(1), 159-168.

https://doi.org/10.1016/j.pcad.2017.01.001

Gallagher, G.M. (2020, May 12). Adolescent HIV prevention: Overcoming the PrEP “purview paradox”. ContagionLive Newsletter. Retrieved from https://www.contagionlive.com/news/adolescent-hiv-prevention-overcomingprep-purview-paradox

Geter, A., Herron, A.R., \& Sutton, M.Y. (2018). HIV-related stigma by healthcare providers in the United States: A systematic review. AIDS Patient Care and STDs, 32(10), 418-424. https://doi.org/10.1089/apc.2018.0114 
Golemon, L. (2019). Medical overtesting and racial distrust. Kennedy Institute of Ethics Journal, 29(3), 273-303. https://doi.org/10.1353/ken.2019.0025

Grant, R.M., Lama, J.R., Anderson, P.L., McMahan, V., Liu, A.Y., Vargas, L., ... iPrEx Study Team. (2010). Preexposure chemoprophylaxis for HIV prevention in men who have sex with men. New England Journal of Medicine, 363(27), 2587-2599. https://doi.org/10.1056/nejmoa1011205

Grossman, H.A. (2006). Addressing the need for HIV specialists: The AAHIVM perspective. The AIDS Reader, 16(9), 479. Retrieved from https://go.gale.com/ps/anonymous?id=GALE\%7CA152193190\&sid=googleSchol $\operatorname{ar} \& v=2.1 \& i t=r \& l i n k a c c e s s=a b s \& i s s n=10530894 \& p=A O N E \& s w=w$

Goedel, W.C., Bessey, S., Lurie, M.N., Katie, B., Sullivan, P.S., Nunn, A.S. \& Marshall, B.D.L. (2020). Projecting the impact of equity-based preexposure prophylaxis implementation on racial disparities in HIV incidence among MSM. AIDS, 34(10), 1509-1517. https://dx.doi.org/ 10.1097/QAD.0000000000002577

Goparaju, L., Praschan, N.C., Warren-Jeanpiere, L., Experton, L.S., Young, M.A., \& Kassave, S. (2017). Stigma, partners, providers, and costs: Potential barriers to PrEP uptake among US women. Journal of AIDS and Clinical Research, 8(9), 730. https://dx.doi.org/10.4172\%2F2155-6113.1000730

Gullette, D.L., Wright, P.B., Booth, B.M., Feldman, Z., \& Stewart, K.E. (2009). Stages of change, decisional balance, and self-efficacy in condom use among rural African American stimulant users. Journal of the Association of Nurses in AIDS Care, 20(6), 428-441. https://dx.doi.org/10.1016\%2Fj.jana.2009.04.003 
Hall, J. (2008). Cross-sectional survey design. Encyclopedia of Survey Research

Methods. http://dx.doi.org/10.4135/9781412963947.n120

Henny, K.D., \& Jefferies, K.L. (2019). Ending the hiv epidemic in the United States must begin with the South. AIDS and Behavior, 23(Suppl 3), 221-223. https://doi.org/10.1007/s10461-019-02686-3

Herbst, J.H., Jacobs, E.D., Finlayson, T.J., McKleroy, V.S., Neumann, M.S., Crepaz, N., \& HIV/AIDS Prevention Research Synthesis Team. (2008). Estimating HIV prevalence and risk behaviors of transgender persons in the United States: A systematic review. AIDS and Behavior, 12, 1-17. https://doi.org/10.1007/s10461007-9299-3

Highleyman, L. (2016, June 24). PrEP use is rising fast in US, but large racial disparities remain. NamAIDS Map. Retrieved from http://www.aidsmap.com/news/jun2016/prep-use-rising-fast-us-large-racial-disparities-remain

Hirao, K., Andrews, S., Kuroki, K., Tadokoro, T., Kita, S., Ose, T., ... Maenaka, K. (2020). Structure of HIV-2 Nef reveals features distinct from HIV-1 involved in immune regulation. iScience, 1(24). https://doi.org/10.1016/j.isci.2019.100758

HIV specialist. (n.d.). American Academy of HIV Medicine. Retrieved from https://aahivm.org/hiv-specialist/

Horberg, M., \& Raymond, B. (2013). Financial policy issues for HIV pre-exposure prophylaxis: Cost and access to insurance. American Journal of Preventive Medicine, 44(1 Suppl 2), S125-128. https://doi.org/10.1016/j.amepre.2012.09.039 
Horberg, M. (2013). PrEP: “Access and cost from private sector payor”. HIV initiative of Kaiser Permanente and Care Management Institute. PowerPoint. Retrieved from www.iapac.org/tasp_prep/presentations/TPSlon12_Panel7_Horberg.pdf

Horwath, C.C. (1999). Applying the transtheoretical model to eating behavior change: Challenges and opportunities. Nutritional Research Reviews, 12(2), 281-317. https://doi.org/10.1079/095442299108728965

Huang, Y.A., Zhu, W., Smith, D.K., Harris, N., \& Hoover, K.W. (2018). HIV preexposure prophylaxis, by race and ethnicity, United States 2014-2016. Morbidity and Mortality Weekly Report, 67(41), 1147-1150. http://dx.doi.org/10.15585/mmwr.mm6741a3external icon

Huerga, H., Venables, E., Ben-Farhat, J., van Cutsem, G., Eilman, T., \& Kenyon, C. (2017). Higher risk sexual behavior is associated with unawareness of HIVpositivity and lack of viral suppression - implications for treatment as prevention. Scientific Reports, 7(16117). https://doi.org/10.1038/s41598-017-16382-6

Janis, I.L., \& Mann, L. (1977). Decision making: A psychological analysis of conflict, choice, and commitment. London, UK: Cassel \& Collier Macmillian.

Kaiser Family Foundation. (2019, March 5). U.S. federal funding for HIV/AIDS: Trends over time. Retrieved from https:/www.kff.org/hivaids/fact-sheet/u-s-federalfunding-for-hivaids-trends-over-time/\#footnote-394843-1

Kanny, D., Jeffries, W.L., Chapin-Bardales, Denning, P., Cha, S., Finlayson, T., ... National HIV Behavioral Surveillance Study group. (2019). Racial/ethnic disparities in HIV preexposure prophylaxis among men who have sex with men- 
23 urban areas, 2017. Morbidity and Mortality Weekly Report, 68(37), 801-806. http://dx.doi.org/10.15585/mmwr.mm6837a2

Katz, R.V., Green, B.L., Kressin, N.R., Kegeles, S.S., Wang, M.Q., James, S.A., ... McCallum, J.M. (2008). The legacy of the Tuskegee Syphilis Study: Assessing its impact on willingness to participate in biomedical studies. Journal of Health Care for the Poor and Underserved, 19(4), 1168-1180.

https://dx.doi.org/10.1353\%2Fhpu.0.0067

Kelly, C.F., Kahle, E., Siegler, A., Sanchez, T., Del Rio, C., Sullivan, P.S., \& Rosenberg, E.S. (2015). Applying a PrEP continuum of care for men who have sex with men in Atlanta, Georgia. Clinical Infectious Diseases, 61(10), 1590-1597. https://dx.doi.org/10.1093/cid/civ664

Kerlon, A., Forde, A., \& Preston, R. (2016). Social accountability of the physician assistant: A fit-for-purpose health workforce. The Journal of Physician Assistant Education, 1(27), 43-46. https://doi.org/10.1097\%2FJPA.0000000000000053

Krakower, D.S., \& Mayer, K.H. (2016). The role of healthcare providers in the roll out of PrEP. Current Opinion in HIV and AIDS, 11(1), 41-48. http://doi.org/ 10.1097/COH.0000000000000206

Krakower, D.S., Ware, N., Mitty, J.A., Maloney, K., \& Mayer, K.H. (2014). HIV providers' perceived barriers and facilitators to implementing pre-exposure prophylaxis in care settings: A qualitative study. AIDS Behavior, 18(9), 17121721. https://doi.org/10.1007/s10461-014-0839-3

Kumar, V., Abbas, A.K., \& Aster. J.C. (2018). Robbins basic pathology (10 ${ }^{\text {th }}$ ed.). Philadelphia, PA: Elsevier. 
Laurencin, C.T., Murdock, C.J., Laurencin, L., \& Christensen, D.M. (2018). HIV/AIDS and the African American community 2018: A decade call to action. Journal of Racial and Ethnic Health Disparities, 5, 449-458.

http://dx.doi.org/10.1007/s40615-018-0491-0

Leech, A.A., Christiansen, C.L., Linas, B.P., Jacobsen, D.M., Morin. I., \& Drainoni, M-L (2020) Healthcare practitioner experiences and willingness to prescribe preexposure prophylaxis in the US. PLoS ONE 15(9), e0238375. https://doi.org/10.1371/journal.pone.0238375

Li, L., Wu, Z., Zhaoc, Y., Jia, M., \& Yan, Z. (2007). HIV-related stigma in health care settings: A survey of service providers in China. AIDS Patient Care and STDs, 21(10), 753-762. https://dx.doi.org/10.1089\%2Fapc.2006.0219

Lindau, S.T., Jerome, J., Miller, K., Monk, E., \& Garcia, P. (2006). Mothers on the margins: Implications for eradicating perinatal HIV. Social Sciences in Medicine, 62(1), 59-69. https://doi.org/10.1016/j.socscimed.2005.05.012

Lipsy, M. W., \& Hurley, S. M. (1998). Design sensitivity: statistical power for applied experimental research. Handbook of applied social research methods. Thousand Oaks, CA: Sage Publications, 39-68.

Liu, A., Cohen, S., Follansbee, S., Cohan, D., Sachdev, D., Weber S., \& Buchbender, S. (2014). Early experiences implementing pre-exposure prophylaxis (PrEP) for HIV prevention in San Francisco. PLoS Med, 11(3): e1001. https://doi.org/10.1371/journal.pmed.1001613

Liu, K.T., Kueh, Y.C., Arifin, W.N., Kim, Y., \& Kuan, G. (2018). Application of transtheoretical model on behavioral changes, and amount of physical activity 
among university students. Frontiers in Psychology, 9(2402).

https://doi.org/10.3389/fpsyg.2018.02402

Littell, J.H., \& Girvin, H. (2002). Stages of change: A critique. Behavior Modification, 26(2), 223-273. https://doi.org/10.1177\%2F0145445502026002006

Logo, M.K., Danawi, H., Ferraro, A. (2017). Prescribing HIV PrEP and education needs among care providers. Journal of Social, Behavioral, and Health Sciences, 11(1), 202-214. https://doi.org/10.5590/jsbhs.2017.11.1.14

Makwe, C.C., \& Giwa-Osagie, O. (2013). Sexual and reproductive health in HIV serodiscordant couples. African Journal of Reproductive Health (17)4, 99 106. Retrieved from https://www-jstororg.proxy.mul.missouri.edu/stable/24362091

Marrazzo, J.M., Ramjee, G., Richardson, B.A., Gomez, K., Mgodi, N., Nair, G., ... Dai, J.Y. (2015). Tenofovir-based preexposure prophylaxis for HIV infection among African women. The New England Journal of Medicine, 372, 509-518. https://dx.doi.org/10.1056/NEJMoa1402269

Marks, S.J., Merchant, R.C., Clark, M.A., Liu, T., Rosenberger, J.G., .. Mayer, K.H. (2017). Potential healthcare insurance and provider barriers to pre-exposure prophylaxis utilization among young men who have sex with men. AIDS Patient Care and STDs, 31(11), 470-478. https://dx.doi.org/10.1089\%2Fapc.2017.0171 Marshall, S.A., Brewington, K.M., Allison, M.K., Haynes, T.F., \& Zaller, N.D. (2017). Measuring HIV-related stigma among healthcare providers: A systematic review. AIDS Care, 29(11), 1337-1345. https://doi.org/10.1080/09540121.2017.1338654 
Mayer, K.H., Agwu, A., \& Malebranche, D. (2020). Barriers to the wider use of preexposure prophylaxis in the United States: A narrative review. Advances in. Therapy, 37, 1778-1811. https://doi.org/10.1007/s12325-020-01295-0

McManus, K.A., \& Powers, S., Killelea, A., Tello-Trillo, S., \& McQuade, E.R. (2020). Regional disparities in qualified health plans' prior authorization requirements for HIV pre-exposure prophylaxis in the United States. Journal of The American Medical Association Network, 3(6), e207445. https://dx.doi.org/10.1001/jamanetworkopen.2020.7445

Mehta, S.A., Silvera, R., Bernstein, K., Holzman, R.S., Aberg, J.A., \& Daskalakis, D.C. (2011). Awareness of post-exposure prophylaxis in high-risk men who have sex with men in New York City. Sexually Transmitted Infections, 87(4), 344-348. https://doi.org/10.1136/sti.2010.046284

Mullins Kowalczyk, T.L., Idolne, C.R., Zimet, G.D., \& Kahn, J.A. (2018). Primary care physician attitudes and intentions toward the use of HIV pre-exposure prophylaxis in adolescents in one metropolitan region. Journal of Adolescent Health, 84(5), 581-588. https://doi.org/10.1016/j.jadohealth.2018.10.300

Murshid, M.A., \& Mohaidin, Z. (2017). Models and theories of prescribing decisions: A review and suggested new model. Pharmaceutical Practice, 15(2), 990. https://dx.doi.org/10.18549\%2FPharmPract.2017.02.990

National Center for HIV/AIDS, Viral Hepatitis, STD, and TB Prevention. (2017). CDC Fact sheet: HIV among African Americans [PDF file]. https://www.cdc.gov/nchhstp/newsroom/docs/factsheets/cdc-hiv-aa-508.pdf 
National Center for HIV/AIDS, Viral Hepatitis, STD, and TB Prevention. (2018, March 6a). 2018 conference on retroviruses and opportunistic infections. Retrieved from https:/www.cdc.gov/nchhstp/newsroom/2018/croi-2018.html

National Center for HIV/AIDS, Viral Hepatitis, STD, and TB Prevention. (2018, March 6b). HIV prevention pill not reaching most Americans who could benefitespecially people of color. Retrieved from https://www.cdc.gov/nchhstp/newsroom/2018/croi-2018-PrEP-press-release.html Neblett, R.C., Davey-Rothwell, M., Chander, G., \& Latkin, C.A. (2011). Social network characteristics and HIV sexual risk behavior among urban African American women. Journal of Urban Health, 88, 54-65. https://doi.org/10.1007/s11524-0109513-x

Nigg, C.R., Geller, K.S., Motl, R.W., Horwath, C.C., Wertin, K.K., \& Dishman, R.K. (2011). A research agenda to examine the efficacy and relevance of the transtheoretical model for physical activity behavior. Psychology, Sports, and Exercise, 12(1), 7-12. https://dx.doi.org/10.1016\%2Fj.psychsport.2010.04.004

Nguyen, P.T., Gilmour, S., Le, P.M., Nguyen, T.T., Tanuma, J., \& Nguyen, H.V. (2019). Factors associated with high-risk behaviors of people newly diagnosed with HIV/AIDS: Results from a cross-sectional study in Vietnam. AIDS Care. https://doi.org/10.1080/09540121.2020.1761519

Nussle, J. (2008, November 20). Update of statistical area definitions and guidance on their uses. Office of Management and Budget. [PDF]. Retrieved from https://web.archive.org/web/20101104180847/http://www.whitehouse.gov/sites/d efault/files/omb/assets/omb/bulletins/fy2009/09-01.pdf 
Oka, K. (2003). Stages of change for exercise behavior and self-efficacy for exercise among middle-aged adults. Japanese Journal of Public Health, (3), 208-215. Retrieved from https://www.researchgate.net/publication/10795929_Stages_of_change_for_exerc ise_behavior_and_self-efficacy_for_exercise_among_middle-aged_adults O’Byrne, P., Orser, L., \& Jacob, J.D. (2019). The costs of HIV pre-exposure prophylaxis (PrEP) care delivery: Comparing specialists, primary care, and PrEP-RN. Sexuality Research and Social Policy, 17, 326-333. https://doi.org/10.1007/s13178-019-00391-3

Ojikutu, B.O., Bogart, L.M., Higgins-Biddle, M., Dale, S., Allen, W., Dominique, T., \& Mayer, K.H. (2018). Facilitators and barriers to pre-exposure prophylaxis (PrEP) use among Black individuals in the United States: Results from the National Survey on HIV in the Black Community (NSHBC). AIDS Behavior, 22(11), 3576-3587. https://dx.doi.org/10.1007\%2Fs10461-018-2067-8

Okoye, A.A., \& Picker, L.J. (2014). CD4+ T cell depletion in HIV infection: Mechanisms of immunological failure. Immunology Reviews, 254(1), 54-64. https://dx.doi.org/10.1111\%2Fimr.12066

Patel, R.R., Chan, P.A., Harrison, L.C., Mayer, K.H., Nunn, A., Mena, L.A., \& Powderly, W.G. (2018). Missed opportunities to prescribe HIV pre-exposure prophylaxis by primary care providers in Saint Louis, Missouri. LGBT Health, 5(4), 250265.https://doi.org/10.1089/lgbt.2017.0101

Pallonen, U.E., Timpson, S.C., Williams, M.L., \& Ross, M.W. (2009). Stages of consistent condom use, partner intimacy, condom use attitude, and self-efficacy in 
African American crack cocaine users. Archives of Sex Behavior, 38(1), 149-158. https://dx.doi.org/10.1007\%2Fs10508-008-9391-4

Paxton, R.J., Nigg, C.R., Motl, R.W., McGee, K., McCurdy, D., Matthai, C.H.,...Dishman, K. (2008). Are constructs of the transtheoretical model for physical activity measured equivalently between sexes, age groups, and ethnicities? Annals of Behavioral Medicine, 35(3), 308-318. https://doi.org/10.1007/s12160-008-9035-x

Petroli, A., Owczarzak, J., Walsh, J.L., Mcauliffe, T.L., Bogart, L.M., \& Kelly, J.A. (2016). PrEP awareness, familiarity, comfort, and prescribing experience among US primary care providers and HIV specialists. AIDS and Behavior, 21(5), 12561267. https://dx.doi.org/10.1007\%2Fs10461-016-1625-1

Plosker, G.L. (2013). Emtricitabine/tenofovir disoproxil fumarate: A review of its use in HIV-1 pre-exposure prophylaxis. Drugs, 73(3), 279-291. https://doi.org/10.1007/s40265-013-0024-4

Poteat, T.C., Keatley, J., Wilcher, R., \& Schwenke, C. (2016). Evidence for action: A call for the global HIV response to address the needs of transgender populations. Journal of the International AIDS Society, 19(suppl 2), 1-4. http://dx.doi.org/10.7448/IAS.19.3.21193

Poteat, T.C., Wirtz, A., Malik, M., Cooney, E., Cannon, C., Hardy, D.W., ... Yamanis, T. (2019). A gap between willingness and uptake: Findings from mixed methods research on HIV prevention among Black and Latina transgender women. Journal of Acquired Immune Deficiency Syndrome, 82(2), 131-140.

https://dx.doi.org/10.1097/QAI.0000000000002112 
Powell, W., Richmond, J., Mohottige, D., Yen, I., Joslyn, A., \& Corbie-Smith, G. (2019). Medical mistrust, racism, and delays in preventive health screening among African-American men. Behavioral Medicine, 45(2), 102. http://dx.doi.org/10.1080/08964289.2019.1585327

Prochaska, J.O., DiClemente, C.C., \& Norcross, J.C. (1992). In search of how people change: Applications to addictive behaviors. American Psychologists, 47(9), 1102-1114. https://psycnet.apa.org/doi/10.1037/0003-066X.47.9.1102

Prochaska, J.O., \& DiClemente, C.C. (2005). The transtheoretical approach. J.C., Norcross \& M.R. Goldfried (Eds.). Handbook of psychotherapy ( $2^{\text {nd }}$ ed., pp. 147171). New York, NY: Oxford.

Prochaska, J.O., Redding, C.A., \& Evers, K.E. (2008). The transtheoretical model and stages of change. In K. Glanz, B.K. Rimer, \& K. Viswanath (Eds.), Health behavior and health education ( $4^{\text {th }}$ ed., pp. 97-117). San Francisco, CA: Wiley.

Quinn, K., Dickson-Gomez, J., Zarwell, M., Pearson, B., \& Lewis, M. (2019). “A gay man and a doctor are just like, a recipe for destruction": How racism and homonegativity in healthcare settings influence PrEP uptake among young Black MSM. AIDS and Behavior, 23, 1951-1963. https://doi.org/10.1007/s10461-0182375-z

Rael, C.T., Martinez, M., Giguere, R., Bockting, W., MacCrate, C., Mellman, W., ... Carballo-Dieguez, A. (2018). Barriers and facilitators to oral PrEP use among transgender women in New York City. AIDS and Behavior, 22, 3627-3636. https://doi.org/10.1007/s10461-018-2102-9 
Ransome, Y., Bogart, L.M., Kawachi, I., Kaplan, A., Mayer, K.H., \& Ojikutu, B. (2020). Area-level risk and socioeconomic factors associated with willingness to use PrEP among Black people in the U.S. South. Annals of Epidemiology, 42, 33-41. https://doi.org/10.1016/j.annepidem.2019.11.002

Reif, S., Geonnotti, K.L., \& Whetten, K. (2006). HIV infection and AIDS in the deep South. American Journal of Public Health, 96(6), 970-973. https://dx.doi.org/10.2105\%2FAJPH.2005.063149

Reif, S., Safley, D., McAllester, C., Wilson, E., \& Whetten, K. (2017). State of HIV in the deep South. Journal of Community Health, 42, 844-853. https://doi.org/10.1007/s10900-017-0325-8

Rice, W.S., Stringer, K.L., Sohail, M., Crockett, K.B., Atkins, G.C., Kudroff, K., ... Turan, B. (2019). Accessing pre-exposure prophylaxis (PrEP) perceptions of current and potential PrEP users in Birmingham, Alabama. AIDS Behavior, 23(11), 2966-2979. https://doi.org/10.1007/s10461-019-02591-9

Riddell, J., Amico, K.R., \& Mayer, K.H. (2018). HIV preexposure prophylaxis: A review. Journal of the American Medical Association, 319(12), 1261-1268. https://doi.org/ 10.1001/jama.2018.1917

Rintamaki, L.S., Scott, A.M., Kosenko, K.A., \& Jensen, R.E. (2007). Male patient perceptions of HIV stigma in health care contexts. AIDS Patient Care, 21(12), 956-969. https://doi.org/10.1089/apc.2006.0154

Rogers, S.J., Tureski, K., Cushnie, A., Brown, A., Bailey, A., \& Palmer, Q. (2014). Layered stigma among healthcare and social service providers toward key 
affected populations in Jamaica and The Bahamas. AIDS Care, 26(5), 538-546. https://doi.org/10.1080/09540121.2013.844762

Ronen, K., Sharma, A., \& Overbaugh, J. (2015). HIV transmission biology: Translation for HIV prevention. AIDS, 29(17), 2219-2227.

https://dx.doi.org/10.1097\%2FQAD.0000000000000845

Ruane, P.J., Clarke, A., Post, F.A., Schembri, G., Jessen, H., Trottier, B., ... McCallister, S. (2019, November 6-9). PE3/16 - phase 3 randomized, controlled DISCOVER study of daily emtricitabine/tenofovir alafenamide (F/TAF) or emtricitabine/tenofovir disoproxil fumarate (F/TDF) for HIV pre-exposure prophylaxis (PrEP): Week 96 results $[$ Abstract $]$. 17 $7^{\text {th }}$ Annual European AIDS Conference, Basel, Switzerland. https://www.professionalabstracts.com/eacs2019/iplanner/\#/presentation/1683

Sayles, J.N., Ryan, G.W., Silver, J.S., Sarkisian, C.A., \& Cunningham, W.E. (2007). Experiences of social stigma and implications for healthcare among a diverse population of HIV positive adults. Journal of Urban Health, 84, 814-828. https://doi.org/10.1007/s11524-007-9220-4

Schuster, M.A., Collins, R., Cunningham, W.E., Zierler, S., Wong, M., Tu, W., \& Kanouse, D.E. (2005). Perceived discrimination in clinical care in a nationally representative sample of HIV-infected adults receiving health care. Journal of General Internal Medicine, 20(9), 807-813. https://dx.doi.org/10.1111\%2Fj.15251497.2005.05049.x 
Scott, H., \& Volberding, P.A. (2019). HIV screening and preexposure prophylaxis guidelines: Following the evidence. Journal of the American Medical Association Network, 321(22), 2172-2174. https://dx.doi/org/10.1001/jama.2019.2590

Setia, M.S. (2016). Methodology series module 3: Cross-sectional studies. Indian Journal of Dermatology, 61(3), 261-264. https://dx.doi.org/10.4103\%2F00195154.182410

Sevelius, J.M., Keatley, J., Calma, N., \& Arnold, E. (2016). 'I am not a man': Transspecific barriers and facilitators to PrEP acceptability among transgender women. Global Public Health, 11(7-8), 1060-1075. https://doi.org/10.1080/17441692.2016.1154085

Shaw, G.M., \& Hunter, E. (2012). HIV transmission. Cold Spring Harbor Perspectives on Medicine, 2(11), a006965. https://dx.doi.org/10.1101\%2Fcshperspect.a006965

Shepherd, D.A. \& Suddaby, R. (2017). Theory building: A review and integration. Journal of Management 43(1), 59-86. https://doi.org/10.1177\%2F0149206316647102

Shover, C.L., Shoptaw, S., Javanbakht, M., Lee, S-J., Bolan, R.K., Cunningham, N.J., ... Gorbach, P.M. (2019). Mind the gaps: Prescription coverage and HIV incidence among patients receiving pre-exposure prophylaxis from a large federally qualified health center in Los Angeles, California. AIDS and Behavior, 23(10), 2730-2740. https://doi.org/10.1007/s10461-019-02493-w

Showa, S.P., Nyadadza, F., \& Hove-Musekwa, S.D. (2019). On the efficiency of HIV transmission: Insights through discrete time HIV models. PLOS One. https://doi.org/10.1371/journal.pone.0222574 
Siegler, A. J., Bratcher, A., Weiss, K.M., Mouhanna, F., Ahlschlager, L., \& Sullivan, P.S. (2018a). Location location location: an exploration of disparities in access to publicly listed pre-exposure prophylaxis clinics in the United States. Annals of Epidemiology, 28(12), 858-864. https://doi.org/10.1016/j.annepidem.2018.05.006

Sieglar, A.J., Mouhanna, F., Giler, R.M., McCallister, S., Young, H., Jones, J., ... Sullivan, P.S. (2018b). Distribution of active PrEP prescriptions and the PrEP-toneed ratio, US q2, 2017. 25th Conference on Retroviruses and Opportunistic Infections. Boston, MA [Abstract]. Retrieved from https://www.croiconference.org/abstract/distribution-active-prep-prescriptionsand-prep-need-ratio-us-q2-2017/

Silapaswan, A., Krakower, D., \& Mayer, K.H. (2017). Pre-exposure prophylaxis: A narrative review of provider behavior and interventions to increase PrEP implementation in primary care. Journal of Internal Medicine, 32(2), 192-198. https://dx.doi.org/10.1007\%2Fs11606-016-3899-4

Smith, D.K., Van Handel, M., Wolitski, R.J., Stryker, J.E., Hall, H.I., Prejean, J., ... Valleroy, L.A. (2015). Vital signs: estimated percentages and numbers of adults with indications for preexposure prophylaxis to prevent HIV acquisition-United States, 2015. Morbidity and Mortality Weekly Report, 64(46), 1291-1295. Retrieved from https://www.cdc.gov/mmwr/preview/mmwrhtml/mm6446a4.htm

Smith, D.K., Mendoza, M.C., Stryker, J.C., \& Rose, C.E. (2016). PrEP awareness and attitudes in a national survey of primary care clinicians in the United States, 20092015. Public Library of Science One, 11(6), e0156592. https://doi.org/10.1371/journal.pone.0156592 
Smith, D.K., Van Handel, \& Grey, J.A. (2018). By race/ethnicity, Blacks have highest number needing PrEP in the United States, 2015. 25th Conference on Retroviruses and Opportunistic Infections. Boston, MA [Abstract]. Retrieved from https://www.croiconference.org/abstract/raceethnicity-blacks-have-highestnumber-needing-prep-united-states-2015/

Sullivan, P.S., Mena, L., Elopre, L., \& Siegler, A.J. (2019). Implementation strategies to increase PrEP uptake in the south. Current HIV/AIDS Reports, 16, 259-269. https://doi.org/10.1007/s11904-019-00447-4

Sutton, M.Y., Gray, S.C., Elmore, K., \& Gaul, Z. (2017). Social determinants of HIV disparities in the Southern United States and in counties with Historically Black Colleges and Universities (HBCUs), 2013-2014. PLOS One. https://doi.org/10.1371/journal.pone.0170714

Stevens, J. P. (2009). Applied multivariate statistics for the social sciences (5th ed.). Mahwah, NJ: Routledge Academic.

Stone, V.E., Mansourati, F.F., Poses, R.M., \& Mayer, K.H. (2001). Relation of physician specialty and HIV/AIDS experience to choice of guideline-recommended antiretroviral therapy. Journal of General Internal Medicine, 16(6), 360-368. https://dx.doi.org/10.1046\%2Fj.1525-1497.2001.016006360.x

Stringer, K. L., Turan, B., Mccormick, L., Durojaiye, M., Nyblade, L., Kempf, M. C., ... Turan, J. M. (2016). HIV- related stigma among healthcare providers in the deep south. AIDS and Behavior, 20(1), 115-125. https://doi.org/10.1007/ s10461-0151256-y 
Tellalian, D., Maznavi, K., Bredeek, U.F., \& Hardy, W.D. (2013). Pre-exposure prophylaxis (PrEP) for HIV infection: Results of a survey of HIV healthcare providers evaluating their knowledge, attitudes, and prescribing practices. AIDS Patient Care, 27(10), 553-559. https://doi.org/10.1089/apc.2013.0173

Terndrup, C., Streed, C.G., Tiberio, P., Black, M., Davis, J., Apfel, A., ... Berkenblit, G. (2019). A cross-sectional survey of internal medicine resident knowledge, attitudes, behaviors, and experiences regarding pre-exposure prophylaxis for HIV infection. Journal of General Internal Medicine, 34(7), 1258-1278. http://dx.doi.org/10.1007/s11606-019-04947-2

The United States President's Emergency Plan for AIDS Relief. (2019). 2019 Annual report to congress. Retrieved from https://www.state.gov/wpcontent/uploads/2019/09/PEPFAR2019ARC.pdf

Thigpen, M.C., Kebaabetswe, P.M., Paxton, L.A., Smith, D.K., Rose, C.E., Henderson, F.L.,...Chirwa, L.I. (2012). Antiretroviral preexposure prophylaxis for heterosexual HIV transmission in Botswana. The New England Journal of Medicine, 367, 423-434. https://doi/org.10.1056/NEJMoa1110711

Thomson, K.A., Baeten, J.M., Mugo, N.R., Bekker, L-G., Celum, C.L., \& Heffron, R. (2016). Tenofovir-based oral PrEP prevents HIV infection among women. Current Opinion in HIV and AIDS, 11(1), 18-26. https://dx.doi.org/10.1097\%2FCOH.0000000000000207

Thran, S.L., \& Hixson, J.S. (2000). Physician surveys: Recent difficulties and proposed solutions. ASA 2000 Proceedings, 233-237. 
Turner, L., Roepke, A., Wardell, E., \& Teitelman, A.M. (2017). Do you PrEP? A review of primary care provider knowledge of PrEP and attitudes on prescribing PrEP. Journal of the Association of Nurses in AIDS Care, 29(1), 83-92. https://doi.org/10.1016/j.jana.2017.11.002

Underhill, K., Operario, D., Mimiaga, M. J., Skeer, M. R. \& Mayer, K. H. (2011). Implementation science of pre-exposure prophylaxis: Preparing for public use. Current HIV/AIDS Reports, 7(4), 210-219. https:/doi.org/10.1007/s11904-010$0062-4$

U.S. Census Bureau (2016). Census regions and divisions of the United States. Retrieved from https://www2.census.gov/geo/pdfs/maps-data/maps/reference/us_regdiv.pdf

U.S. Department of Health and Human Services. (2020, July 10). Pre-exposure prophylaxis (PrEP). https://aidsinfo.nih.gov/understanding-hiv-aids/factsheets/20/85/pre-exposure-prophylaxis--prep-

U.S. Public Health Service. (2014). Preexposure prophylaxis for the prevention of HIV infection in the United States - 2014: A clinical practice guideline. [PDF]. Retrieved from https://www.cdc.gov/hiv/pdf/prepguidelines2014.pdf

Van Damme, L., Corneli, A., Ahmed, K., Agot, K., Lombard, J., Kapiga, S., ... Monedi, M.C. (2012). Preexposure prophylaxis for HIV infection among African Women. The New England Journal of Medicine, 367, 411-422.

https://dx.doi.org/10.1056/NEJMoa1202614

Vaughn, K., Dillon, P.J., \& Kedia, S.K. (2018). Barriers to PrEP uptake: Perspectives of community health workers in the Mid-south region of the United States. Journal 
of HIV/AIDS \& Social Services, 4, 295-312.

https://doi.org/10.1080/15381501.2019.1655512

Velicer, W.F., DiClemente, C.C., Rosi, J.S., \& Prochaska, J.O. (1990). Relapse situations and self-efficacy: An integrative model. Addictive Behaviors, 15(3), 271-283. https://doi.org/10.1016/0306-4603(90)90070-e

West, R. (2005). Time for a change: Putting the transtheoretical (stages of change) model to rest. Addiction, 100(8), 1036-1039. https://doi.org/10.1111\%2Fj.13600443.2005.01139.x

Wingood, G.M., DiClemente, R.J., Mikhail, I., Hubbard McCree, D., Davies, S.L., Hardin, J.W., ... Saag, M. (2007). HIV discrimination and the health of women living with HIV. Women Health, 46(2-3), 99-112. https://doi.org/10.1300/j013v46n02_07

Wingood, G.M., Dunkie, K., Camp, C., Patel, S., Painter, J.E., Rubtsova, A., \& DiClemente, R.L. (2013). Racial differences and correlates of potential adoption of pre-exposure prophylaxis (PrEP): Results of a national survey. Journal of the Acquired Immunodeficiency Syndrome, 63(01), S95-S101.

https://dx.doi.org/10.1097\%2FQAI.0b013e3182920126

Woo, B.F., Lee, J.X., \& Tam, W.W. (2017). The impact of the advanced practice nursing role on quality of care, clinical outcomes, patient satisfaction, and cost in the emergency and critical care setting: A systematic review. Human Resources for Health, 15(1), 63. https://doi.org/10.1186\%2Fs12960-017-0237-9 
Xie, Z., St. Clair, P., Goldman, D.P., \& Joyce, G. (2019). Racial and ethnic disparities in medication adherence among privately insured patients in the United States. PLOS One, 14(2), e0212117. https://doi.org/10.1371/journal.pone.0212117

Young, R.M., \& Meyer, I.H. (2005). The trouble with "MSM" and "WSW": Erasure of the sexual minority person in public health discourse. American Journal of Public Health, 95(7), 1144-1149. https://doi.org/10.2105/AJPH.2004.046714 


\section{APPENDIX A \\ Email Recruitment Script}

Welcome to the Primary Care Provider PrEP Prescribing Practices: Southern United States Study

Dear Participant,

Hi. My name is Daryl Traylor and I'm a PhD candidate at the University of Missouri Sinclair School of Nursing and an incoming osteopathic medical student at the University of The Incarnate Word School of Osteopathic Medicine. I'm looking for actively licensed physicians, advanced practice registered nurses, and physician assistants who practice primary care medicine in one or more of the following states: Alabama, Arkansas, Florida, Georgia, Louisiana, Mississippi, North Carolina, South Carolina, Tennessee, and Texas to participate in a research study! If you decide to take part, I'm asking you to complete one, confidential 10-12-minute Qualtrics survey. No identifying information will be collected.

Study Purpose: I want to understand primary care provider HIV pre-exposure prophylaxis (PrEP) prescribing practices for African Americans residing in the Southern United States and I want to identify barriers to and opportunities for primary care provider HIV PrEP prescribing.

The survey is totally confidential. No identifying information will be collected, and you are free to decline answering any question that you do not feel comfortable answering.

Are you interested in participating? Click here to check eligibility and complete the survey if eligible: https://missouri.qualtrics.com/jfe/form/SV_1HRFqaZtD1ylDQp

Feel free to share this email with colleagues you think might also be interested!

Need more info? Email dotcf2@mail.missouri.edu or call/text: (623) 295-9081.

Daryl Traylor, M.S., MPH

University of Missouri Doctoral Student

(623) 295-9081

Dotcf2@mail.missouri.edu 


\section{APPENDIX B \\ Social Media Recruitment Scripts}

\section{Social Media Post (Facebook, LinkedIn)}

Hi. My name is Daryl Traylor and I'm a PhD student at the University of Missouri Sinclair School of Nursing. I am conducting a study that seeks to understand primary care provider HIV pre-exposure prophylaxis (PrEP) prescribing practices for African Americans residing in the Southern United States and I want to identify barriers to and opportunities for primary care provider HIV PrEP prescribing.

I am asking you to please complete an anonymous survey that will take about 15 minutes to complete. The following link provides more information about eligibility. If eligible, would you please take a few minutes to complete this survey?

Here is the link! https://missouri.qualtrics.com/jfe/form/SV_1HRFqaZtD1ylDQp

I am also asking you to please distribute this survey to your colleagues. This survey may provide valuable insights that will allow for the development of interventions that are focused on encouraging PCPs to actively screen their African American patients for HIV and PrEP indications, as well as to prescribe PrEP. Thank you so much for your time and assistance!

\section{$\underline{\text { Twitter/Instagram }}$}

Are you a licensed physician, APRN, or physician assistant? Do you practice primary care medicine? If yes, you may be eligible to participate in a study that examines PCP PrEP prescribing practices. For more information: https://missouri.qualtrics.com/jfe/form/SV_1HRFqaZtD1ylDQp 


\title{
Primary Care Provider PrEP Prescribing Practices: Southern United States
}

\author{
Are you a primary care provider? \\ Do you practice primary care medicine in the Southern \\ United States?
}

\section{Purpose}

- The purpose of this study is to learn about primary care provider attitudes, training, and experience with prescribing HIV pre-exposure prophylaxis ("PrEP") to African Americans residing in the Southern United States.

\section{Location}

- This is an anonymous, online survey that will take approximately 10 to 12 minutes to complete.

\section{Are you eligible?}

18 years of age or older

- Actively licensed physician, APRN, or PA

- Understand written English

- Practice primary care medicine in one or more of the following states: $A L, A R, F L$, GA, LA, MS, NC, SC, TN, \& TX

If you are eligible and wish to participate, click here:

https://missouri.qualtrics.com/ife/form/SV 1HRFqaZtD1vIDQp
If you wish to participate, you can take a picture of this image with your phone:

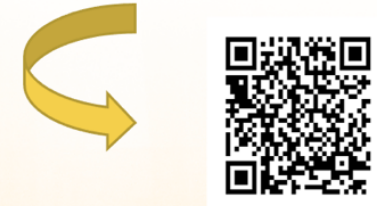

If you're unsure if you meet the requirements, call or email the principal investigator:

- Daryl Traylor, M.S., MPH, PhD candidate

- Email: dotcf2@mail.missouri.edu

- Phone number: (623) 295-9081

\section{University of Missouri}




\section{APPENDIX D \\ Permission to Adapt Survey Instrument}

Friday, April 30, 2021 at 23:32:28 Central Daylight Time

Subject: Re: Seeking permission to use survey instrument listed in "A cross-sectonal survey of internal medicine resident knowledge, attitudes, behaviors, and experiences regarding pre-exposure prophylaxis for HIV infection"

Date: Wednesday, February 19, 2020 at 11:12:20 AM Central Standard Time

From: Traylor, Daryl (MU-Student)

To: Christopher Terndrup

Good morning Dr. Terndrup,

Thank you for the quick response to my inquiry; I am very excited and am eager to move forward with my research! I will give the proper and customary aYribu9on to you and your team in my disserta9on. As I move through this process, I will keep you in the loop regarding my progress and I'll send you a copy of my proposal a[er my commiYee approves it (Hopefully in April). Once the study has been concluded, I will send you a copy of the completed disserta9on.

Thank you again!

Daryl

\section{Daryl O. Traylor, M.S., MPH, CHES}

$\mathrm{PhD}$ Student | Sinclair School of Nursing University of Missouri-Columbia M 480-482-2741 | E dotcf2@mail.missouri.edu

Sent from my iPhone

Health equity for Black women can only happen if we recognize and address persistent biases in our health care system. We're facing a maternal health crisis, and like any other crisis, it must be treated as a maYer of public health. Kamala Harris

On Feb 19, 2020, at 9:50 AM, Christopher Terndrup <terndrup@ohsu.edu> wrote:

Hi Daryl,

I heard back from all the key stakeholders. All is good to go! Just please be sure to cite us and any additional acknowledgement is appreciated. 
Springer (via JGIM) owns the article, but it's published now so able to use as long as cited. Would love to see your manuscript as you prepare it!

Thanks, and best of luck! So happy you are doing this work.

Take care,

Christopher Terndrup, MD Assistant Professor of Medicine

Interim Medical Director- Internal Medicine Clinic at Marquam Hill

Assistant Program Director for Ambulatory Medicine- Internal Medicine Residency

Program General Internal Medicine \& Geriatrics

Oregon Health and Science University

Pronouns: $\mathrm{He} / \mathrm{Him} / \mathrm{His}$

503-494-0599

From: Traylor, Daryl (MU-Student) [daryl.traylor@mail.missouri.edu]

Sent: Tuesday, February 18, 2020 8:13 AM

To: Christopher Terndrup

Subject: Re: Seeking permission to use survey instrument listed in "A cross-sectional survey of internal medicine resident knowledge, attitudes, behaviors, and experiences regarding pre-exposure prophylaxis for HIV infection"

Thank you Dr. Terndrup,

This is great news and I eagerly look forward to hearing from you.

Daryl O. Traylor, M.S., MPH, PhD (student), CHES University of Missouri-Columbia Sinclair School of Nursing dotcf2@mail.missouri.edu

"At the beginning of the fourth decade of the HIV epidemic, profound stigma and discrimination is a fact of life for those with the disease..." Sean Strub, HIV Activist

On Feb 18, 2020, at 10:12 AM, Christopher Terndrup <terndrup@ohsu.edu> wrote:

Hi Daryl,

Thanks for the update. I am fine with this but am waiting to hear back from my

colleagues- there is an original survey from Blackstock's article, so I need to confirm with those authors.

Shouldn't take too much longer- I will get back to you! -Chris

From: Traylor, Daryl (MU-Student) [daryl.traylor@mail.missouri.edu] Sent: Tuesday, February 18, 2020 8:11 AM

To: cterndr1@jhmi.edu

Cc: Christopher Terndrup 
Subject: Seeking permission to use survey instrument listed in "A cross-sectional survey of internal medicine resident knowledge, attitudes, behaviors, and experiences regarding pre-exposure prophylaxis for HIV infection"

Good morning Dr. Terndrup,

My name is Daryl Traylor and I am a doctoral student at the University of Missouri completing a dissertation in the Sinclair School of Nursing. I am writing to ask written permission to use the instrument that you and your team reported using in the journal article, "A cross-sectional survey of internal medicine resident knowledge, attitudes, behaviors, and experiences regarding pre-exposure prophylaxis for HIV infection," in my dissertation research study. My research study, will involve examining knowledge, attitudes, behaviors, and barriers to HIV PrEP prescribing for African Americans by primary care providers (physicians and mid-level providers) in the Southern United States. My research is being supervised by my dissertation chair and advisor, Dr. Maithe Enriquez.

If granted permission to use your instrument, I will add one or two additional questions that seek to address the stage of adoption, based on the Precaution Adoption Process Model, of PrEP prescribing by study participants. Other than that, I will only be modifying the demographic questions to reflect the fact that my study population will be prescribers who are out of training. My dissemination plan will include emailing the instrument to providers using Qualtrics, posting the instrument to two Facebook groups that I am part of (i.e., these are physicians who are mentoring non-traditional pre-med students), and disseminating paper copies at several national professional conventions that hope to attend in the fall.

Additionally, I would also appreciate receiving, if available, access to any supplemental material(s) that will help me administer the instrument and analyze the results; for example, (1) the test questionnaire, (2) the standard instructions for administering the test, and (3) scoring procedures.

Finally, in addition to using the instrument, I also ask your permission to reproduce it in my dissertation appendix. The dissertation will be published in the University of Missouri Institutional Repository at https://mospace.umsystem.edu/xmlui/ and deposited in the ProQuest Dissertations \& Theses database. I would like to use and reproduce your instrument under the following conditions:

I will use the instrument only for my research study and will not sell or use it for any other purposes I will include a statement of attribution and copyright on all copies of the instrument. If you have a specific statement of attribution that you would like for me to include, please provide it in your response.

At your request, I will send a copy of my completed research study to you upon completion of the study and/or provide a hyperlink to the final manuscript 
If you do not control the copyright for these materials, I would appreciate any information you can provide concerning the proper person or organization I should contact.

If these are acceptable terms and conditions, please indicate so by replying to me through e-mail at dotcf2@mail.missouri.edu.

Kindest regards,

Daryl O. Traylor, M.S., MPH, CHES

Ph.D. student in Nursing \& Health Innovation Sinclair Fellow 2018-2020

S336 Sinclair School of Nursing,

The University of Missouri-Columbia, MO 65211

Email: dotcf2@mail.missouri.edu

"At the beginning of the fourth decade of the HIV epidemic, profound stigma and discrimination is a fact of life for those with the disease..." Sean Strub, HIV Activist 


\title{
APPENDIX E
}

\author{
Instrument
}

\section{INFORMED CONSENT}

\section{University of Missouri Sinclair School of Nursing}

\section{TITLE OF STUDY: Primary Care Provider PrEP Prescribing Practices: Southern United States}

INVESTIGATOR(S): Daryl Traylor, $\mathrm{PhD}(\mathrm{c})$. For questions or concerns about the study, you may contact Daryl Traylor at 480-482-0740 or via email dotcf2@mail.missouri.edu.

\section{Purpose of the Study}

You are invited to participate in this research study. The purpose of this research study is to learn about primary care provider (PCP) training experiences and knowledge, attitudes, and behaviors regarding prescribing HIV pre-exposure prophylaxis ("PrEP") for African Americans residing in the Southern United States. This anonymous survey should take approximately 10 to 15 minutes to complete.

\section{Participants}

You are being asked to participate in this study because you fit these criteria: 1) You are a licensed and practicing physician who has completed residency training, a nurse practitioner, or a physician assistant 2) You practice primary care medicine 3) Your medical practice is located in one or more of the following states: Alabama, Arkansas, Georgia, Florida, Louisiana, Mississippi, North Carolina, South Carolina, Tennessee, or Texas.

\section{Procedures}

If you volunteer to participate in this study, you will be asked to do the following: Complete an online survey using the Qualtrics platform.

\section{Benefits of Participation}

There will be no direct benefits to you as a participant in this study. However, I hope to learn more about the HIV PrEP prescribing practices of primary care as they pertain to African Americans in the Southern United States. I hope that the results will then be used to improve primary care provider HIV PrEP prescribing practices for African Americans residing in Southern United States.

\section{Risks of Participation}

There are minimal anticipated risks in this study. Personal questions are asked, which may make you feel uncomfortable. However, the survey does not ask you to provide identifying information such as name, address, email address, and phone number. Your 
answers will not be readily linked to you. In addition, all results will be reported as a group.

\section{Cost/Compensation}

There will be no financial cost to you to participate in this study. The study will take about 10-15 minutes of your time.

\section{Confidentiality}

All information gathered in this study will be kept anonymous. As stated earlier, no reference will be made in written or oral materials that could link you to this study. All records will be stored on a password protected, encrypted hard drive for 3 years after completion of the study. After the storage time, the information gathered will be destroyed as appropriate by

me.

\section{Voluntary Participation}

Your participation in this study is voluntary. You may refuse to participate in this study or in any part of this study. You may withdraw at any time. You are encouraged to ask questions about this study at the beginning or any time during the research study.

You may contact the University of Missouri Institutional Review Board (IRB) if you:

- Have any questions about your rights as a study participant:

- Want to report any problems or complaints; or

- Feel under any pressure to take part or stay in this study.

- The IRB is a group of people who review research studies to make sure the rights of participants are protected. Their phone number is (573) 882-3181.

\section{Participant Consent}

I have read the above information and agree to participate in this study. I have been able to ask questions about the research study. I am at least 18 years of age.

Do you consent to participate in this study?

$\square$ Yes

No

The next set of questions will ask you about your eligibility for this study. Thank you for your responses.

Are you 18 years of age or older?

$$
\square \text { Yes }
$$


Are you a licensed physician, Advanced Practice Registered Nurse, or Physician Assistant?

$\square$ Yes

$\square$ No

Do you currently practice primary care medicine?

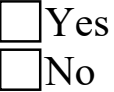

In which of the following states do you practice primary care medicine in? Check all that apply:

\begin{tabular}{ll}
$\square$ Alabama \\
\hline$\square$ Arkansas \\
$\square$ Georgia \\
$\square$ Florida \\
$\square$ Louisiana \\
$\square$ Mississippi \\
$\square$ North Carolina \\
$\square$ South Carolina \\
$\square$ Tennessee \\
$\square$ Texas \\
$\square$ None of the above
\end{tabular}

Block 1

PrEP stands for "Pre-Exposure Prophylaxis", the use of any medicine to prevent a disease before exposure to that disease. For the purposes of this survey, the term refers to the use of an oral antiretroviral medication taken on a daily basis by people at high risk of exposure to HIV to prevent HIV infection. Truvada, a combination of two antiretroviral medications tenofovir disoproxil fumarate and emtricitabine, was approved for PrEP in 2012 by the FDA and recommended in 2014 by the CDC. Descovy, a combination of emtricitabine and tenofovir alafenamide, was approved by the FDA in 2019. Any healthcare provider who is authorized to write prescriptions can write a prescription for PrEP. You do not have to be an HIV specialist or infectious disease specialist to write a prescription for PrEP.

1. Do you regularly write prescriptions for PrEP for your African American patients who have PrEP indications?

$\square$ Yes, I have been for less than 6 months.

$\square$ No, but I intend to in the next 30 days.

$\square$ No, but I intend to in the next 6 months.

$\square$ No, and I do not intent to in the next 6 months. 


\section{Block 2}

Listed below are several possible facilitators of prescribing PrEP. How important is each of these facilitators to you in deciding whether or not to prescribe PrEP for your African American patients who have PrEP indications?

2. How important are the following in your decision to prescribe PrEP?

\begin{tabular}{|c|c|c|c|c|c|}
\hline & $\begin{array}{l}\text { 1. Not } \\
\text { important }\end{array}$ & $\begin{array}{l}\text { 2. Slightly } \\
\text { important }\end{array}$ & $\begin{array}{l}\text { 3. Moderately } \\
\text { important }\end{array}$ & $\begin{array}{c}\text { 4. Very } \\
\text { important }\end{array}$ & $\begin{array}{l}\text { 5. Extremely } \\
\text { important }\end{array}$ \\
\hline $\begin{array}{l}\text { PrEP training } \\
\text { during residency }\end{array}$ & 0 & 0 & 0 & 0 & 0 \\
\hline $\begin{array}{l}\text { Staff or providers } \\
\text { in your clinic who } \\
\text { are knowledgeable } \\
\text { about PrEP } \\
\text { provision }\end{array}$ & O & O & O & O & O \\
\hline $\begin{array}{l}\text { Access to } \\
\text { resources such as } \\
\text { PrEP prescription } \\
\text { guidelines and } \\
\text { protocols }\end{array}$ & O & O & O & O & O \\
\hline $\begin{array}{l}\text { On-site support } \\
\text { (i.e., risk reduction } \\
\text { or adherence } \\
\text { counselors, social } \\
\text { workers) }\end{array}$ & O & O & O & O & O \\
\hline $\begin{array}{l}\text { Clinic inservice } \\
\text { PrEP training }\end{array}$ & O & O & O & O & O \\
\hline $\begin{array}{l}\text { Knowledge of } \\
\text { PrEP's efficacy }\end{array}$ & O & O & O & O & O \\
\hline $\begin{array}{l}\text { Patient motivation } \\
\text { or "buy in" to } \\
\text { consistently and } \\
\text { properly use PrEP } \\
\text { as prescribed }\end{array}$ & O & O & O & O & O \\
\hline $\begin{array}{l}\text { Peers who } \\
\text { prescribe PrEP }\end{array}$ & O & O & O & O & O \\
\hline $\begin{array}{l}\text { Patient access to } \\
\text { financial } \\
\text { incentives that } \\
\text { would lower the } \\
\text { cost of PrEP } \\
\end{array}$ & O & O & O & O & O \\
\hline $\begin{array}{l}\text { Streamlined } \\
\text { insurance prior } \\
\text { authorization } \\
\text { procedures }\end{array}$ & O & O & O & O & O \\
\hline
\end{tabular}


Listed below are several possible barriers of prescribing PrEP. How important is each of these barriers to you in deciding whether or not to prescribe PrEP for your African American patients who have PrEP indications?

3. How important are the following in your decision to prescribe PrEP?

\begin{tabular}{|c|c|c|c|c|c|}
\hline & $\begin{array}{c}1 . \text { Not } \\
\text { important }\end{array}$ & $\begin{array}{l}\text { 2. Slightly } \\
\text { important }\end{array}$ & $\begin{array}{l}\text { 3. Moderately } \\
\text { important }\end{array}$ & $\begin{array}{c}\text { 4. Very } \\
\text { important }\end{array}$ & $\begin{array}{c}\text { 5. Extremely } \\
\text { important }\end{array}$ \\
\hline $\begin{array}{l}\text { Lack of provider } \\
\text { training/education } \\
\text { regarding PrEP }\end{array}$ & 0 & 0 & 0 & 0 & 0 \\
\hline $\begin{array}{l}\text { Lack of clinic } \\
\text { leadership support } \\
\text { regarding PrEP }\end{array}$ & 0 & 0 & 0 & 0 & 0 \\
\hline $\begin{array}{l}\text { Lack of clinical } \\
\text { guidelines/protocols } \\
\text { for } \\
\text { prescribing/monitoring } \\
\text { PrEP }\end{array}$ & O & O & O & 0 & O \\
\hline $\begin{array}{l}\text { Clinic and lab } \\
\text { monitoring } \\
\text { requirements (e.g., } \\
\text { seeing patient and } \\
\text { obtaining HIV tests } \\
\text { and STI screening } \\
\text { every } 3 \text { months; } \\
\text { checking renal } \\
\text { function every } 6 \\
\text { months) } \\
\end{array}$ & O & O & O & O & O \\
\hline $\begin{array}{l}\text { Staffing time } \\
\text { constraints related to } \\
\text { risk reduction and } \\
\text { PrEP adherence } \\
\text { counseling }\end{array}$ & 0 & 0 & 0 & 0 & 0 \\
\hline $\begin{array}{l}\text { Lack of insurance } \\
\text { coverage and out-of- } \\
\text { pocket patient costs } \\
\text { for PrEP and related } \\
\text { care (e.g., lab work) }\end{array}$ & 0 & 0 & 0 & 0 & 0 \\
\hline $\begin{array}{l}\text { Likelihood of low } \\
\text { adherence to PrEP }\end{array}$ & 0 & 0 & 0 & O & 0 \\
\hline $\begin{array}{l}\text { Likelihood of HIV } \\
\text { resistance developing }\end{array}$ & 0 & 0 & 0 & 0 & 0 \\
\hline $\begin{array}{l}\text { Patients may engage } \\
\text { in riskier behavior } \\
\text { while on PrEP }\end{array}$ & O & ○ & o & ○ & O \\
\hline $\begin{array}{l}\text { Insufficient evidence } \\
\text { of PrEP's effectiveness }\end{array}$ & 0 & 0 & 0 & 0 & 0 \\
\hline
\end{tabular}

\section{Block 3}

The following questions are about your current personal and practice demographics.

4. What is your age? 
5. What is your gender?

$\square$ Male

$\square$ Female

$\square$ Gender queer/Non-conforming

Transgender

$\square$ Prefer not to answer

6. With respect to sexual orientation, how do you self-identify?

\begin{tabular}{l}
$\square$ Heterosexual \\
$\square$ Gay \\
\hline Lesbian \\
$\square$ Bisexual \\
\hline$\square$ Other \\
$\square$ Prefer not to answer
\end{tabular}

7. With respect to race, how do you self-identify (Select all that apply)?

$\square$ Asian or Asian American

$\square$ Black or African American

$\square$ Native Hawaiian and Pacific Islander

$\square$ White

Multiracial

$\square$ Other

Prefer not to answer

8. Do you identify as being Hispanic or Latino?

\begin{tabular}{|l}
$\square$ Yes \\
$\square$ No
\end{tabular}

9. I am a...

$\square$ Physician

$\square$ Advanced Practice Registered Nurse

$\square$ Physician Assistant

10. What is your highest degree completed?

$\square$ Doctor of Osteopathic Medicine (D.O.)

Medical Doctor (M.D.)

Master of Science - Nursing (MSN) or equivalent

Doctor of Nursing Practice (DNP)

$\square$ Master of Science - Physician Assistant (MSPA) or equivalent

$\square$ Doctor of Medical Science - Physician Assistant (DMSPA) or equivalent 
11. How would you classify the geographic area you practice in?

$\square$ Urban - The U.S. Census Bureau defines an urban area as an area with 50,000 or more people.

$\square$ Suburban - The U.S. Census Bureau defines suburban areas as those areas that lie on the fringes of urban areas and are in easy commuting distance of urban areas.

$\square$ Rural - The U.S. Census Bureau defines a rural area as any area outside of urban and suburban areas with a population of 0 to 49,999 people.

12. What is the zip code of your primary care practice?

13. How many years have you practiced primary care healthcare?

14. For each racial/ethnic category, please mark the percentage of each group that makes up your clinic patient population. Please give your best estimate.

\begin{tabular}{l|cccccc}
\hline \multicolumn{2}{c}{} & $\begin{array}{c}\text { African } \\
\text { American }\end{array}$ & White & $\begin{array}{c}\text { American } \\
\text { Indian / Alaska } \\
\text { Native }\end{array}$ & $\begin{array}{c}\text { Latinx } \\
\text { Asian }\end{array} \begin{array}{c}\text { Native } \\
\text { Hawaiian or } \\
\text { Pacific } \\
\text { Islander }\end{array}$ \\
\hline $0 \%$ & 0 & 0 & 0 & 0 & 0 & 0 \\
$1-25 \%$ & 0 & 0 & 0 & 0 & 0 & 0 \\
$26-50 \%$ & 0 & 0 & 0 & 0 & 0 & 0 \\
$51-75 \%$ & 0 & 0 & 0 & 0 & 0 & 0 \\
$76-100 \%$ & 0 & 0 & 0 & 0 & 0 \\
\hline
\end{tabular}

15. Do you routinely screen your African American patients for HIV?

$\square$ Yes

16. Have you ever written a prescription for PrEP for an African American patient?

\begin{tabular}{l}
$\square$ Yes \\
\hline$\square$ No
\end{tabular}

17. Do you routinely write PrEP prescriptions for your African American patients?

\begin{tabular}{l}
$\square$ Yes \\
\hline$\square$ No
\end{tabular}

18. Have you ever referred an African American patient for a PrEP prescription (e.g., to a PrEP provider or Infectious Disease / HIV clinic)?

$\checkmark$ Yes 
$\square$ No

19. Do you routinely refer African American patients for PrEP prescriptions (e.g., to a PrEP provider or Infectious Disease / HIV clinic)?

$\square$ Yes

$\square$ No

20. Before this survey, had you ever heard of PrEP?

$\square$ Yes

$\square$ No

21. Have you received specific training on PrEP?

$\square$ Yes

Thank you for completing this survey! 


\section{VITA}

Daryl O’Neal Traylor was born November 10, 1971 in Houston, Texas. In May 2010, Daryl graduated with bachelor's degrees in Microbiology and Community Health Promotion with a minor in Sociology, from Arizona State University (ASU) and Northern Arizona University (NAU) respectively. Later, in 2011, while serving as a member of AmeriCorps VISTA, Daryl started work on master's degrees in Pharmacology \& Toxicology and Public Health, at Michigan State University and he completed his studies in August of 2015.

In 2010, Daryl started teaching for NAU and he taught in the Community Health program until 2015. Since that time, Daryl has taught for St. Petersburg College, Arizona State University-Downtown, Paradise Valley Community College, and A.T. Still University College of Graduate Health Studies. He has taught undergraduate and graduate public health, pharmacology, pathophysiology, and medical terminology. Besides these experiences, Daryl has worked as an EMT-Paramedic (civilian and military), HIV/AIDS health educator, and laboratory scientist in medical research.

Daryl decided to pursue his PhD in 2018 at the University of Missouri's Sinclair School of Nursing. His research interests include understanding primary care provider PrEP prescribing practices, the development of a beauty salon-based HIV prevention intervention, and stress \& resilience in African American communities during the COVID-19 pandemic. After completing his doctoral studies, Daryl will be starting medical school at the University of the Incarnate Word School of Osteopathic Medicine in San Antonio, Texas. Ultimately, Daryl would like to work in underserved communities in the Southwestern U.S. providing health and public health services. 